\title{
COAL ASH BEHAVIOR IN REDUCING ENVIRONMENTS (CABRE) III
}

\section{Year 6 - Activity 1.10 - Development of a National Center for Hydrogen Technology}

\section{Topical Report}

Prepared for:

AAD Document Control

National Energy Technology Laboratory

U.S. Department of Energy

626 Cochrans Mill Road

PO Box 10940, MS 921-107

Pittsburgh, PA 15236-0940

Cooperative Agreement No. DE-FE0003466

Performance Monitor: Meghan Napoli

Prepared by:

Joshua J. Stanislowski Alexander Azenkeng Donald P. McCollor Kevin C. Galbreath

Robert R. Jensen

Brent M. Lahr

Energy \& Environmental Research Center University of North Dakota 15 North 23rd Street, Stop 9018

Grand Forks, ND 58202-9018 


\section{EERC DISCLAIMER}

LEGAL NOTICE This research report was prepared by the Energy \& Environmental Research Center (EERC), an agency of the University of North Dakota, as an account of work sponsored by the U.S. Department of Energy (DOE) National Energy Technology Laboratory (NETL), the North Dakota Industrial Commission, and a consortium of industrial sponsors. Because of the research nature of the work performed, neither the EERC nor any of its employees makes any warranty, express or implied, or assumes any legal liability or responsibility for the accuracy, completeness, or usefulness of any information, apparatus, product, or process disclosed or represents that its use would not infringe upon privately owned rights. Reference herein to any specific commercial product, process, or service by trade name, trademark, manufacturer, or otherwise does not necessarily constitute or imply its endorsement or recommendation by the EERC.

\section{DOE ACKNOWLEDGMENT}

This report was prepared with the support of DOE NETL Cooperative Agreement No. DEFE0003466. However, any opinions, findings, conclusions, or recommendations expressed herein are those of the author(s) and do not necessarily reflect the views of DOE.

\section{DOE DISCLAIMER}

This report was prepared as an account of work sponsored by an agency of the United States Government. Neither the United States Government, nor any agency thereof, nor any of their employees makes any warranty, express or implied, or assumes any legal liability or responsibility for the accuracy, completeness, or usefulness of any information, apparatus, product, or process disclosed, or represents that its use would not infringe upon privately owned rights. Reference herein to any specific commercial product, process, or service by trade name, trademark, manufacturer, or otherwise does not necessarily constitute or imply its endorsement, recommendation, or favoring by the United States Government or any agency thereof. The views and opinions of authors expressed herein do not necessarily state or reflect those of the United States Government or any agency thereof. 


\title{
COAL ASH BEHAVIOR IN REDUCING ENVIRONMENTS (CABRE) III
}

\section{Year 6 - Activity 1.10 - Development of a National Center for Hydrogen Technology}

\begin{abstract}
The Energy \& Environmental Research Center (EERC) has been conducting research on gasification for six decades. One of the objectives of this gasification research has been to maximize carbon conversion and the water-gas shift process for optimal hydrogen production and syngas quality. This research focus and experience were a perfect fit for the National Center for Hydrogen Technology ${ }^{\circledR}\left(\mathrm{NCHT}^{\circledR}\right)$ Program at the EERC for improving all aspects of coal gasification, which ultimately aids in the production and purification of hydrogen. A consortia project was developed under the NCHT Program to develop an improved predictive model for ash formation and deposition under the project entitled "Coal Ash Behavior in Reducing Environments (CABRE) III: Development of the CABRE III Model." The computer-based program is now applicable to the modeling of coal and ash behavior in both entrained-flow and fluidized-bed gasification systems to aid in overall gasification efficiency. This model represents a significant improvement over the CABRE II model and runs on a Microsoft Windows PC platform.
\end{abstract}

The major achievements of the CABRE III model are partitioning of inorganic transformations between various phases for specific gas cleanup equipment; slag property predictions, including standard temperature-viscosity curves and slag flow and thickness; deposition rates in gasification cleanup equipment; provision for composition analysis for all input and output streams across all process equipment, including major elements and trace elements of interest; composition analysis of deposit streams for various deposit zones, including direct condensation on equipment surfaces (Zone A), homogeneous particulate deposition (Zone B), and entrained fly ash deposition (Zone C); and physical removal of ash in cyclones based on $\mathrm{D}_{50}$ cut points.

Another new feature of the CABRE III model is a user-friendly interface and detailed reports that are easily exportable into Word documents, Excel spreadsheets, or as pdf files. The user interface provides stepwise guides with built-in checks for efficient entry of required input data on fuels of interest to allow a successful execution of the model.

The model was developed with data from several fuels selected by the sponsors, including bituminous coal, subbituminous coal, lignite, and petroleum coke (petcoke). The data from these fuels were obtained using small pilot-scale entrained-flow and fluidized-bed gasifiers at the Energy \& Environmental Research Center (EERC).

The CABRE III model is expected to further advance the knowledge base for the $\mathrm{NCHT}^{\circledR}$ Program and, more importantly, allow for prediction of the slagging and fouling characteristics of fuels in reducing environments. The information obtained from this program will potentially also assist in maintaining prolonged gasifier operation free from failure or facilitate troubleshooting to minimize downtime in the event of a problem. 


\section{TABLE OF CONTENTS}

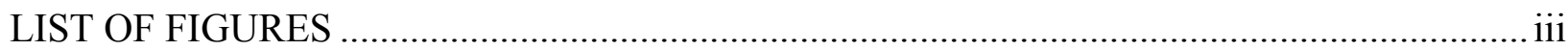

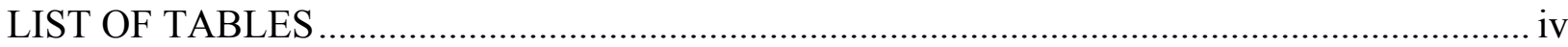

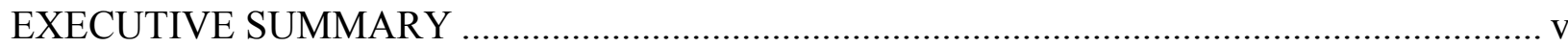

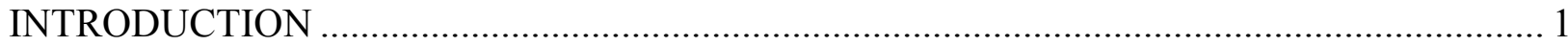

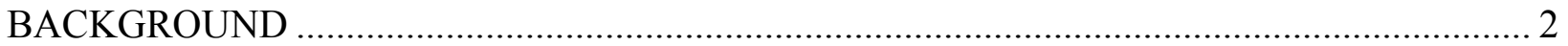

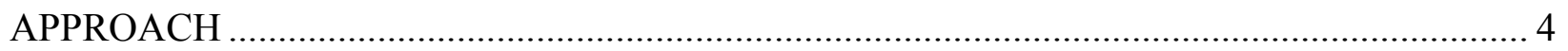

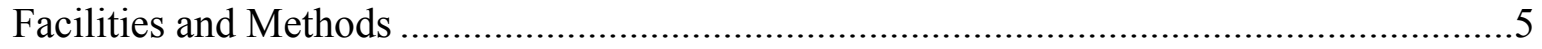

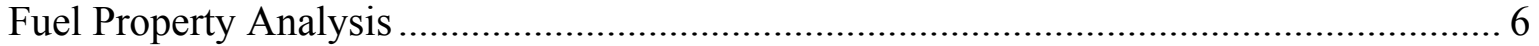

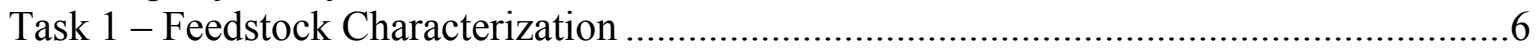

Composition Analysis of Coals, Slags, and Deposits.............................................. 7

Description of QEMSCAN ............................................................................ 7

Viscosity Measurements .................................................................................. 8

Slag-Refractory Interaction Tests ..................................................................... 10

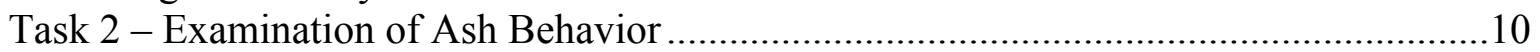

Task 3 - Evaluation of Ash Behavior in Bench-Scale Systems .........................................11

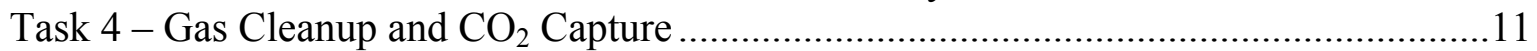

Task 5 - Modeling of Ash Behavior ...............................................................................12

Computer Modeling with Aspen Plus ${ }^{\circledR}$ and FactSage ${ }^{\mathrm{TM}}$........................................ 12

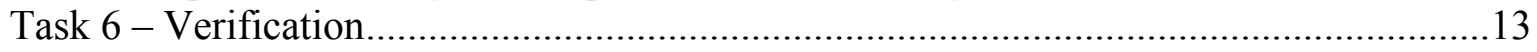

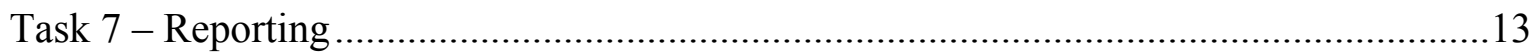

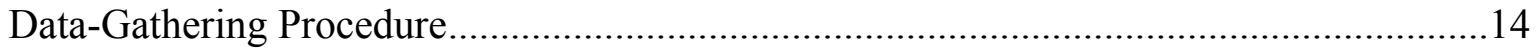

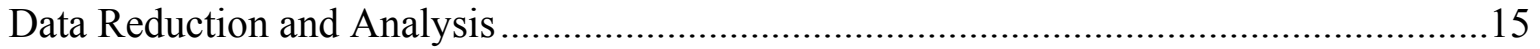

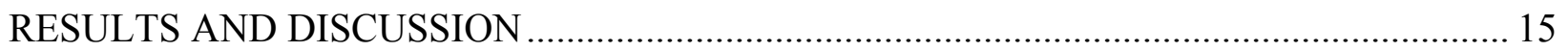

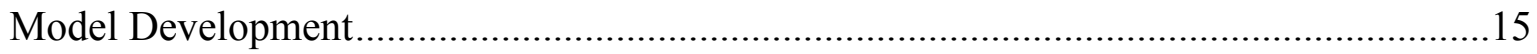

Program Description .................................................................................... 15

Program Components .................................................................................... 16

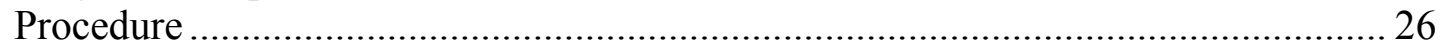

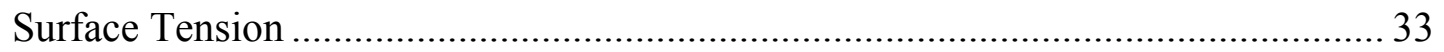

Model User Interface Development .................................................................................

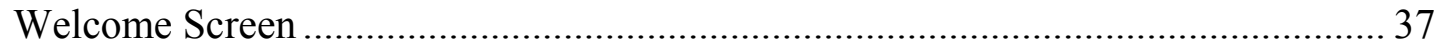

Gasifier Session Screen ..................................................................................... 37

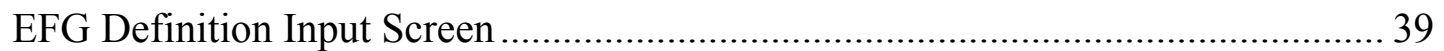

FBG Definition Input Screen............................................................................. 39

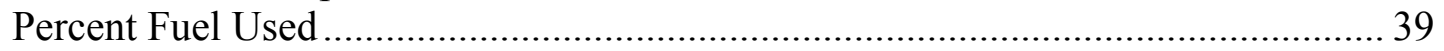

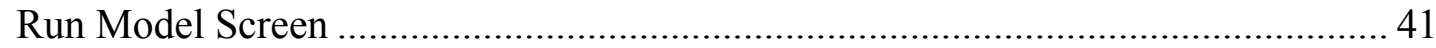

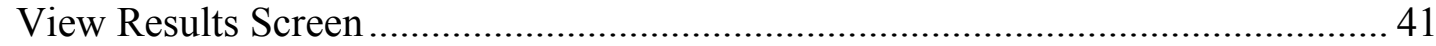

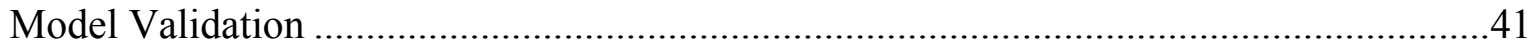

Continued... 


\section{TABLE OF CONTENTS (continued)}

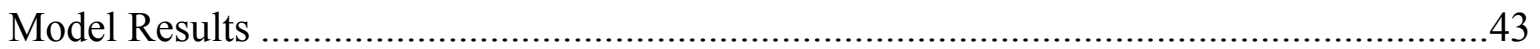

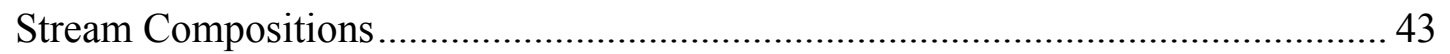

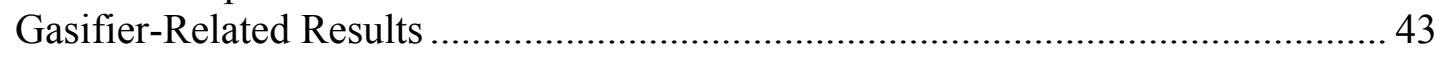

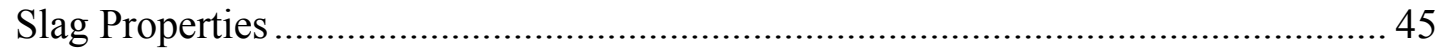

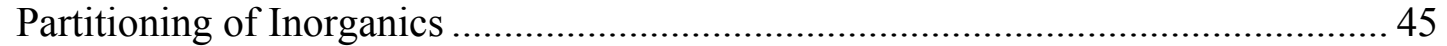

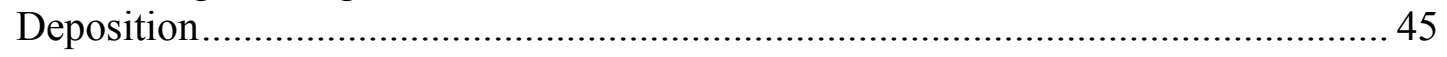

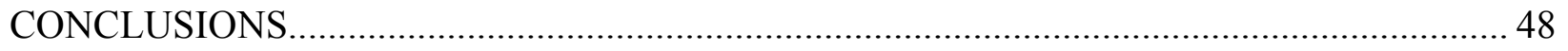

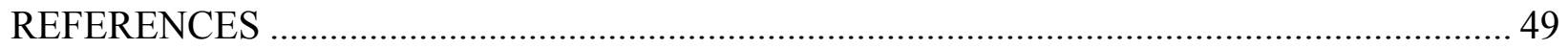

DATA REDUCTION AND ANALYSIS ..........................................................

CABRE III PROGRAM USER MANUAL .............................................................Appendix B 


\section{LIST OF FIGURES}

1 Schematic of the QEMSCAN system .................................................................. 8

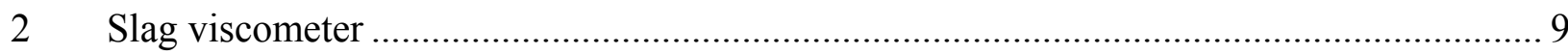

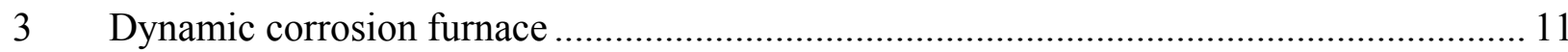

4 Gas-phase sodium and potassium species predicted by FactSage for Center lignite ......... 13

5 Gas-phase sodium and potassium species predicted by FactSage for Falkirk lignite ......... 14

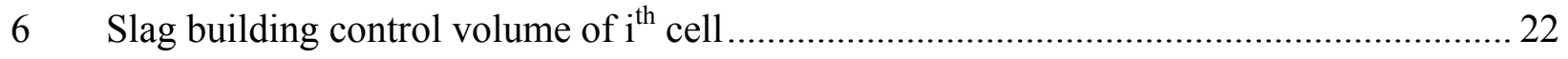

7 Rosin-Rammler particle-size distribution formalism .......................................... 35

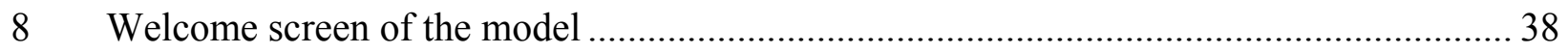

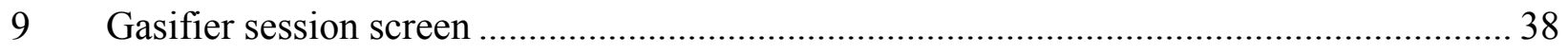

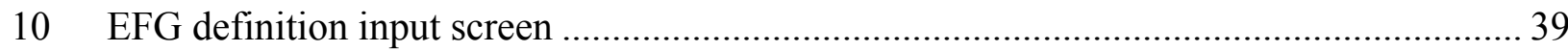

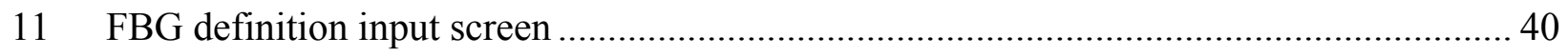

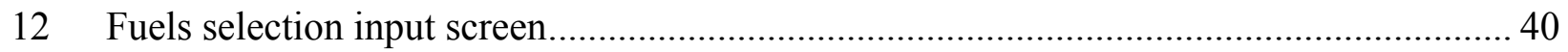

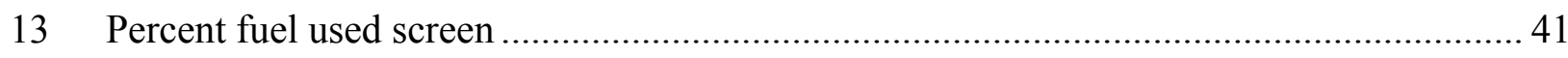

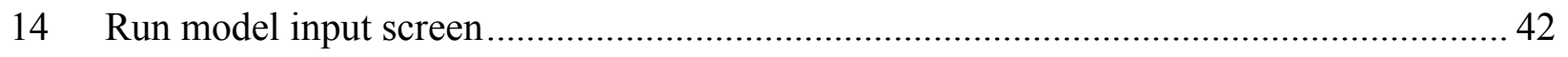

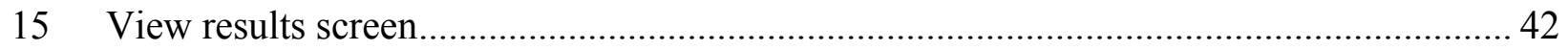

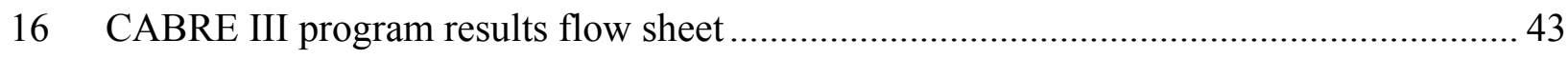

17 Distribution of major and trace elements in fly ash and slag ..................................... 44

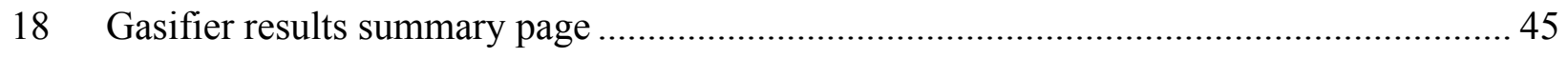

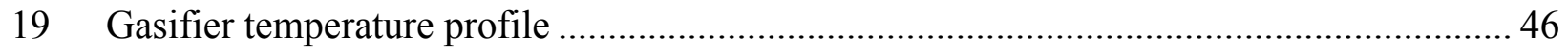

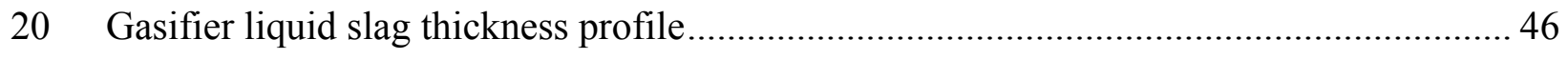

21 Viscosity-temperature curve for Falkirk lignite ................................................. 47

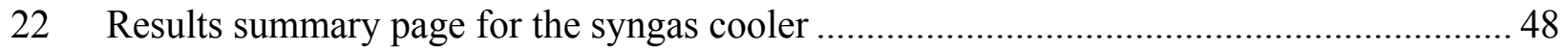




\section{LIST OF TABLES}

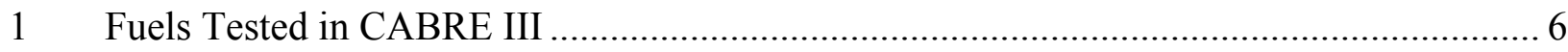

2 Chemical Fractionation Protocol............................................................................. 7

3 Average Major Elements Partitioning Between Slag and Fly Ash for Various Fuels ........ 18

$4 \quad$ Selected Trace Element Partitioning Between Slag and Fly Ash ................................. 19

$5 \quad$ Recommended Constants for Temperature-dependent Heat Capacity............................. 31

6 Partial Molar Volumes of Components Obtained from Mills et al. ............................... 32

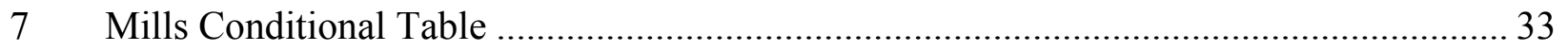

8 Distribution of Major and Trace Elements in Fly Ash and Slag ................................... 44

9 Calculated Slag Properties at Various Gasifier Zones .............................................. 47 


\section{COAL ASH BEHAVIOR IN REDUCING ENVIRONMENTS (CABRE) III}

\section{Year 6 - Activity 1.10 - Development of a National Center for Hydrogen Technology}

\section{EXECUTIVE SUMMARY}

The Energy \& Environmental Research Center (EERC) has been conducting research on gasification for six decades. One of the objectives of this gasification research has been to maximize carbon conversion and the water-gas shift process for optimal hydrogen production and syngas quality. This research focus and experience were a perfect fit for the National Center for Hydrogen Technology ${ }^{\circledR}\left(\mathrm{NCHT}^{\circledR}\right)$ Program at the EERC for improving all aspects of coal gasification, which ultimately aids in the production and purification of hydrogen. A consortia project was developed under the NCHT Program to develop an improved predictive model for ash formation and deposition under the project entitled "Coal Ash Behavior in Reducing Environments (CABRE) III: Development of the CABRE III Model.”

The development and implementation of the Coal Ash Behavior in Reducing Environments (CABRE) III modeling program, which is the main activity of Year 6 of the overall CABRE III project, has been completed. The model provides a prediction of coal ash behavior in reducing environments such as gasification systems and represents a significant improvement over the CABRE II model. The CABRE III model also includes the capability to model a fluidized-bed gasifier (FBG) to predict the extent of deposition and deposition rate in the syngas cooler as well as other parameters. The ultimate goal of the CABRE III model is to help engineers operate a gasifier at maximum efficiency, thereby enhancing the quantity and quality of the syngas products, including hydrogen and carbon monoxide, two of the most important products.

The program was developed based on semiempirical relationships that can be found in the literature and/or correlations of experimental data obtained from a small pilot-scale entrainedflow gasifier (EFG) and a bench-scale FBG at the Energy \& Environmental Research Center (EERC). A limited amount of available data from full-scale gasifiers was used in some cases. The main focus of the program is to predict the partitioning of coal ash as it progresses through the various unit operations, beginning with the gasifier, which facilitates the understanding of various inorganic transformations and their potential impact on system equipment. At each stage, the fraction of volatile, nonvolatile, and deposited ash constituents, as well as their detail compositions including major and trace element partitioning, is determined. In addition, slag flow, viscosity, and other slag physical properties in the gasifier are predicted.

The model was developed with data from several fuels selected by the sponsors, including bituminous coal, subbituminous coal, lignite, and petroleum coke (petcoke). The data from these fuels were obtained using a small pilot-scale EFG and FBG at the EERC.

The major achievements of the CABRE III model include:

- Partitioning of inorganic transformations between various phases for specific gas cleanup equipment. 
- Slag property predictions including standard temperature-viscosity curves and slag flow and thickness.

- Deposition rates in the gasification cleanup equipment.

- Provision of composition analysis for all input and output streams across all process equipment, including major elements and trace elements of interest.

- Specific composition analysis of deposit streams for various deposit zones: direct condensation on equipment surfaces (Zone A), homogeneous particulate deposition (Zone B), and entrained fly ash deposition (Zone C).

- Physical removal of ash in cyclones based on $\mathrm{D}_{50}$ cut points in EFGs and FBGs.

A new feature of the CABRE III model is a user-friendly interface and an ability to produce detailed reports that are easily exportable into Word documents, Excel spreadsheets, or pdf files. Example screen shots of the user interface, showing the welcome screen (left), gasifier session screen (middle), and results screen (right) are displayed in Figure ES-1. The user interface provides stepwise guides with built-in checks for efficient supply of required input data on fuels of interest to allow a successful execution of the model.

The results from the CABRE III model are expected to further advance the knowledge base for the NCHT Program and, more importantly, allow for prediction of the slagging and fouling characteristics of the fuel and to evaluate its behavior under reducing environments. The information obtained from this program will potentially also assist in maintaining prolonged and more efficient gasifier operation free from failure or facilitate troubleshooting to minimize downtime in the event of a problem.

This topical report summarizes the development of the CABRE III model. It does not contain the detailed data analysis collected for coals; experimentally generated slag, deposits, and fly ash, or sponsor-supplied slag and ash deposits. A previous topical report (1) was submitted in 2011 which summarized and described in detail much of the data development that was subsequently used to build the CABRE III predictive model.

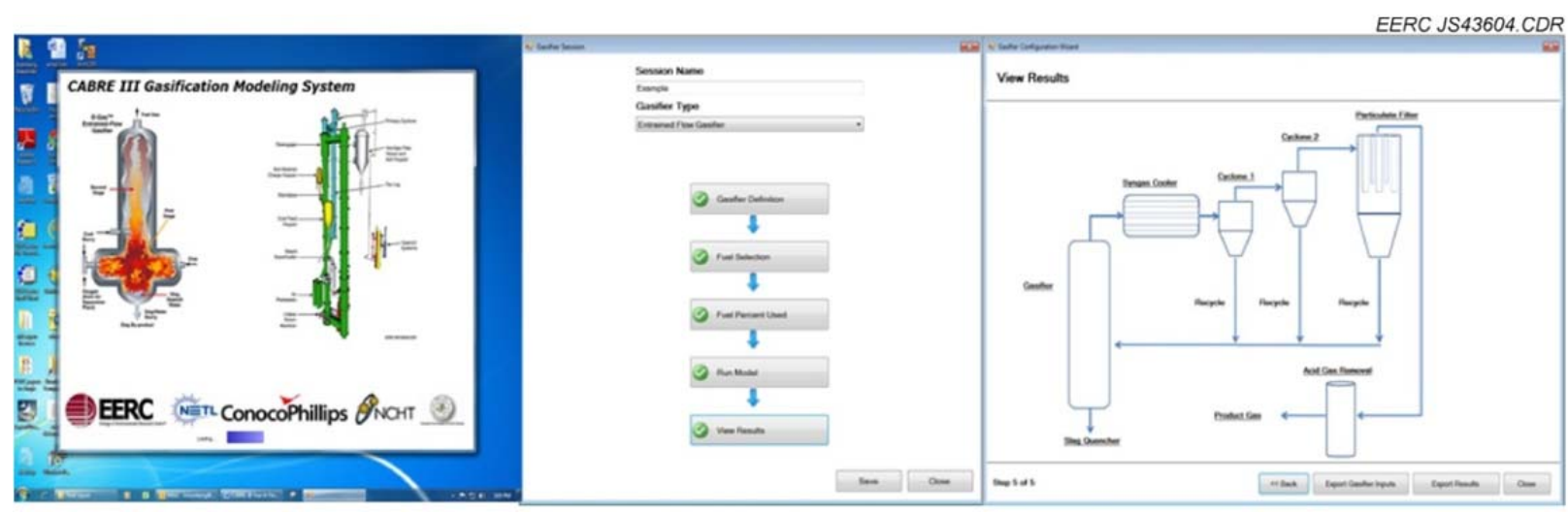

Figure ES-1. Graphical user interface screenshots for welcome screen (left), gasifier session screen (middle), and view results screen (right). 


\title{
COAL ASH BEHAVIOR IN REDUCING ENVIRONMENTS (CABRE) III: DEVELOPMENT OF THE CABRE III MODEL
}

\author{
Year 6 - Activity 1.10 - Development of a National Center for Hydrogen Technology
}

\section{INTRODUCTION}

Using the world's coal reserves will come under increased scrutiny over the next decade because of an ever-growing concern over global climate change. The public perception is that coal will always be a large pollution challenge compared to other energy sources. While it is true that coal emits more greenhouse gases per unit energy produced than fuels like oil or natural gas, new technologies are being developed that will reduce emissions to near zero from coal-fired plants. Estimates have shown that the world demand for energy is going to increase by $50 \%$ over the next 25 years. There is no doubt that these energy demands will be met in part through increased coal usage. As we continue to increase the worldwide standard of living while maintaining the health of the environment, understanding how to utilize coal in a cleaner, more efficient, and cost-effective manner will be one of the greatest challenges of the 21 st century. In this regard, coal gasification offers the best opportunity to cleanly and efficiently produce fuels and energy from coal and renewable resources while realizing carbon capture and sequestration at lower costs than traditional combustion facilities.

Hydrogen production in the United States is not a new concept, since there are economic business sectors that consume hydrogen at a significant level. Should the United States move toward other uses of this clean energy fuel such as stationary fuel cell power, automobile fuel cell systems, and specialized off-road utility and vehicle power such as forklifts, then there is great opportunity for hydrogen generation through coal gasification. Presently, natural gas is the most common resource used in the production of hydrogen. Coal is not a major source for hydrogen, but is an excellent energy medium which, when coupled with steam gasification and water-gas shift processing, becomes a very sustainable and cost-competitive mode of hydrogen production.

Work at the Energy \& Environmental Research Center (EERC) has been ongoing for over six decades in coal gasification research. Coal gasifier technologies can now be matched with coal compositions and process schemes that maximize the production of hydrogen. Some highermoisture low-rank coals for example can achieve hydrogen production to the level of $50 \%$ of synthetic gas volume. Research related to improving gasification system efficiency by, for example, alleviating fouling, slagging, and other ash and particulate-handling and emissions challenges is, therefore, a win-win situation for hydrogen production.

Although gasification of carbonaceous fuels is not a new concept, there is still limited experience with the technology, primarily because of the preference toward simpler and cheaper combustion facilities. As the concern over global climate change mounts, more companies and utilities will be looking for cost-effective ways to deal with $\mathrm{CO}_{2}$, and coal gasification will undoubtedly get more attention. To address this concern, successful design, implementation, and operation of new gasification facilities will require an increased understanding of the fate and 
behavior of fuelborne impurities or ash-forming components in reducing environments. More importantly, the economic implications related to system performance and reliability include slag flow control, slag attack on refractory, ash deposition on heat-transfer surfaces, corrosion and erosion of system materials, and gas cleanup. Minimizing the potential for these ash-related problems is a fundamental objective in designing and operating gasifiers to produce hydrogen, liquid fuels, chemicals, power, and $\mathrm{CO}_{2}$.

Therefore, the Coal Ash Behavior in Reducing Environments (CABRE) III project was designed to assess these ash-related challenges in reducing environments by evaluating several fuel options and blends in a pilot-scale entrained-flow gasifier (EFG) and/or fluidized-bed gasifier (FBG), with the aim to better understand inorganic transformation mechanisms and, hence, proposed strategies for ameliorating the difficulties. The information obtained from this project and the predictive model that was developed will assist industry in maintaining prolonged gasifier operation. The model will also be useful for facilitating fuel selection and for troubleshooting to minimize downtime in the event of a problem, with the overall objective being to enhance efficient performance and operational reliability in current state-of-the-art gasification systems that handle a variety of fuels, particularly EFGs and FBGs.

To achieve this goal, a multiyear consortium involving multiple sponsors, including ConocoPhillips, the North Dakota Industrial Commission (NDIC), and the U.S. Department of Energy (DOE) National Energy Technology Laboratory (NETL), with the Energy \& Environmental Research Center (EERC) as project lead, was organized. The aim of the CABRE III project was to provide a model and associated fundamental information on ash behavior such that gasifier improvements can be realized in full-scale systems. In addition to the considerable amount of detailed information that is available, the project is promoting communication between sponsors and personnel interested in deposition problems in EFGs, FBGs and, possibly, other gasification systems based on sponsor input.

This topical report summarizes the development of the predictive model and does not contain all of the detailed analyses of coals and experimentally and field-derived fly ash, deposits, and slags. A previous report (1) was submitted in 2011 which summarized and described in detail much of the data development that was used to formulate model algorithms presented in this report.

\section{BACKGROUND}

The EERC has been involved in research on coal ash behavior in reducing environments since 1990, when the first cooperative project, entitled "Coal Ash Behavior in Reducing Environments (CABRE I)," began. This project involved both private industry sponsors such as Dow, Texaco, Shell Development Company, and the Electric Power Research Institute (EPRI) and DOE. About a year after the commencement of the first CABRE project, the Netherlands Energy Research Foundation (ECN) joined the CABRE I consortium. Given the state of gasification technologies both in the United States and worldwide at the time, the CABRE I project focused on developing a fundamental understanding of the ash formation and deposition mechanisms that occur in EFG systems (2). 
Among the successes of the CABRE I project were the development of a scanning electron microscopy point count (SEMPC) routine to perform computer-controlled analysis of coal gasification deposits; the development of a new mineral classification program, MINCLASS, to identify and quantify mineral and amorphous phases in a gasification deposit; the development of specific inorganic transformation mechanisms involving pyrite, calcite, organically associated calcium and sodium, and various clay minerals that lead to the formation of deposits and development of greater strength in the formed deposits; the finding that the formation and decomposition of sulfides greatly affect deposit formation within specific temperature ranges; and the derivation of predictive indices for expressing the severity of high-, intermediate-, and low-temperature ash deposit formation within a gasification system based on coal ash constituents and system engineering parameters. Despite the significant advancements made during the CABRE I project toward a better understanding of the transformations of inorganic minerals during coal gasification, additional information on the physicochemical transformations of inorganic constituents in gasification systems was still lacking, which prompted a follow-on Phase II project.

In 1996, CABRE II was initiated, which was also a consortium of industry and federal funding agencies in the United States and the Netherlands, including ECN, Krupp Uhde, Elcogas, Novem, Babcock-Hitachi K.K., KEMA, EPRI, and DOE, with the EERC as the lead organization. CABRE II was a 3-year project focused on using the fundamental knowledge gained in CABRE I to fill existing knowledge gaps with experimental research and technologies. The primary objectives for CABRE II included advancement of the fundamental understanding of vapor-phase and fine particulate formation in EFG systems through bench-scale testing in a pressurized EFG (PEFG); identification of mechanisms involved in deposit sintering and strength development under gasification conditions via laboratory-scale tests; development and testing deposit mitigation in gasification systems; and initiation of the development of applied indices for predicting ash deposition in an entrained gasification system as functions of coal properties, system configurations, and operating parameters. One key product was a set of deposition indices that were coded into a computer-based model that would predict ash deposition severity in several prescribed zones of an entrained-flow gasifier.

The accomplishments of CABRE II were numerous, including the design and construction of a PEFG simulator at ECN in the Netherlands, which was operated in a reliable and stable manner on a routine basis at $\leq 1500^{\circ} \mathrm{C}$ and $\leq 10$ bar; the development of inorganic transformation and partitioning algorithms to predict ash particle-size and composition distribution (PSCD) from computer-controlled scanning electron microscopy (CCSEM) coal analysis input data, chemical fractionation, proximate, ultimate, heating value, and coal ash chemical composition; derivation of four indices based on predicted PSCDs for predicting deposition in gasification systems as a function of coal properties, system configurations, and operating parameters; and a Windows-based computer program to calculate index values corresponding to four different gas temperature regimes in a generic slagging gasifier (3).

Although the successes of CABRE I and CABRE II were remarkable $(2,3)$, the development of advanced technologies in the years after the projects warranted a reevaluation of previously developed techniques to assess their suitability to current technologies. In addition, the enactment of more stringent emission control regulations resulted in the installation of 
advanced pollution control devices that were not considered during the CABRE I and II projects. Furthermore, attention shifted from predominantly coal-only fuels being used in gasification systems to blended coals and/or coal-biomass blends to address concerns related to global warming and climate change. The results of the studies conducted in CABRE I and II became limited in application to the new gasification systems and operating conditions. Some of the major questions raised for the newer gasifier systems, which were not applicable and hence not addressed in CABRE I and II, included a wide range of feedstocks such as petroleum coke, biomass, and low-rank coals; slag-refractory interactions under gasification conditions using these new feedstocks; reliable predictions of slag properties, especially viscosity, based on coal ash composition; hot-gas cleanup issues to remove sulfur and mercury; and the impact of coal quality and options for $\mathrm{CO}_{2}$ separation and capture (3).

In light of the limitations identified in part because of advancing technologies and the shifting paradigm about clean energy sources, a third phase of the consortium project (CABRE III) was proposed, with the major goal to provide state-of-the-art tools that enable matching fuel characteristics with gasification system design and operation to optimize performance and enhance availability. Some of the challenges are extremely difficult to evaluate experimentally in current gasification systems, especially when working under high-pressure conditions. Consequently, computer models are now key tools for providing useful information relating fuel characteristics to gasification system design and operation, particularly the capability to predict performance based on fuel properties and operating conditions. Hence, it was desired to transform the analysis and test results obtained in the CABRE III project into a modeling program to provide this predictive capability. The program was designed to include modules to better predict slag viscosity and flow, deposition and reaction of ash and slag with refractory surfaces, deposition of ash on gas-cooling surfaces, and interactions of ash in gas filtration and cleanup components.

The concept of the original CABRE model was updated to include additional information on partitioning, deposition, slag flow, and removability. In addition, a model was built based on fluid-bed gasification, using the results of the fluidized-bed testing. The model is similar to the models developed for entrained-flow gasification but focuses on fluidization velocity and ashbed material agglomeration potential.

\section{APPROACH}

The CABRE III model provides an opportunity for users to improve their fundamental understanding of fuel quality parameters that affect gasification performance by focusing on the chemical, mineralogical, thermobarometric, and rheological properties of fuel gasification ashes. In addition, the CABRE III model also provides more evaluation tools for gasifier design engineers and operators to assess coal requirements and optimize operating conditions. A series of indexes for predicting ash deposition in both EFG and FBG systems as a function of coal properties, system configuration, and operating parameters were developed and packaged in a user-friendly computer program. Current fundamental understanding of ash formation, slag flow, ash deposition, and removal of particulate- and gas-phase species was coupled with applied engineering understanding. The CABRE III model provides information that can be used to 
develop mitigation methods for the types of problematic fuel ash-derived species in EFG systems and bed agglomeration in FBG systems. In addition to evaluating ash deposition and slag flow control issues in gasifier vessels, ash deposition downstream of the gasifier in coolers and collection devices can be evaluated.

In Year 6 of the CABRE III project, the main focus was to develop an improved model for predicting coal ash behavior and inorganic transformations in reducing environments such as gasification systems. Involvement of industrial sponsors ensured applied research directed toward full-scale systems. The project structure promoted interaction between industrial sponsors, research personnel, and DOE managers which made for meaningful dialogue and facilitation of excellent science and results.

\section{Facilities and Methods}

The model was developed with data from several fuels selected by the sponsors, including bituminous coal, subbituminous coal, lignite, and petroleum coke (petcoke). The data from these fuels were obtained using in-house EERC laboratories and the pilot-scale EFG and FBG facilities at the EERC.

For a complete characterization of these fuels, the EERC has several capabilities for testing and analyzing several different types of natural resources pertaining to the energy industry, including the Fuels Laboratory for performing analysis of fuel properties (proximate, ultimate, heating value, loss on ignition, ash content, etc.); Natural Materials Analytical Research Laboratory (NMARL) equipped with several electron microscopes and x-ray-based apparatus for various microscopic analyses (x-ray diffraction [XRD]), CCSEM, SEMPC, QEMSCAN [quantitative evaluation of minerals by scanning electron microscopy], x-ray fluorescence [XRF], and electron backscatter diffraction [EBSD]), and Analytical Research Laboratory (ARL) for various advanced analytical techniques (gas chromatography [GC]-mass spectroscopy [MS] and GC-atomic emission spectroscopy [GC-AES], etc.). In addition to the various laboratories, there are several pilot-scale facilities, including an EFG and FBG, which were used for performing pilot-scale tests described in this study. All of these facilities apply standard procedures such as ASTM International methods, in addition to the EERC-developed procedures specific to fuels and natural resource characterization and energy conversion system testing.

The project was divided into several tasks including 1) characterization of sponsors selected fuels; 2) evaluation of adverse ash effects on relatively cool surfaces; 3) evaluation of the gasification performance of selected feedstocks in a pilot-scale EFG and bench-scale FBG equipped with gas cleanup systems; 4) gas cleanup and $\mathrm{CO}_{2}$ separation evaluation and testing; 5) development of predictive models for slag flow, refractory surface deposition and reaction, deposition on gas-cooling equipment, and hot-gas filtration; 6) verification of models using case studies of full-scale gasification systems; and 7) reporting and information dissemination to the sponsors. The data gathered from other project tasks have been used to develop the model.

A brief description of some of the advanced equipment and EERC-developed and/or standard procedures mentioned above, which were used for characterization and testing, is provided below. 


\section{Task 1 - Feedstock Characterization}

The fuels and blends that were selected by the sponsors for testing during this project are shown in Table 1. Extensive characterization of these fuels and blends included standard analyses to determine fuel properties such as proximate, ultimate, heating value, and ash chemical composition. In addition, more advanced techniques such as trace element analyses, CCSEM, and chemical fractionation were carried out to determine the association and abundance of major, minor, and trace elements in the fuels. The mode of occurrence and chemical speciation of the inorganic components in coal influence their transformations and fate during gasification, and so it is important to analyze these constituents in both coal and the resulting ash or slag. Ash and slag samples generated from the fuels and/or blends were also analyzed to determine slag viscosity and to evaluate their interactions with the refractory material in a gasification environment.

\section{Fuel Property Analysis}

Proximate and ultimate analyses of the fuels were performed using ASTM Methods D3172, D5142, and D3176. Fuel ash elemental oxide compositions were determined using wavelength-dispersive XRF (WDXRF) spectrometry, as described in ASTM D4326. Coal mineralogy and mineral grain-size distributions were determined using CCSEM, similar to the procedures described by Galbreath and others (4). The identities, concentrations, and size distributions of minerals in coal are very useful for predicting and understanding the causes of ash deposition.

Chemical fractionation analyses were performed to determine the content of inorganic and organic mineral associations of major and minor elements in the lower-rank coals provided by the project sponsors. The chemical fractionation procedure estimates the distribution of seven elements $(\mathrm{Na}, \mathrm{Mg}, \mathrm{Al}, \mathrm{K}, \mathrm{Ca}, \mathrm{Ti}$, and $\mathrm{Fe}$ ) among the organic and inorganic phases in coal. The procedure is based on the differences in solubility of coal constituents in stirred solutions of deionized water $\left(\mathrm{H}_{2} \mathrm{O}\right), 1 \mathrm{M}$ ammonium acetate $\left(\mathrm{NH}_{4} \mathrm{OAc}\right)$, and $1 \mathrm{M}$ hydrochloric acid $(\mathrm{HCl})(5,6)$. Knowledge of the distribution of inorganic constituents in coal is useful in predicting the physical and chemical transformations that occur during coal combustion and gasification. Chemical fractionation is especially valuable when examining the inorganic constituents in lowrank coals, which contain significant quantities of inorganic metals in the form of salts of organic acid groups.

Table 1. Fuels Tested in CABRE III

\begin{tabular}{lccc}
\hline Fuel/Blend & Fuel Type & Source & Sponsor \\
\hline Falkirk & Lignite & North Dakota & NDIC \\
Center & Lignite & North Dakota & NDIC \\
Illinois No. 6 & Bituminous coal & Illinois & ConocoPhillips \\
Petcoke & Petcoke & Illinois & ConocoPhillips \\
\hline
\end{tabular}


A brief description of the chemical fractionation procedure is as follows. A 40-80-g sample of coal was ground to -200 mesh and dried in a vacuum oven to constant weight. The coal was analyzed for ash content (ASTM D3174) and major and minor elements by WDXRF according to ASTM D4326. The coal was then subjected to successive extraction treatments, as summarized in Table 2. After each extraction, the coal mixture was filtered and a portion of the residue was analyzed for ash content (ASTM D3174) and major and minor elements. The chemical data and ash contents for the original unleached coal and residues were utilized in mass balance calculations to determine the elemental losses relative to the original unfractionated coal from each extraction. The elements removed by $\mathrm{H}_{2} \mathrm{O}$ are primarily associated with water-soluble minerals (e.g., halite, thenardite). Exchangeable ions, principally elements associated with montmorillonite (clays) and salts of organic acids are removed by $\mathrm{NH}_{4} \mathrm{OAc}$. $\mathrm{HCl}$ removes elements associated with acid-soluble minerals (e.g., calcite, dolomite, siderite) and organic coordination complexes. Elements remaining in the final residue are presumably associated with insoluble minerals (i.e., clays, quartz, and pyrite).

\section{Composition Analysis of Coals, Slags, and Deposits}

The chemical compositions of the raw fuels, ash, and slags were determined by one or more of several techniques at the EERC, including QEMSCAN, CCSEM, XRD, XRF, and EBSD. The CCSEM, XRF, and XRD analyses are standard procedures commonly employed to quantity mineral types, quantities, and compositions. QEMSCAN functions in a way similar to SEM, except that it does not provide a quantitative chemical composition for material samples. A brief description of QEMSCAN follows.

\section{Description of QEMSCAN}

QEMSCAN is an automated mineral analysis system that is based on the standard SEM technique. The main components of the instrument include a Carl Zeiss SEM system chamber and motherboard, four high-speed energy-dispersive spectrometry (EDS) silicon drift detectors (SDD) made by Bruker AXS and proprietary software for mineral classification and quantification, which was developed by FEI Company (7). The software runs on a PC platform with a standard 32-bit Windows operating system. The major difference between QEMSCAN and a standard SEM system is that QEMSCAN uses a higher-energy electron beam with an accelerating voltage of $25 \mathrm{kV}$ and higher specimen current of $5 \mathrm{nA}$. By combining these factors with up to four of the new, fast SDD EDS detectors, the QEMSCAN system is thus designed to optimize the speed of analysis. A schematic of the system is shown in Figure 1. It is an effective tool for determining mineral and amorphous-phase types present in coal or ash deposits.

Table 2. Chemical Fractionation Protocol

\begin{tabular}{lccc}
\hline Reagent & Quantity, $\mathrm{mL}$ & Temperature, ${ }^{\circ} \mathrm{C}$ & Duration, $\mathrm{h}$ \\
\hline $\mathrm{H}_{2} \mathrm{O}$ & 100 & $\sim 25$ & 24 \\
$1 \mathrm{M} \mathrm{NH}_{4} \mathrm{OAc}^{*}$ & 100 & 70 & 24 \\
$1 \mathrm{M} \mathrm{HCl}^{* *}$ & 100 & 70 & 24 \\
\hline
\end{tabular}

* Extraction performed in triplicate.

** Extraction performed in duplicate. 


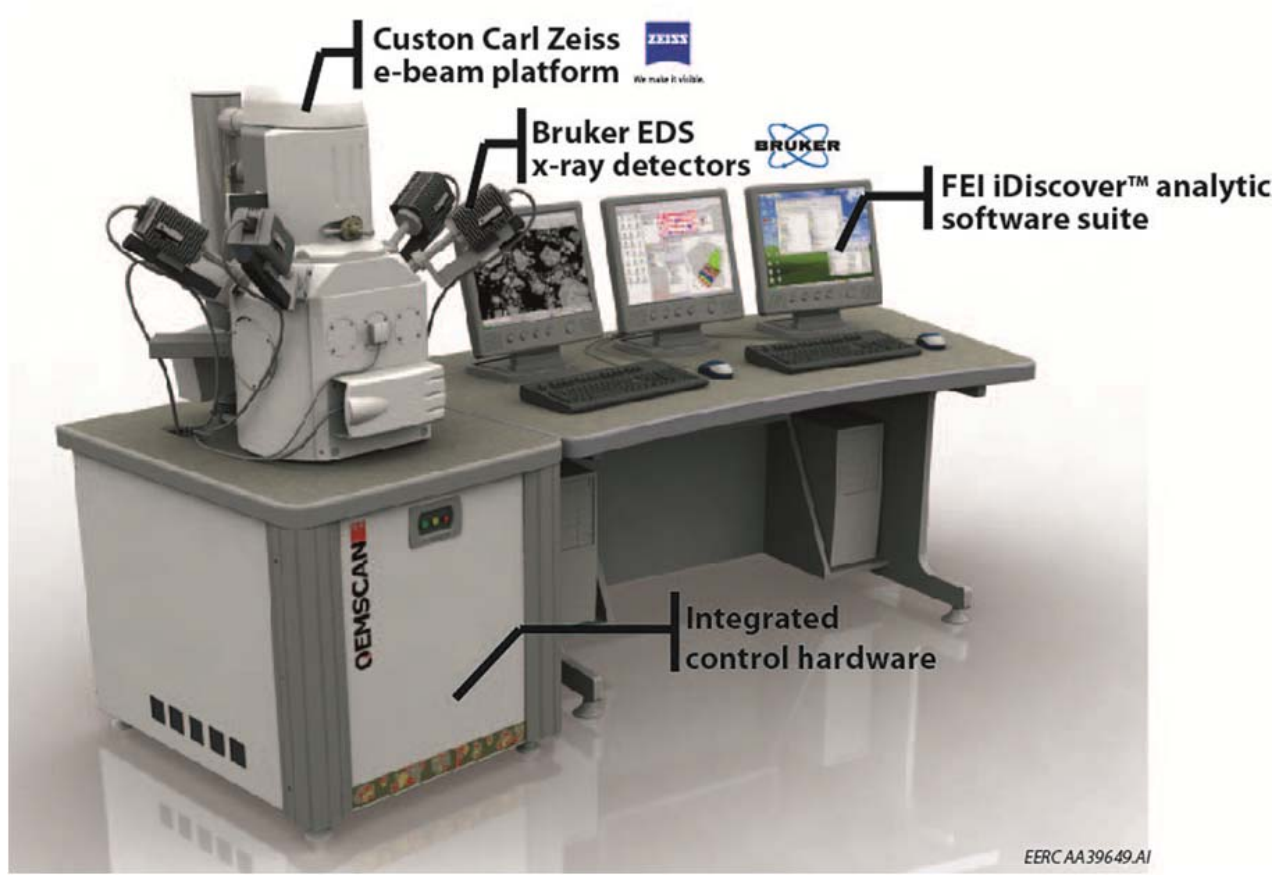

Figure 1. Schematic of the QEMSCAN system.

Gasification deposit and fly ash samples were analyzed for major and minor elemental oxide concentrations using WDXRF according to ASTM D4326. Deposit and fly ash samples were also analyzed for loss on ignition (LOI) according to ASTM D7348-08. A limited number of samples were also analyzed using the QEMSCAN system. XRD analyses were performed on a couple of deposit samples. XRD patterns were collected over a 5-60 2-theta angle with a Bruker D8 Advance theta-theta $\mathrm{x}$-ray diffractometer system operating at $40 \mathrm{kV}$ and $40 \mathrm{~mA}$, with system geometry consisting of a parallel incident beam Goebel mirror to monochromatize and collimate $\mathrm{Cu} \mathrm{K} \alpha$ radiation, 0.02 2-theta steps, and 7 to $15 \mathrm{sec} / \mathrm{step}$. Diffraction peaks were identified using the Bruker EVA evaluation software utilizing the International Centre for Diffraction Data (ICDD) PDF-2 inorganic and organic powder diffraction database.

\section{Viscosity Measurements}

To perform viscosity measurements on fuel ashes, representative coal samples were ashed at $750^{\circ} \mathrm{C}$ to remove all combustible materials. A slag was then prepared by melting the ash at $1550^{\circ} \mathrm{C}$ in a platinum crucible under a reducing atmosphere. The molten ash was quenched by pouring it on a brass plate at room temperature. The slag was then crushed, placed in a platinumrhodium crucible, and reheated in the viscometer under reducing conditions to approximately $1550^{\circ} \mathrm{C}$ to begin testing. The viscosity is subsequently measured as the temperature is dropped, holding at each temperature until viscosity is stabilized. 
A Haake VT550 ViscoTester ${ }^{\circledR}$ (Figure 2), which is a rotating-bob viscometer with a rotating measuring head, was used in this project. The spindle is submerged into the slag until the slag just covers its top, and then it is rotated at $45.3 \mathrm{rpm}$. The viscosity testing was performed in a reducing atmosphere of $95 \% \mathrm{Ar}$ and $5 \% \mathrm{H}_{2}$. The torque applied to the viscometer is then converted to an electrical signal which is sent to a computer with a data acquisition program that determines the viscosity of the slag. The viscosity range of 10 to 1000 poise is attainable for the VT550 system. Prior to making measurements, the viscometer was calibrated with National Institute of Standards and Technology (NIST) silicate glass 710a. The accuracy of the viscosity measured with this equipment was about $95 \%$.

Measurement of the viscosity of high-temperature slags such as gasifier slags can be challenging because most viscometers are designed for room-temperature measurements. However, many researchers have found that the rotating-bob viscometer is a good candidate to measure the viscosity of gasifier slags $(8,9)$, especially the rotational viscometer, which gives good results for liquid silicates in the relevant viscosity range of 10 to $10,000 \mathrm{~Pa} \cdot \mathrm{s}(10,11)$. Although this approach has been recommended as adequate, it was found in this project that, practically, it can be difficult to measure $T_{c v}$ reliably because the time frame for making measurements is not long enough for the slag to attain equilibrium prior to measurement. However, for the purpose of this project, carried out on a small pilot-scale gasifier, this limitation is not an issue because it normally takes about the same time frame, i.e., 10-15 min, for the slag to run down the walls of the gasifier. Hence, the results under these conditions were considered representative of gasifier slag conditions. Typical steps to measure the viscosity of ash and slag samples in this project are as follows:

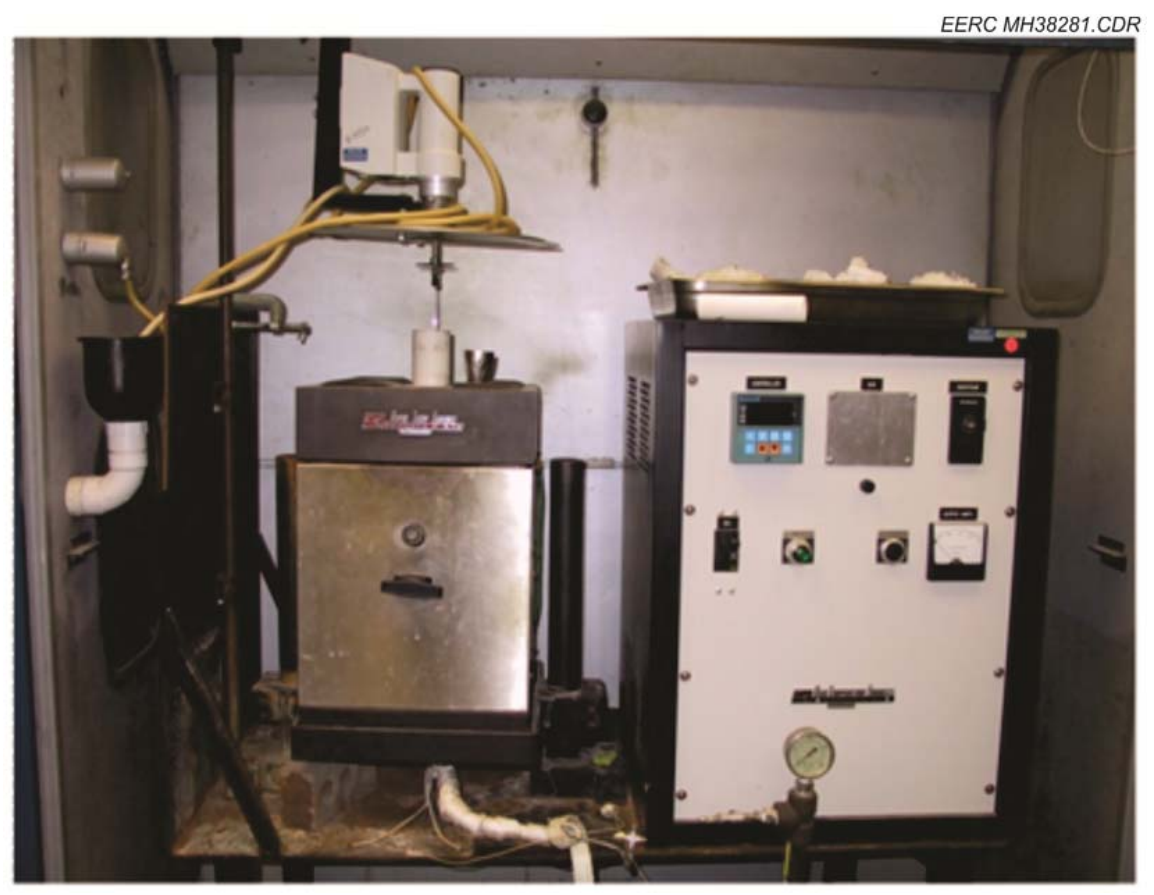

Figure 2. Slag viscometer. 
1. Ash the sample at $750^{\circ} \mathrm{C}$ under reducing conditions to remove all of the gasifiable materials (a mix of $\mathrm{CO}$ and $\mathrm{CO}_{2}$ is present in the oven).

2. Melt the ash or the ash blend at $1500^{\circ} \mathrm{C}$ in a platinum crucible.

3. Quench the sample at room temperature.

4. Crush the slag.

5. Place the slag in a platinum-rhodium crucible ( $10 \%$ rhodium for rigidity of the crucible).

6. Reheat the slag to $1400^{\circ} \mathrm{C}$.

7. Begin testing the viscosity.

8. Subsequently measure the viscosity while keeping the temperature constant (holding the temperature constant for about 10 to 15 minutes to allow the slag to stabilize and simulate operating conditions).

\section{Slag-Refractory Interaction Tests}

The EERC's bench-scale dynamic corrosion furnace (DCF) was designed to simulate the flow of slag on a refractory brick surface. As shown in Figure 3, a groove is machined in the refractory brick, which is then placed in the DCF. Finely ground slag is fed onto the top of the refractory, where it melts and flows down the groove. After a specified number of hours, the brick is removed and cross-sectioned. A SEM is used to determine the extent of slag penetration and the composition of the slag-refractory interface. Deeper penetration may be indicative of a more problematic and corrosive or reactive slag.

\section{Task 2 - Examination of Ash Behavior}

This task involved evaluation of slag flow, ash interaction with refractories, and ash interaction with cooling surfaces and gas cleanup devices. Slags were prepared by ashing selected fuel feedstocks. The slag viscosity as a function of temperature was measured in a laboratory-scale rotating-bob viscometer using a simulated gasification atmosphere. Similar viscosity measurements were performed on selected slag samples obtained from bench- and pilot-scale testing and from full-scale gasification systems. These results were correlated with the extensive fuel feedstock analyses to improve the prediction of viscosity and slag flow. Slags were also tested in the EERC dynamic slag application furnace (DSAF) to evaluate slag attack on a suite of refractory materials selected by the sponsors. In the course of the examination of gas cleanup systems, filter and cooling surfaces were analyzed to determine the extent of the interaction of condensing ash components on these surfaces. 


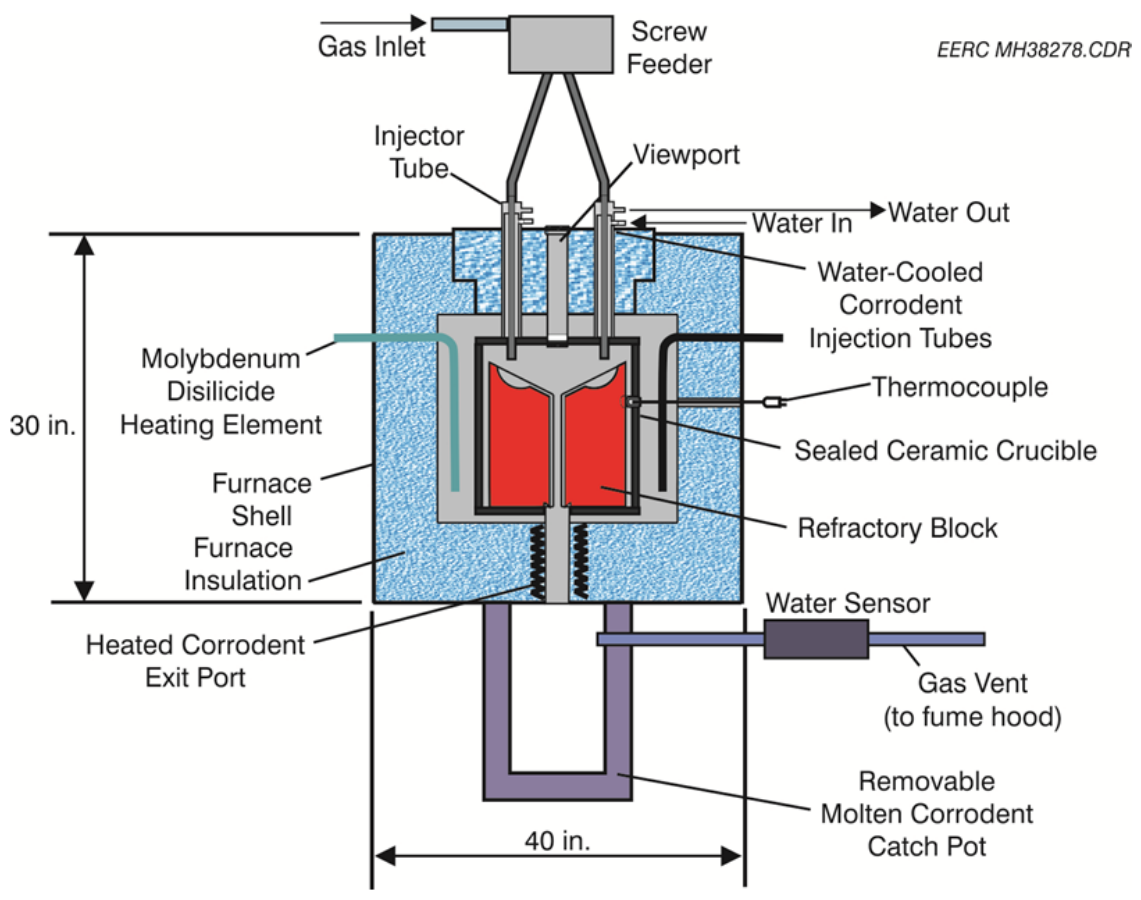

Figure 3. Dynamic corrosion furnace.

\section{Task 3 - Evaluation of Ash Behavior in Bench-Scale Systems}

Small pilot- and bench-scale gasification systems at the EERC were used to evaluate ash and slag behavior. A bench-scale FBG and a bench-scale EFG were used for the testing. The aim of the tests was to evaluate the effects of operating temperature, air-blown versus oxygen-blown operation, oxidant-to-fuel ratio, steam-to-fuel ratio, bed material selection, and gettering agents on ash behavior. Ash and/or slag samples were taken from the gasification units as well as from downstream units: cyclone(s), filter vessels, and other gas cleanup equipment. Ash samples were evaluated using standard analytical techniques such as SEM morphology. Additionally, samples were analyzed using advanced ESBD, which can provide a point-by-point analysis that can determine crystalline phases and the difference between amorphous and crystalline regions.

\section{Task 4 - Gas Cleanup and $\mathrm{CO}_{2}$ Capture}

During evaluation of ash and slag behavior, syngas was produced and tested in gas cleanup schemes to evaluate the potential for $\mathrm{CO}_{2}$ separation. In the case of the FBG, a cyclone and candle filter were used together to remove the ash in the syngas stream. This enabled an evaluation of the elemental and mineral composition of the ash as a function of particle size. Slag and fly ash samples were taken from the EFG and also analyzed in detail. Fly ash samples were analyzed by the SEM technique.

The effects of ash and other syngas contaminants such as sulfur on $\mathrm{CO}_{2}$ capture technologies were also evaluated. Parameters such as syngas contamination, pressure, and temperature are all of great importance when selecting a $\mathrm{CO}_{2}$ separation technology. Although 
some amine-based technologies used for $\mathrm{CO}_{2}$ capture are sulfur-tolerant, sulfur can irreversibly poison the sorbent. Warm-gas $\mathrm{CO}_{2}$ separation is of particular interest because of the potential to reduce the high cost of dealing with $\mathrm{CO}_{2}$. Several $\mathrm{CO}_{2}$ collection options were evaluated based on the syngas characteristics, and at least one technology was tested on the bench-scale systems.

\section{Task 5 - Modeling of Ash Behavior}

Computer models are now key tools for providing useful information relating fuel characteristics to gasification system design and operation, particularly the capability to predict performance based on fuel properties and operating conditions. Hence, it was desired to transform the analysis and test results obtained from this project into a modeling program to provide this predictive capability. The program was designed to include modules to better predict slag viscosity and flow, deposition and reaction of ash and slag with refractory surfaces, deposition of ash on gas-cooling surfaces, and interactions of ash in gas filtration and cleanup components.

The new CABRE III model includes additional information on partitioning, deposition, slag flow, and deposit removability. In addition, a model was built based on fluid-bed gasification, using the results of the fluidized-bed testing. The fluidized-bed model has more of a focus on fluidization velocity and ash-bed material agglomeration potential.

\section{Computer Modeling with Aspen Plus ${ }^{\circledR}$ and FactSage ${ }^{\mathrm{TM}}$}

AspenTech's Aspen Plus software was used to develop process flow models and detailed mass and energy balances. Aspen Plus calculates mass balance, energy balance, chemical reaction equilibrium, phase equilibrium, and has some capability to perform kinetic evaluations. Although Aspen software was used to develop the CABRE III Program, the final CABRE III model does not require Aspen Plus to run the program. For users who have an Aspen license, Aspen will enhance the overall results. Specifically, gas compositions and gasifier outlet temperatures can be determined by integrating Aspen with the CABRE III program. Aspen Plus also has a set of built-in equations that are used to determine properties of fuel based on proximate, ultimate, and sulfur analysis. Properties such as enthalpy and density are determined and then utilized to perform the overall mass and energy balance on the system, including the expected temperature and composition based on Gibbs free energy minimization.

The FactSage program was also used to predict some volatile inorganic species in the fuels. FactSage is a commercially available thermochemical equilibrium program package that predicts the amounts of solid-, liquid-, and gas-phase chemical species as a function of temperature by minimization of Gibbs free energy for the system. Once an initial system composition is set, FactSage determines equilibrium concentrations of solid, liquid, aqueous, and gas species over a specified temperature range. Normally, at least 700 elements and compounds are considered in the calculations. FactSage also calculates the amount and composition of a silicate-based liquid slag as a function of temperature using the viscosity of the liquid-phase material predicted by one of the literature viscosity models. It should be noted that FactSage calculations are based on equilibrium, whereas the product gas from a gasifier is in a "frozen 
equilibrium," with the reaction kinetics at lower temperature too slow for the system to reach actual thermodynamic equilibrium.

Although the FactSage calculations are based on thermodynamic equilibrium, they can provide valuable predictions of the partitioning of volatile elements to the gas phase and the temperature of subsequent condensation during gasification. For example, Figures 4 and 5 show the predicted amounts of gas-phase sodium and potassium species in a typical gasification environment for the Center Mine and Falkirk Mine lignite ashes. The calculations indicate that significantly more $\mathrm{K}$ and $\mathrm{Na}$ species will be in the gas phase for the Center Mine lignite. Hence, as the CABRE III model developed, some FactSage calculation results were incorporated. In particular, FactSage was also used to predict the transformation of volatile trace elements for which limited experimental data are available in the literature.

\section{Task 6 - Verification}

The model predictions were compared with operating experience at three selected fullscale gasification systems, chosen to represent different gasifier types as well as a range of fuel feedstocks. In addition, selected samples were obtained, as available, from these full-scale systems for analysis to compare with model predictions and with samples produced in this project. The results were used to make necessary improvements in the model predictions.

\section{Task 7 - Reporting}

The project team worked in close cooperation with the Project Steering Group, which included the committed project sponsors and DOE. Regular updates on overall project progress and results were provided through quarterly and annual reports to the sponsors. In addition,

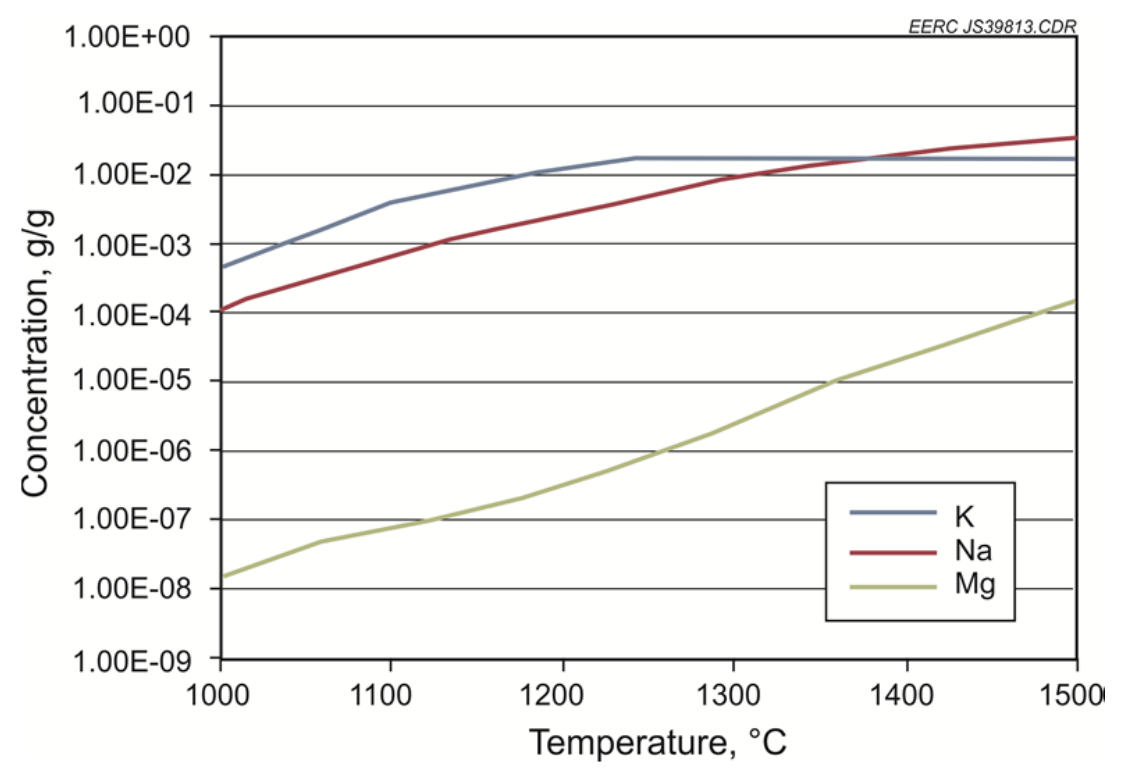

Figure 4. Gas-phase sodium and potassium species predicted by FactSage for Center lignite. 


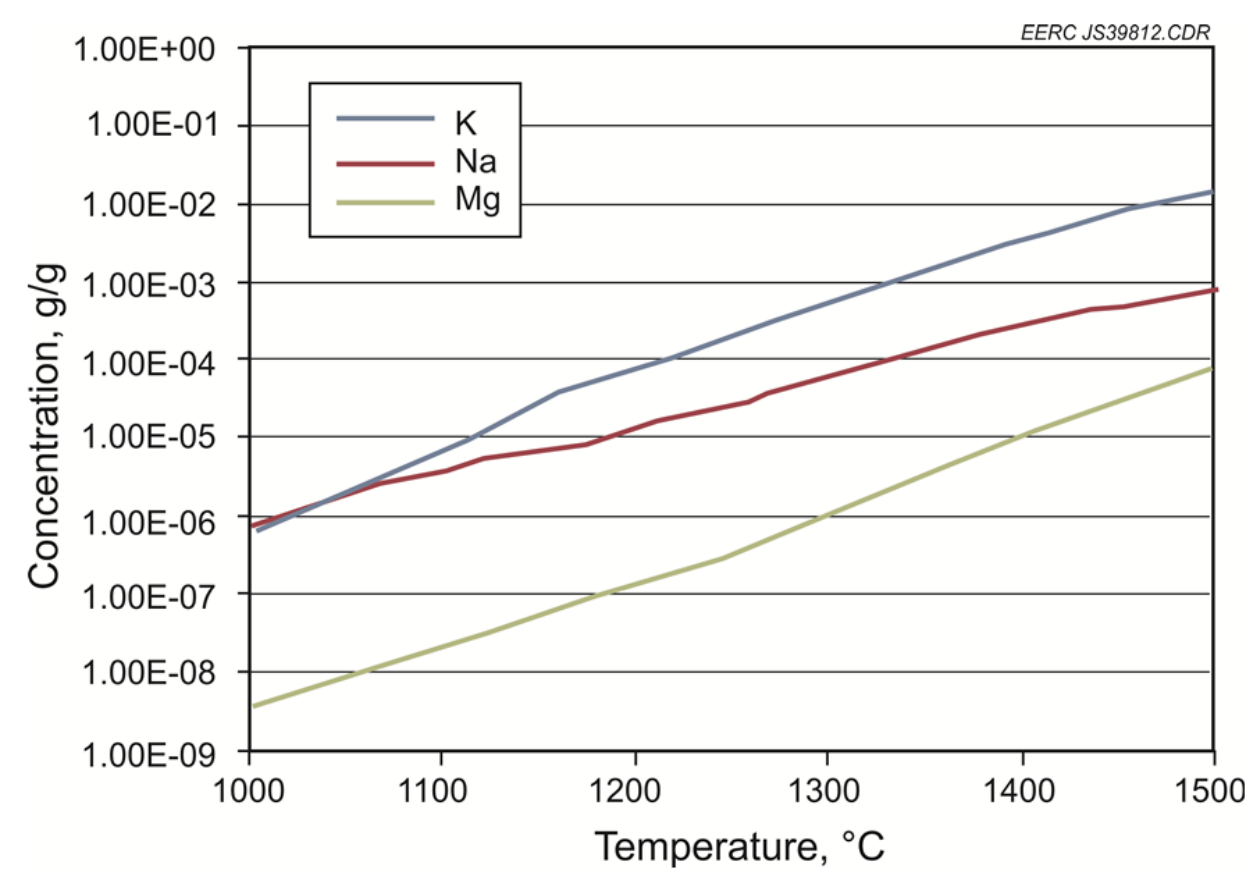

Figure 5. Gas-phase sodium and potassium species predicted by FactSage for Falkirk lignite.

project information of a proprietary nature was conveyed to the individual sponsors separately. This final report provides only a compilation of a few analyses and data results performed in the course of the project. In a previous report in 2011 (1) the majority of the data used to develop model algorithms was presented in great detail along with interpretation of the results and their incorporation into the model development, model validation, and the application of the results and model to gasification systems. This topical report is primarily focused on the principles of assembling the CABRE III model and model results.

\section{Data-Gathering Procedure}

Data were routinely obtained from pilot-scale EFG test runs in order to understand the behavior of coal ash. A test usually consisted of a 5-day run, during which one fuel was gasified using different, predetermined run conditions that are calculated using an Aspen model or as recommended by the sponsors. During a typical run, samples were collected that corresponded to the various combinations of run parameters. At the end of each run, an Excel spreadsheet with all the operational parameters, logged every 30 seconds, was produced. Several screenshots of the command screen were usually taken in order to capture certain run conditions and possible upsets of the system. The syngas was continuously analyzed by a laser gas analyzer (LGA) and a gas chromatograph for confirmation.

To reduce the data to a form that could be analyzed, the data were separated into periods of stable syngas production. The parameters were summarized over the specific time frame during which a sample was collected by calculating the average over the time frame. Based on the stability and the quality of the syngas, specific samples were selected for analysis. For each run, 
it was attempted to produce slag and fly ash for viscosity and elemental analysis while achieving carbon conversion rates close to industrial gasifiers.

After the samples were produced, a LOI test was performed to determine the amount of carbon still unconverted. Carbon was assumed to be the only component in the slag that is still combustible. After the data were summarized and analyses were completed, the operational parameters were compared to the XRF analyses to establish any correlations.

\section{Data Reduction and Analysis}

During a 1-week gasification test run, samples were continuously collected and a subset of these were analyzed in detail using methods previously described. A LOI test was performed on each sample in order to get the mass balance of inorganics in the system using simple expressions given in Appendix A.

Some challenges were encountered with the coal-feeding system during EFG test runs. Therefore, other means of calculating elemental partitioning were investigated using data from Test Run EFG028, and the results showed that the approach shown in Equation 1 was the most reliable approach.

$$
\text { Partitioning }=\frac{\mathrm{x}_{\mathrm{fa}} \mathrm{x}_{\text {elt-fa }}}{\mathrm{x}_{\text {elt-raw }}}
$$

Where $\mathrm{X}_{f a}$ is the fraction of fly ash, $\mathrm{X}_{\text {elt-fa }}$ is the fraction of the element in fly ash and $\mathrm{X}_{\text {elt-raw }}$ is the fraction of the element in coal or raw fuel. A detailed description of data reduction and analysis, including a description of statistical considerations relevant to partitioning data is provided in Appendix A.

\section{RESULTS AND DISCUSSION}

\section{Model Development}

\section{Program Description}

The CABRE III model provides a prediction of coal ash behavior in reducing environments such as in gasification systems. The program is developed based on semiempirical relationships that can be found in the literature and/or correlations of experimental data obtained from a small pilot-scale EFG at the EERC. A limited amount of available data obtained from full-scale gasifiers was used in some cases. The main focus of the program model is to predict the partitioning of coal ash as it progresses through the various unit operations beginning with the bottom zone of the gasifier. The model facilitates the understanding of various inorganic transformations and their potential impact on system equipment. At each stage, the fraction of volatile, nonvolatile, and deposited ash constituents, as well as their detailed compositions including major and trace element partitioning, is made. In addition, slag flow, corrosion, viscosity, and other slag physical properties in the gasifier are predicted. These estimates allow for prediction of the slagging and corrosion characteristics of the fuel and to evaluate its behavior under reducing environments. 
The information obtained from this program will assist in maintaining prolonged gasifier operation free from failure or facilitate troubleshooting to minimize downtime in the event of a problem. The various components of the program are described in detail as follows.

\section{Program Components}

\section{Partitioning}

Partitioning is performed based on mass balance in the system and assumed to be temperature-independent for the major elements. This assumption is because of the lack of data in the literature and the extreme difficulty of measuring such data experimentally. Three main tasks are accomplished in the partitioning calculations:

- Separation of fuel ash into slag and fly ash fractions

- Major element partitioning

- Trace element partitioning

\section{Slag-Fly Ash Partitioning}

Partitioning of coal gasification products into slag and fly ash in an EFG was determined empirically using a combined set of literature data and experimental data from the CABRE III pilot-scale EFG testing. The overall mass partitioning takes into account the fraction of total fuel ash going to slag and to fly ash, which is different from enrichment factors that only indicate the relative enrichment or depletion of elements in slag or fly ash.

\section{Major Element Partitioning}

The slag and fly ash total fractions are further partitioned into their constituent major components. Normally, to calculate the overall partitioning, the mass balance involving total mass of coal ash, slag, and fly ash must be known. However, this overall ash mass balance is rarely accurately measured or reported for gasification systems. Alternatively, if XRF analysis of the coal, slag, and fly ash is available, the overall partitioning of the fuel ash can be calculated using the analysis results for each element as follows:

$$
W_{c a}=W_{s} * f_{s}+W_{f a} * f_{f a}
$$

Where $W_{c a}$ is the concentration of the element in coal ash in wt $\%$ on an oxide basis, $W_{s}$ is the concentration of the element in slag, $f_{s}$ is the fraction of coal ash that is slag, $W_{f a}$ is the concentration of the element in fly ash, and $f_{f a}$ is the fraction of coal ash that is fly ash. All compositions are normalized such that $f_{s}+f_{f a}=1$ or $f_{f a}=1-f_{s}$ and $f_{s}$ and $f_{f a}$ is obtained from the slag-fly ash partitioning above.

The partitioning of a given element, i, according to Equation 2 is independent of any other element, $\mathrm{j} \neq \mathrm{i}$, and it is assumed that the analyses have been normalized to a closure of $100 \%$ by mass on an oxide basis. Thus, a value of $f_{s}$ and $f_{f a}$ can be calculated for each element. Ideally, the same value would be obtained for $f_{s}$ and $f_{f a}$ from the calculation for each element, but because of 
uncertainties in the sampling and/or analysis, this is rarely the case. To correct for such uncertainties and to minimize the effect of elements present in low concentrations for which the relative error in the analysis is higher, such as $\mathrm{TiO}_{2}$, a weighted average of $f_{s}$ and $f_{f a}$ was determined for slag and fly ash, respectively. That is, each calculated value of $f_{s}$ and $f_{f a}$ was multiplied by the concentration (fraction) of that element in the original coal ash and then taking the average. Once the weighted average value of $f_{s}$ and $f_{f a}$ are known, the mass of each element in the slag and in the fly ash can be calculated. The ratio of these masses gives the partitioning of each individual major element between slag and fly ash. For normal fuels such as coal, the major elements considered are $\mathrm{SiO}_{2}, \mathrm{Al}_{2} \mathrm{O}_{3}, \mathrm{Fe}_{2} \mathrm{O}_{3}, \mathrm{TiO}_{2}, \mathrm{P}_{2} \mathrm{O}_{5}, \mathrm{CaO}, \mathrm{MgO}, \mathrm{Na}_{2} \mathrm{O}$, and $\mathrm{K}_{2} \mathrm{O}$. However, for petcoke, nickel and vanadium constitute a special case. These are considered to be major elements, since their concentrations (reported as $\mathrm{NiO}$ and $\mathrm{V}_{2} \mathrm{O}_{5}$ ) are often present in the percent range compared to other fuels such as coal, where $\mathrm{Ni}$ and $\mathrm{V}$ are present in the ppm range and so considered to be trace elements. The partitioning of these special case elements is described below.

Little information was found in the literature regarding partitioning in full-scale EFGs. Hence, values were obtained for a Prenflo gasifier operating with Pittsburgh No. 8 bituminous coal, Ruhr A and Ruhr B brown coals, and a Saar brown coal, found in Clarke (12). Pilot-scale CABRE III tests of Center and Falkirk lignite, along with earlier tests of Kosse and Red Hills lignite, were used to obtain average partitioning values for the overall fuel ash and for the major elements. These results are given in Table 3. It should be noted that the Prenflo results for overall partitioning are somewhat higher than those for the EFG tests. It is not known if this difference is due to the difference in pilot- versus full-scale effects or to the difference in gasifier type.

\section{Elemental Slag-Fly Ash Partitioning Based on User-Supplied Total Partitioning}

To provide more flexibility in the partitioning module, the option for the user to specify overall partitioning between slag and fly ash for a particular EFG was included as variable for slag-fly ash partitioning. To allow this, a regression analysis was performed on the partitioning of major elements $\left(\mathrm{SiO}_{2}, \mathrm{Al}_{2} \mathrm{O}_{3}, \mathrm{Fe}_{2} \mathrm{O}_{3}, \mathrm{TiO}_{2}, \mathrm{P}_{2} \mathrm{O}_{5}, \mathrm{CaO}, \mathrm{MgO}, \mathrm{Na}_{2} \mathrm{O}\right.$, and $\left.\mathrm{K}_{2} \mathrm{O}\right)$ from the Prenflow (12) data and data obtained from the EERC's EFG. A linear regression of the fraction of each element partitioning to fly ash versus the overall average portioning was performed. The regressions were constrained to pass through the origin of the Cartesian axes, which corresponds to $100 \%$ slag and no fly ash. The results of the regression analysis give the following expressions for the fraction of the element in fly ash and slag, respectively:

$$
\begin{aligned}
& f_{\text {elt }}^{f a}=f_{\text {user }}^{f a} * m \\
& f_{\text {elt }}^{s}=1-f_{\text {elt }}^{f a}
\end{aligned}
$$

Where $f_{\text {elt }}^{f a}$ is the fraction of the element in the fly ash, $f_{\text {elt }}^{s}$ is the fraction of the element in slag, $f_{\text {user }}^{f a}$ is the total user-supplied fraction of fly ash produced, and $m$ is the slope of the linear regression analysis for that element. 
Table 3. Average Major Elements Partitioning Between Slag and Fly Ash for Various Fuels

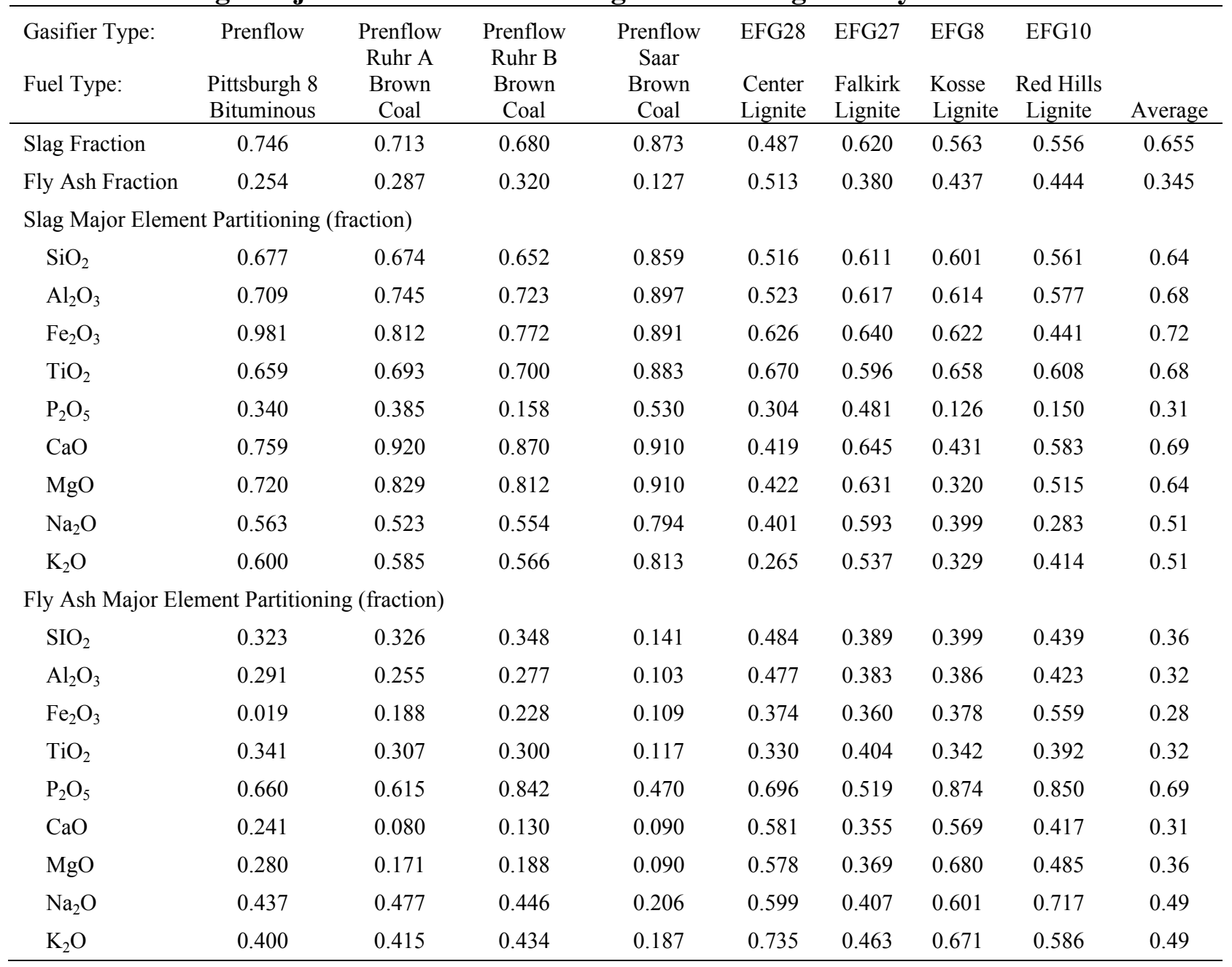

\section{Partitioning of Ni and V as Major Elements in Petroleum Coke}

The procedure for calculating major element partitioning described above failed for $\mathrm{Ni}$ and $\mathrm{V}$ because there was no elemental closure on the pilot-scale EFG-35 test run that was performed on petcoke. Therefore, equilibrium thermodynamic calculations were used to estimate the partitioning of these elements, which predicted that the great majority of the vanadium and nickel will be in the solid phase at typical gasifier gas outlet temperatures. Results of the thermodynamic calculations show that 0.895 and 0.984 of nickel and vanadium, respectively, will be in the solid phase. These values have been used in the model to estimate the fractional partitioning of $\mathrm{Ni}$ and $\mathrm{V}$ to slag.

\section{Trace Element Partitioning}

The 1990 Clean Air Act Amendments identified compounds of 11 inorganic trace elements as hazardous air pollutants (HAPs). These trace elements are $\mathrm{Be}, \mathrm{Cr}, \mathrm{Mn}, \mathrm{Co}, \mathrm{Ni}, \mathrm{As}, \mathrm{Se}, \mathrm{Cd}, \mathrm{Sb}$, $\mathrm{Hg}$, and $\mathrm{Pb}$ and are of concern in gasification systems because of their potential for emissions. 
Consequently, the predictions for these elements have been implemented into the model. Two other trace elements, $\mathrm{Zn}$ and $\mathrm{Ge}$, are also included because of their reported potential for deposition from the product gas stream.

Coal, slag, and fly ash samples from EFG-27 (Falkirk lignite), EFG-28 (Center lignite), EFG-29 (Illinois No. 6 bituminous coal), and EFG-35 (petcoke) were analyzed for these elements. As with the major elements, these analysis results exhibited a lack of closure because of uncertainties in sampling and analysis. Hence, the procedure to obtain the partitioning fractions for the trace elements is as follows:

1. Measure concentrations $(\mu \mathrm{g} / \mathrm{g})$ of each element in slag and fly ash.

2. Multiply the concentration of each element by the overall mass of slag-fly ashpartitioning fractions for that fuel to get the mass of each trace element in slag and fly ash, assuming that these trace elements partition in a way similar to the bulk fuel ash.

3. Add the values of each element in slag and fly ash to obtain the "total" mass of each element.

4. The fractional partitioning of each trace element between slag and fly ash is calculated as the mass of each trace element in slag or fly ash divided by the "total" mass of the element obtained in Step 3 above.

An example of the partitioning data obtained using this method of calculation is given in Table 4.

Table 4. Selected Trace Element Partitioning Between Slag and Fly Ash

\begin{tabular}{lcc}
\hline Element & Slag Fraction & Fly Ash Fraction \\
\hline $\mathrm{Be}$ & 0.794 & 0.206 \\
$\mathrm{Cr}$ & 0.852 & 0.148 \\
$\mathrm{Mn}$ & 0.916 & 0.084 \\
$\mathrm{Co}$ & 0.931 & 0.069 \\
$\mathrm{Ni}$ & 0.895 & 0.105 \\
$\mathrm{Zn}$ & 0.600 & 0.400 \\
$\mathrm{Ge}$ & 0.874 & 0.126 \\
$\mathrm{As}$ & 0.643 & 0.357 \\
$\mathrm{Se}$ & 0.691 & 0.309 \\
$\mathrm{Cd}$ & 0.492 & 0.508 \\
$\mathrm{Sb}$ & 0.347 & 0.653 \\
$\mathrm{Hg}$ & 0.906 & 0.094 \\
$\mathrm{~Pb}$ & 0.220 & 0.780 \\
\hline
\end{tabular}


Estimates of the partitioning between slag and fly ash have been implemented for additional elements including Li, B, Sc, Ga, Br, Rb, Y, Zr , Nb, Mo, Tc, Ru, Rh, Pd, Ag, In, Sn, Te, I, Cs, La, Ce, Pr, Nd, Pm, Sm, Eu, Gd, Tb, Dy, Ho, Er, Tm, Yb, Lu, Hf, Ta, W, Re, Os, Ir, Pt, $\mathrm{Au}, \mathrm{Tl}, \mathrm{Bi}, \mathrm{Po}, \mathrm{At}, \mathrm{Fr}, \mathrm{Ra}, \mathrm{Ac}, \mathrm{Th}, \mathrm{Pa}$, and U. None of these elements is considered to be of significance in entrained-flow gasification, but they have been included in the event one or more of them become of interest. The fraction of each of these elements partitioning to fly ash is estimated from the fraction that is volatilized at a given product exit gas temperature. An average concentration of each element was taken to be the midpoint of the typical concentration range in coals given by Swaine (13) for the available components. Equilibrium thermodynamic calculations were performed using the major elemental ash components of the CABRE III Center lignite coal to determine the gas-phase fractions of the components of interest that were not available in the paper. A typical gasification atmosphere at a pressure of $16 \mathrm{~atm}$ was used, but without $\mathrm{CO}, \mathrm{CO}_{2}$, and $\mathrm{CH}_{4}$. Removal of these gases from the calculations results in the other major gas components $\left(\mathrm{H}_{2}, \mathrm{H}_{2} \mathrm{O}, \mathrm{H}_{2} \mathrm{~S}\right.$, and $\left.\mathrm{COS}\right)$ remaining relatively constant over the calculation temperature range. Calculations were performed for each of the trace elements individually, which ignores possible interactions between the trace elements.

Nonlinear regression analysis was performed on the predicted gas-phase concentrations for each species, and the fitted curve was of the form:

$$
\text { Flyashfract }=a * e^{b * T}+c
$$

where $a, b$, and $c$ are constants for the curve fitted to the calculated gas-phase data and $\mathrm{T}$ is the temperature in Kelvin. The calculated curve is constrained not to exceed a fraction of 1 during calculation. In the case of $\mathrm{Tc}, \mathrm{Ru}, \mathrm{Tm}$, and $\mathrm{Ra}$, where no concentration data were provided Swaine (13), a value of $1 \times 10^{-6} \mu \mathrm{g} / \mathrm{g}$ was used for these calculations. No thermodynamic data were available for $\mathrm{Pm}, \mathrm{Po}, \mathrm{At}, \mathrm{Fr}, \mathrm{Ac}$, and $\mathrm{Pa}$, and no constants for the regression curve are provided.

\section{Slag Corrosion}

Because of the very limited amount of information available on the corrosion of various refractory materials, no reliable prediction of slag corrosion attack could be made because statistically relevant correlations and development of prediction equations were not possible. Limited data points were available only for the extent of effective diffusivity for Serv95 and Aurex95P, and a few data were measured during CABRE III testing. In this case, the general expression used for calculating effective diffusivity $\left(D_{e f f}\right)$ is given by:

$$
D_{\text {eff }}=\frac{h^{2}}{2 t}
$$

Where $h$ is the penetration (cm) and $t$ is the time (s). Based on only three data points available, a regression analysis was made to obtain a simple empirical equation for estimating the effective diffusivity. The diffusivity calculated from measured penetration and time was correlated with base/acid ratio of the fuels to obtain a simple power expression of the form shown in Equation 7. Using the diffusivity estimated with Equation 6, an estimate is made about the penetration 
distance of slag into the refractory with time to make a qualitative prediction of the behavior of the slag on the refractory with time.

$$
y=a x^{-b}
$$

Where $a$ and $b$ are constants, $y$ represents the effective diffusivity, and $x$ is the base/acid ratio.

Because of the very small amount of data available, this module is deemed to be a "crude" prediction and improved prediction relationships can only be developed when more experimental data are available. The key assumptions made in this basic model include the following:

- No temperature dependence.

- No direct spalling prediction, but extent of penetration and slag properties can be used to make qualitative predictions.

- Only two refractories, Serv95 and Aurex95P, are included.

- Only two fuels considered: Freedom lignite for Serv95 and petcoke+PRB flux for both Serv95 and Aurex95P.

As indicated above, because of the very limited data and the crude nature of the developed equations, the implementation of this corrosion attack scheme was omitted because it could lead to unreliable predictions. In future projects and depending on whether more data are available, an improved algorithm can be developed for predicting slag attack on refractory surfaces. The data from the testing are available in the previous topical report (1).

\section{Slag Flow Model}

In the CABRE III program, the slag flow model implemented is based on the one developed by Seggiani (14). In any slag flow model, several physical properties of the coal slag are required, including temperature of critical viscosity $\left(\mathrm{T}_{\mathrm{cv}}\right)$, viscosity, density, heat capacity, and thermal conductivity. The $\mathrm{T}_{\mathrm{cv}}$ is generally dependent on the composition of the slag, while the other properties depend on both composition and temperature. Although there are several viscosity models in the literature, as described in an excellent review by Vargas et al. (9), we have used a viscosity model that was developed at the EERC based on experiments carried out in previous CABRE program phases (i.e., CABRE I and II). This viscosity model is described in the physical properties section.

In Seggiani's slag-building model, a discretized approach is used, where the behavior of the building slag on the gasifier walls is described by developing mass, energy, and momentum conservation equations for each volume element called a cell, shown schematically in Figure 6. The underlying assumptions are based on those originally proposed by Reid and Cohen (15) as follows: 


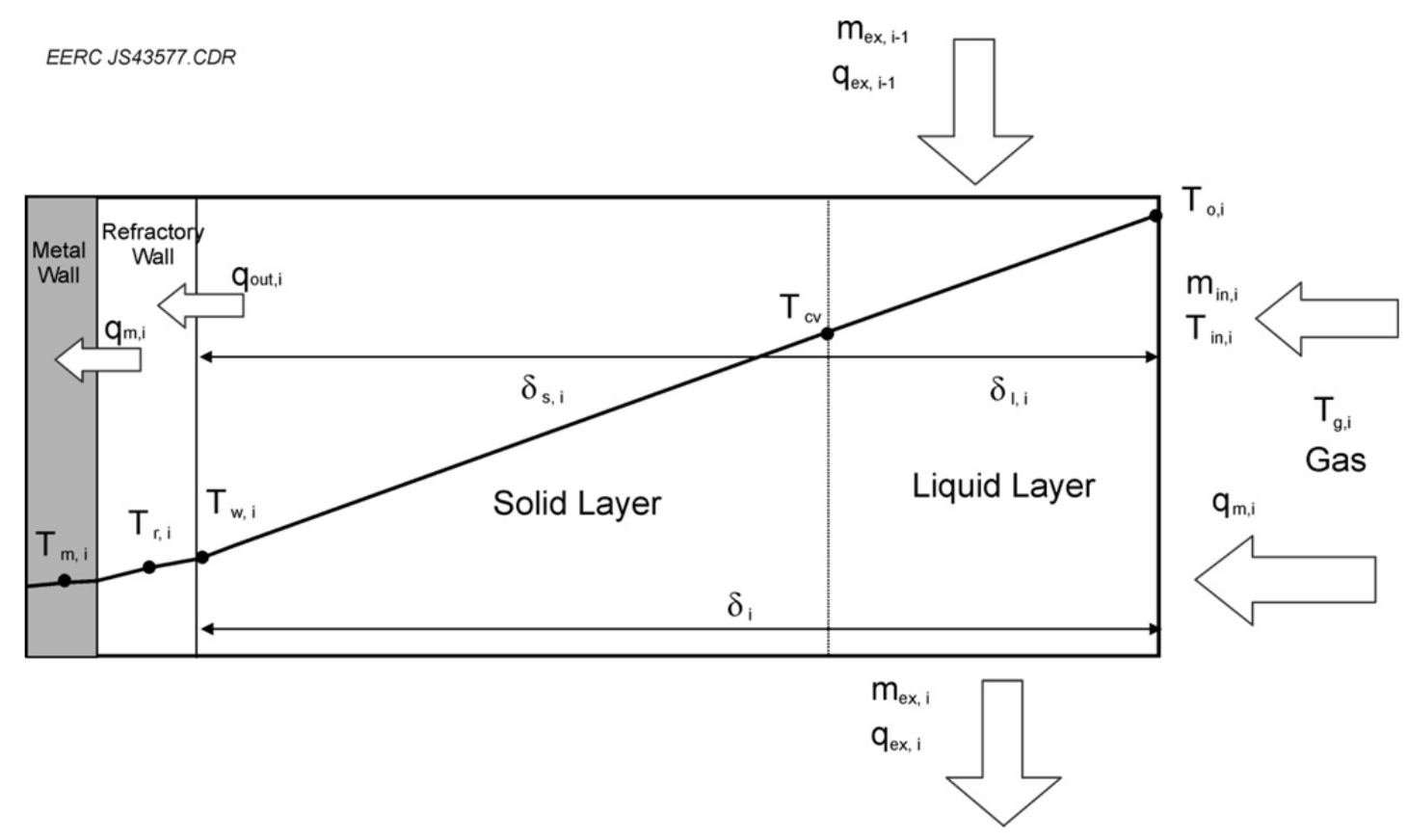

Figure 6. Slag-building control volume of $\mathrm{i}^{\text {th }}$ cell (14).

- The transition temperature between the solid and liquid slag layers is the temperature of critical viscosity.

- The flow of liquid slag is Newtonian, and the flow at temperature below $T_{\mathrm{cv}}$ is negligible.

- The shear stress between the gas and slag layer is negligible.

- The temperature profile across the slag layer is linear.

- The heat transfer occurs normal to the surface.

- The model was written in linear coordinates, owing to the large difference between the slag deposit thickness and the gasifier radius.

- The density, specific heat capacity, and thermal conductivity of the slag are independent of temperature.

In our model, some of the assumptions stated above, which were used in Seggiani's model, are believed to not be suitable and have been modified. However, the equations formulated by Seggiani are essentially the same for slag flow model, but the calculation of slag properties that are used in the flow model are based on different algorithms. The EERC's slag flow model differs from Seggiani's in that it uses a: 
1. Different expression for $\mathrm{T}_{\mathrm{cv}}$.

2. Temperature-dependent equation for specific heat capacity.

3. Temperature-dependent equation for thermal conductivity.

4. Different viscosity model developed at the EERC to calculate slag viscosity.

\section{Calculation of $T_{c v}$}

The determination of $\mathrm{T}_{\mathrm{cv}}$ for coal slags has varying expressions in the literature and is, in particular, dependent on slag properties. Because of this large variation, viscosity-temperature curves for several slags were plotted and used as a guide to determine the $\mathrm{T}_{\mathrm{cv}}$ that was used in the slag flow model. Based on the acidic and basic properties of the slags, the following three conditions were established and used to determine the corresponding $\mathrm{T}_{\mathrm{cv}}$ using the Riboud viscosity equation:

For and acid/base $(\mathrm{A} / \mathrm{B})$ ratio $<0.8$, target viscosity at $\mathrm{T}_{\mathrm{cv}}$ of $10 \mathrm{~Pa} \cdot \mathrm{s}$ is used.

For $\mathrm{A} / \mathrm{B}$ ratio $>1.5$, target viscosity at $\mathrm{T}_{\mathrm{cv}}$ of $50 \mathrm{~Pa} \cdot \mathrm{s}$ is used.

For $0.8<\mathrm{A} / \mathrm{B}<1.5$, target viscosity at $\mathrm{T}_{\mathrm{cv}}$ of $25 \mathrm{~Pa} \cdot \mathrm{s}$ is used.

Because the viscosity function used in the Riboud model is nonanalytical, a numerical approach was developed to determine the $T_{\mathrm{cv}}$ for the target viscosity cutoff. This approach involves starting from the highest possible temperature of the gasifier and calculating the viscosity and then decrementing the temperature and calculating the viscosity until the target viscosity is obtained. The corresponding temperature of the target viscosity is used as the $\mathrm{T}_{\mathrm{cv}}$, which is passed on to the slag flow module.

\section{$T_{c v}$ for Extremely Basic Fuels}

In the specific case of Center lignite and, possibly, other fuels that are extremely basic (A/B ratio of 0.5 or less), the target viscosity of $10 \mathrm{~Pa} \cdot \mathrm{s}$ was found to be inaccurate in predicting a $T_{c v}$ that agrees with the experiments carried out during the CABRE III tests. Detailed analysis and comparison of the model versus experiment based on data collected or predicted from Center lignite showed that the Riboud model predicts viscosity values that are about $3 \mathrm{~Pa} \cdot \mathrm{s}$ smaller than the experiment near the critical viscosity point $\left(\sim 1050^{\circ}\right.$ to $\left.1100^{\circ} \mathrm{C}\right)$; all other points in the hightemperature regime $\left(\sim 1150^{\circ}\right.$ to $\left.1700^{\circ} \mathrm{C}\right)$ were in reasonable agreement. The model predicts a rather gentle change from the high- to low-temperature regimes, whereas experiments showed an abrupt change at the critical viscosity. Also, the slag composition predicted by the CABRE III model was found to not agree well with the composition obtained from XRF analysis, which further increased the error margin between the viscosity predicted by the model for Center lignite and what was measured in experiments. From the comparisons and taking into account these differences between the model and experiment, a revised target critical viscosity of about $0.308 \mathrm{~Pa} \cdot \mathrm{s}$ was found to be suitable for reproducing a $\mathrm{T}_{\mathrm{cv}}$ that is in agreement with the experimental value, which was around $1100^{\circ} \mathrm{C}$ for Center lignite. It is assumed that all other fuels that display similar extremely high basicity will behave in a similar way to Center lignite 
and so the target critical viscosity has been adopted for all such cases in this version of the program.

The error margin between CABRE III slag composition and experimentally measured composition is due to the fact that a weighted average partition fraction for slag and fly ash relative to coal was used. Ideally, this fraction should be the same, but it was found that for several coals used in this study, the fractions were not the same, thus necessitating the use of some average value, which was weighted to reduce the bias in partitioning by certain major elements that are present in much larger amounts, such as silica and alumina.

In the case where the EERC-developed slag-matching approach is used to determine the viscosity, the database has predetermined viscosities, which were either obtained directly from experimental measurements in the literature or derived from temperature-viscosity curves of measured data.

\section{Slag Flow Properties}

The slag thickness and mass flow rate of the leaving slag are calculated for a system assumed to be at steady state, and discrete solutions per unit height for a given cell along the gasifier are calculated. Thus each mass flow rate or slag thickness is relative to an adjacent cell from the top or bottom of the gasifier and does not represent a cumulative flow that can be observed to increase from top to bottom of the gasifier. To obtain a cumulative flow effect, the user would simply add the mass flow rate of the top cell to that of the bottom cell and so on. These values are temperature-dependent because of the increase heat flux associated with higher temperatures; thus liquid slag thickness and mass flow rate both increase with increasing temperature because more solid slag melts into liquid.

On the other hand, the solid slag thickness should decrease with increasing temperature, since more solid slag melts at higher and higher temperatures. Because most gasifiers are not configured to measure the slag-refractory interface and metal-refractory interface temperatures for every zone or discrete cell along the height of the gasifier, an average value of about $500^{\circ} \mathrm{C}$ for the slag-refractory interface and $150^{\circ} \mathrm{C}$ for the refractory-metal wall interface have been assumed in this model. Because of this assumption, the solid slag thickness ends up having a direct dependence only on average slag temperature and so increases with increasing slag temperature - purely a mathematical artifact. Therefore, for an up-fired gasifier the slag thickness and mass flow rate should increase from top zone (cooler) to bottom (hotter) and vice versa for down-fired gasifiers.

The accuracy of the calculated slag flow parameters, i.e., mass flow rate, thickness of liquid and solid slag, and heat flux of leaving mass flow are dependent on key assumptions made in the model. Because it was extremely difficult to find reliable viscosity data for $\mathrm{T}_{\mathrm{cv}}$, the approach described above involving $\mathrm{A} / \mathrm{B}$ ratios and certain viscosity target values was used to calculate $\mathrm{T}_{\mathrm{cv}}$. In the case where the EERC-developed model was used, $\mathrm{T}_{\mathrm{cv}}$ was taken from those in the database, which are obtained from the literature for various slag compositions. 
The determination of an accurate $\mathrm{T}_{\mathrm{cv}}$ is very important in the accurate prediction of slag flow or slag thickness because it defines the point where liquid slag turns to solid. For this version of the program, a best-case estimate has been made based on the approach described above, which takes into account slag A/B properties. Also, the difficulty of measuring temperatures at discretized zones or interfaces places limitations on the expected trend of the solid slag thickness. For example, the temperature at the solid slag-refractory interface (slagrefractory temperature zone) has been approximated by a constant value of $500^{\circ} \mathrm{C}$ based on the Siemens gasifier. Normally, this temperature should vary along the gasifer height. To allow a little flexibility, this variable has been made a user input variable so that it can be customized to gasifier-specific values, but the fact that this parameter is kept constant throughout the gasifier height causes the solid slag thickness to show a reverse trend, i.e., increasing with temperature as opposed to decreasing with temperature along the gasifier height. However, the liquid slag thickness and mass flow rate show the expected trends. Further development work will be needed on this subject, but that requires additional experimental measurements of $\mathrm{T}_{\mathrm{cv}}$ for several different slags of interest and development of techniques for measuring temperatures at desired points and interfaces on modern gasifiers. The heat flux-to-gasifier metal wall has also been calculated, but since the temperature at the refractory-metal wall interface and the average refractory temperature are assumed to be relatively constant along the gasifier height, the computed predictions are the same for all zones.

\section{Properties of Refractory Materials}

The conductivity of 304 stainless steel, used in the model as the metal wall material, is $16.47563 \mathrm{~W} / \mathrm{m} \cdot \mathrm{K}$, which was determined by averaging the conductivity of this steel obtained from the Harbison and Walker heat-transfer Web application site (16) for the temperature range of $100^{\circ}-250^{\circ} \mathrm{C}$. The conductivities were retrieved from the Harbison Web site at every $10^{\circ} \mathrm{C}$ interval. The conductivities of Serv95 and Aurex95P are 3.04531 and $3.81593 \mathrm{~W} / \mathrm{m} \cdot \mathrm{K}$, respectively, which were determined by averaging the values obtained from the heat-transfer Web site (16) over the temperature range of $1000^{\circ}-1800^{\circ} \mathrm{C}$.

\section{Slag Physical Properties}

The main physical properties of slag that were implemented in the model include viscosity, heat capacity, thermal conductivity, density, and surface tension. The algorithms used were obtained from the literature, except for viscosity where an EERC-developed model as well as the Riboud model (17) were implemented.

\section{Viscosity}

The EERC-developed viscosity model uses a similar expression initially developed by Browning et al. (8), where viscosity is given by an Arrhenius-type equation of the form:

$$
\eta=e^{\left(\mathrm{A}+\frac{\mathrm{B}}{\mathrm{T}+\mathrm{C}}\right)}
$$

Where $\eta$ is the viscosity, $\mathrm{A}$ is a constant, $\mathrm{B}$ is an activation energy-type term, $\mathrm{T}$ is the temperature in Kelvin, and $\mathrm{C}$ is the temperature correction factor. In our model, the empirical 
parameters $\mathrm{A}, \mathrm{B}$, and $\mathrm{C}$ are determined for specific coal ashes or slags by nonlinear regression analysis using experimentally measured viscosity-temperature data. The regression analysis was performed using OriginPro 8.5, and because of the complicated function, some of the curves did not converge. Nonetheless, the results can be used to provide reasonable estimates of the constants that were shown to yield reasonable viscosity predictions when compared to experimentally measured viscosities. The accuracy of the EERC-developed model is tied to a set of criteria described in detail below, where three viscosity deviation levels-less than $1 \%$, less than $10 \%$, and less than $30 \%$ - can be achieved, depending on which criterion is met for a given slag.

Regarding function discontinuity, the viscosity function given in Equation 8 is only valid for viscosity ranges of $0-1000 \mathrm{~Pa} \cdot \mathrm{s}$, as was the case in the original derivation by Browning et al. (8). In addition, the function has a discontinuity at certain values of the parameter $\mathrm{C}$. Consequently, the highest viscosity calculated by this function in the CABRE III model is limited to $1000 \mathrm{~Pa} \cdot \mathrm{s}(10,000$ poise). This restriction should not have any practical effect because it is expected that all normal slags will have frozen long before getting to a viscosity of $1000 \mathrm{~Pa} \cdot \mathrm{S}$. The function also appears to artificially predict some very low viscosities in the lowtemperature regime, which are certainly not accurate. Hence, the low-temperature region, which has been determined to correspond to temperatures below $\mathrm{T}_{\mathrm{cv}}$, has also been restricted from returning any results because they are not applicable and are only as a result of the mathematical artifact of the function.

In the model, a database is created with specific ash or slag compositions, experimentally measured viscosities, and temperatures for the slags, which are used for the regressions. For any user input slag composition, a match with database slags is performed based on six levels of criteria, ranked with decreasing level of confidence, 1 being the highest confidence level and 6 being the lowest. The criteria are developed from composition-dependent parameters such as $\mathrm{A} / \mathrm{B}$ ratios and $\mathrm{B} / \mathrm{A}$ ratios, network former-to-network modifier (NFNM) ratios, etc. (see procedure section). Each slag in the database has associating constants, A, B, and C, predetermined by regression analysis and the corresponding $\mathrm{T}_{\mathrm{cv}}$. $\mathrm{T}_{\mathrm{cv}}$ data were either obtained directly from the literature that contained the composition, viscosity, and temperature measurements or derived from viscosity-temperature plots of the data. If the input slag composition matches with any slag in the database, the corresponding parameters $\mathrm{A}, \mathrm{B}$, and $\mathrm{C}$ are taken and used in Equation 8 to calculate the viscosity that is returned as the viscosity of the input slag. If the input slag fails to match any database slag, i.e., none of Criteria Levels 1 to 6 is met, the model defaults to the Riboud viscosity model (17) for the prediction of slag viscosity. The choice of the Riboud model as an alternative to the EERC-developed viscosity model is based on an assessment made of several viscosity models using the results obtained from viscosity measurements in the previous CABRE program. The temperature of critical viscosity is used in the slag flow module to predict slag flow characteristics.

\section{Procedure}

The procedure for predicting viscosity using the EERC-developed model involves the following steps. 


\section{Step 1}

Calculate the following composition-dependent parameters for the input slag and all database slags.

$$
\begin{gathered}
\text { B/A ratio: } \frac{B}{A}=\frac{\mathrm{Fe}_{2} \mathrm{O}_{3}+\mathrm{CaO}+\mathrm{MgO}+\mathrm{Na}_{2} \mathrm{O}+\mathrm{K}_{2} \mathrm{O}}{\mathrm{SiO}_{2}+\mathrm{Al}_{2} \mathrm{O}_{3}+\mathrm{TiO}_{2}} \\
\text { A/B ratio: } \frac{A}{B}=\frac{\mathrm{SiO}_{2}+\mathrm{Al}_{2} \mathrm{O}_{3}+\mathrm{TiO}_{2}}{\mathrm{Fe}_{2} \mathrm{O}_{3}+\mathrm{CaO}+\mathrm{MgO}+\mathrm{Na}_{2} \mathrm{O}+\mathrm{K}_{2} \mathrm{O}} \\
\text { NFNM ratio: } \\
\text { NFNM Ratio }=\frac{3.19 \cdot \mathrm{SiO}_{2}+0.855 \cdot \mathrm{Al}_{2} \mathrm{O}_{3}+1.6 \cdot \mathrm{K}_{2} \mathrm{O}}{0.93 \cdot \mathrm{CaO}+1.5 \cdot e q v \mathrm{FeO}+1,21 \cdot \mathrm{MgO}+0.69 \cdot \mathrm{Na}_{2} \mathrm{O}+1.35 \cdot \mathrm{Mn}_{3} \mathrm{O}_{4}+1.47 \cdot \mathrm{TiO}_{2}}
\end{gathered}
$$

Silica ratio in $\mathrm{wt} \%$ and in $\mathrm{mol} \%$ using the equation:

$$
\text { Si ratio }=\frac{\mathrm{SiO}_{2}}{\mathrm{SiO}_{2}+e q v \mathrm{Fe}_{2} \mathrm{O}_{3}+\mathrm{CaO}+\mathrm{MgO}}
$$

Where

$$
\begin{gathered}
e q v \mathrm{Fe}_{2} \mathrm{O}_{3}=\mathrm{Fe}_{2} \mathrm{O}_{3}+1.11 \mathrm{FeO} \\
e q v \mathrm{FeO}=\mathrm{FeO}+2 \cdot \mathrm{Fe}_{2} \mathrm{O}_{3}
\end{gathered}
$$

According to Browning et al. (8), $\mathrm{K}_{2} \mathrm{O}$ is an indirect network former via the reaction:

$$
2 \mathrm{~K}_{2} \mathrm{O}+\mathrm{Al}^{3+} \rightarrow \mathrm{AlO}_{2}^{-}+4 \mathrm{~K}^{+}
$$

$\mathrm{AlO}_{2}^{-}$species are network formers and so will increase the viscosity of slag if generated by the presence of $\mathrm{K}_{2} \mathrm{O}$ and alumina. Hence, $\mathrm{K}_{2} \mathrm{O}$ is not needed in the NFNM ratio for alumina-free slags.

\section{Step 2}

Calculate the absolute differences of the parameters in Step 1 between the input slag and all database slags.

\section{Step 3}

Calculate the absolute differences of the composition (mol\%) between the input slag and all database slags.

\section{Step 4}

Using the results of Step 3, calculate:

1. Sum of differences. 
2. Maximum difference.

3. Correlation coefficient between input slag molar composition and molar compositions of all slags in database.

\section{Step 5}

Determine the minimum value of each of the following parameters:

1. $\mathrm{B} / \mathrm{A}$ ratio

2. A/B ratio

3. NFNM ratio

4. Silica ratio $(\mathrm{wt} \%)$

5. Silica ratio $(\mathrm{mol} \%)$

6. Sum of differences in molar compositions between input and database slags

7. Maximum difference in molar compositions between input and database slags Step 6

Evaluate the following criteria:

Criterion 1: Compare the composition of input slag with that of database slags and determine if there is a slag in the database for which both $a$ and $b$ below are true for specific limiting values $\mathrm{x}$ :

a. Smallest sum of differences in composition components is $\leq \mathrm{x}$

b. Maximum difference in composition components is $\leq \mathrm{x}$

If $\mathrm{a}$ and $\mathrm{b}$ above are true, then the slag is chosen with very high confidence, i.e., with a deviation in viscosity of less than $1 \%$. If this criterion is not met, proceed to the next criterion.

Criterion 2: Determine if there is a slag in the database for which all of a-d below are true for certain $\mathrm{x}$ values:

a. The smallest absolute difference of NFNM ratio $\leq \mathrm{x}$

b. Absolute difference of $\mathrm{B} / \mathrm{A}$ ratio $\leq \mathrm{x}$

c. Absolute difference Si ratio $(\mathrm{wt} \%) \leq \mathrm{x}$

d. Correlation coefficient of compositions is $\geq x$

If there is a match, choose the slag with some confidence, otherwise go to next criterion.

Criterion 3a: Determine if there is a slag in the database for which all of a-e below are true for certain $\mathrm{x}$ values: 
a. Smallest absolute difference of $\mathrm{B} / \mathrm{A}$ ratio $\leq \mathrm{x}$

b. Absolute difference of NFNM ratio $\leq x$

c. Absolute difference of $\mathrm{A} / \mathrm{B}$ ratio is $\leq \mathrm{x}$

d. Absolute difference of Si ratio ( $\mathrm{mol} \%)$ is $\leq \mathrm{x}$

e. Correlation coefficient of compositions is $\geq x$

If there is a match, choose the slag with some confidence, otherwise go to next criterion.

Criterion 3b: Determine if there is a slag in the database for which all of a-e below are true for certain $\mathrm{x}$ values:

a. Smallest absolute difference of $\mathrm{A} / \mathrm{B}$ ratio $\leq \mathrm{x}$

b. Absolute difference of $\mathrm{B} / \mathrm{A}$ ratio $\leq \mathrm{x}$

c. Absolute difference of NFNM ratio is $\leq x$

d. Absolute difference of Si ratio ( $\mathrm{mol} \%)$ is $\leq \mathrm{x}$

e. Correlation coefficient of compositions is $\geq x$

If there is a match, choose the slag with some confidence, otherwise go to next criterion.

Criterion 3c: Determine if there is a slag in the database for which all of a-d below are true for certain $\mathrm{x}$ values:

a. Smallest absolute difference of Si ratio $(\mathrm{mol} \%)$ is $\leq \mathrm{x}$

b. Absolute difference of $\mathrm{B} / \mathrm{A}$ ratio is $\leq \mathrm{x}$

c. Absolute difference of NFNM ratio is $\leq x$

d. Correlation coefficient of compositions is $\geq x$

If there is a match, choose the slag with some confidence, otherwise go to next criterion.

Criterion 4: Determine if there is a slag in the database for which all of a-d below are true for certain $x$ values:

a. Smallest absolute difference of $\mathrm{B} / \mathrm{A}$ ratio $\leq \mathrm{x}$

b. Absolute difference of $\mathrm{A} / \mathrm{B}$ ratio is $\leq \mathrm{x}$

c. Absolute difference of NFNM ratio is $\leq x$

d. Absolute difference of Si ratio ( $\mathrm{mol} \%)$ is $\leq \mathrm{x}$

If there is a match, choose the slag with some confidence, otherwise go to next criterion.

Criterion 5: Determine if there is a slag in the database for which all of a-e below are true for certain $\mathrm{x}$ values:

a. Smallest Si ratio $(\mathrm{mol} \%)$ is $\leq \mathrm{x}$

b. Absolute difference of $\mathrm{B} / \mathrm{A}$ ratio is $\leq \mathrm{x}$

c. Absolute difference of NFNM ratio is $\leq \mathrm{x}$ 
d. Absolute difference of Si ratio ( $w t \%)$ is $\leq \mathrm{x}$

e. Correlation coefficient of compositions is $\geq x$

If there is a match, choose the slag with some confidence, otherwise go to next criterion.

Criterion 6: Determine if there is a slag in the database for which all of $a$ and $b$ below are true for certain $\mathrm{x}$ values:

a. Smallest absolute difference of Si ratio (wt $\%)$ is $\leq \mathrm{x}$

b. Correlation coefficient of compositions is $\geq \mathrm{x}$

If there is a match, choose the slag with some confidence, otherwise use the Riboud model as the default to calculate viscosity.

\section{Default Viscosity Model - The Riboud Model}

The Riboud viscosity model can be found in a review by Vargas et al. (9). The calculation uses only the components specified in the Riboud original derivation (17), i.e., $\mathrm{SiO}_{2}, \mathrm{Al}_{2} \mathrm{O}_{3}$, $\mathrm{Fe}_{2} \mathrm{O}_{3}, \mathrm{CaO}, \mathrm{MgO}, \mathrm{Na}_{2} \mathrm{O}, \mathrm{K}_{2} \mathrm{O}$, and $\mathrm{MnO}$. These were selected from the full list and renormalized.

In the calculation of other slag properties, additional components used in the derivation of the models are used, but in each case, normalized compositions are calculated. Where $\mathrm{FeO}$ and $\mathrm{Fe}_{2} \mathrm{O}_{3}$ are included in the calculation, $\mathrm{FeO}$ is derived from $\mathrm{Fe}_{2} \mathrm{O}_{3}$ as follows.

\section{Estimation of $\mathrm{FeO}$ from a Given $\mathrm{Fe}_{2} \mathrm{O}_{3}$}

Typical XRF analysis reports major element quantities as oxide $\mathrm{wt} \%$. The amount of iron is often measured as total $\mathrm{Fe}$ in the form of $\mathrm{Fe}_{2} \mathrm{O}_{3}$. In some of the modules used to calculate some slag properties, $\mathrm{FeO}$ was used. Consequently, a method of estimating the corresponding amount of $\mathrm{FeO}$ from known amounts of $\mathrm{Fe}_{2} \mathrm{O}_{3}$ was developed. This is based on reported data on the $\mathrm{FeO}$ and $\mathrm{Fe}_{2} \mathrm{O}_{3}$ concentrations (wt\%) for $10 \mathrm{Fe}$-bearing mineral standards obtained from Fritz et al. (18). A linear correlation fit equation was derived from a plot of wt\% data for $\mathrm{FeO}$ and $\mathrm{Fe}_{2} \mathrm{O}_{3}$ for the 10 Fe-bearing mineral standards. The correlation coefficient $\left(\mathrm{R}^{2}\right)$ obtained was 0.9229 for the equation $\mathrm{y}=\mathrm{ax}+\mathrm{b}$, where $\mathrm{y}=\mathrm{wt} \% \mathrm{Fe}_{2} \mathrm{O}_{3}$ and $\mathrm{x}=\mathrm{wt} \% \mathrm{FeO}$. Hence, the expression for $\mathrm{wt} \%$ $\mathrm{FeO}$ given $\mathrm{wt} \% \mathrm{Fe}_{2} \mathrm{O}_{3}$ was derived as follows:

$$
w t \% \mathrm{FeO}=\left(w t \% \mathrm{Fe}_{2} \mathrm{O}_{3}-\mathrm{b}\right) / \mathrm{a}
$$

\section{Determination of $M n$}

$\mathrm{Mn}$ is also typically measured as $\mathrm{MnO}_{2}$. A crude assumption was made that moles of $\mathrm{MnO}_{2}$ that come in are equal to moles of $\mathrm{MnO}$ or moles of $\mathrm{Mn}_{3} \mathrm{O}_{4}$, where needed, because the amount of $\mathrm{Mn}$ is small and it was assumed to be the total $\mathrm{Mn}$ in the slag system. For a given normalized input stream composition, if the $\mathrm{wt} \%$ of $\mathrm{MnO}$ or $\mathrm{Mn}_{3} \mathrm{O}_{4}$ is desired, it is calculated from the moles by multiplying by the respective molar masses. That is, moles $\mathrm{MnO}_{2}=$ moles 
$\mathrm{MnO}=$ moles $\mathrm{Mn}_{3} \mathrm{O}_{4}$. Hence, wt $\% \mathrm{MnO}=\mathrm{Mwt}(\mathrm{MnO}) \times$ moles and $\mathrm{wt}_{0} \% \mathrm{Mn}_{3} \mathrm{O}_{4}=\mathrm{Mw}\left(\mathrm{Mn}_{3} \mathrm{O}_{4}\right)$ $\times$ moles.

\section{Heat Capacity}

The heat capacity of liquid and solid slag is calculated using the model developed by Mills et al. (19). According to Mills and coworkers, a more general heat capacity expression is given by the Kopp-Neumann equation as:

$$
C_{p}=\sum_{i=1}^{n} x_{i} \bar{C}_{p i}
$$

Where $i$ indicates the various slag components up to $\mathrm{n}, \bar{C}_{p i}$ is the partial molar heat capacity for component $i$, and $x_{i}$ is the mole fraction of component $i$. The temperature dependence of heat capacity is given by:

$$
C_{p}=a+b T-c T^{-2}
$$

Where the recommended values of the constants $a, b$, and $c$ in Mills et al. (19) paper are given in Table 5 for calculating the partial molar heat capacities for solid components. Molar heat capacity values for the liquid slag components, also given in Mills et al. (19) and used in this model, are given in the far right column of Table 5.

\section{Thermal Conductivity}

The effective thermal conductivity, $K_{\text {eff }}$, of liquid and solid slag was calculated according to the model by Mills et al. (20) as follows:

$$
K_{\text {eff }}=A_{\text {eff }} * C_{p} * \rho
$$

Table 5. Recommended Constants for Temperature-Dependent Heat Capacity (19)

\begin{tabular}{lccccc}
\hline Component & $\mathrm{MW}, \mathrm{g} / \mathrm{mol}$ & $\mathrm{a}$ & $\mathrm{b}$ & $\mathrm{c}$ & $\bar{C}_{p i}\left(\mathrm{JK}^{-1} \mathrm{~mol}^{-1}\right)$ \\
\hline $\mathrm{SiO}_{2}$ & 60.08 & 55.98 & 15.4 & 14.48 & 87 \\
$\mathrm{Al}_{2} \mathrm{O}_{3}$ & 101.96 & 115 & 11.8 & 35.15 & 146.4 \\
$\mathrm{Fe}_{2} \mathrm{O}_{3}$ & 159.69 & 98.28 & 77.8 & 14.85 & 191.2 \\
$\mathrm{FeO}$ & 71.85 & 48.78 & 8.36 & 2.8 & 76.6 \\
$\mathrm{TiO}_{2}$ & 79.88 & 75.19 & 1.17 & 18.2 & 111.7 \\
$\mathrm{P}_{2} \mathrm{O}_{5}$ & 141.94 & 182.5 & 46.4 & 45.44 & 242.7 \\
$\mathrm{CaO}$ & 56.08 & 48.82 & 4.52 & 6.52 & 80.8 \\
$\mathrm{MgO}$ & 40.30 & 42.6 & 7.45 & 6.19 & 90.4 \\
$\mathrm{Na} 2 \mathrm{O}$ & 61.98 & 65.7 & 22.6 & 0 & 92 \\
$\mathrm{~K} 2 \mathrm{O}$ & 94.20 & 65.7 & 22.6 & 0 & 74 \\
$\mathrm{MnO}$ & 70.94 & 46.48 & 8.12 & 3.68 & 79.9 \\
\hline
\end{tabular}


Where $A_{\text {eff }}$ is the effective thermal diffusivity, $C_{p}$ is the heat capacity of liquid or solid slag, and $\rho$ is density of slag. In the equation, the effective thermal diffusivity was calculated following an expression developed by Fine et al. (21) as:

$$
A_{e f f}=0.001(1.5-0.5 * \mathrm{~B})+0.018 * \frac{(\mathrm{T} / 1500)^{3}}{(\% \mathrm{FeO})^{0.8}}
$$

Where $\mathrm{T}$ is temperature in degrees Celsius, $\% \mathrm{FeO}$ is the $\mathrm{FeO}$ concentration in $\mathrm{wt} \%$, and $\mathrm{B}$ is the lime/silica ratio (i.e., $\mathrm{wt} \% \mathrm{CaO} / \mathrm{wt}_{0} / \mathrm{SiO}_{2}$ ).

\section{Density}

The density of the slag was calculated according to the formulas found in Mills et al. (20), where the molar volume (V), given by Equation 22, can be calculated from the partial molar volumes, Equation 23, of the various slag constituents. Thus the density can be obtained as in Equation 24, with the recommended partial molar volumes of the components given in Table 6.

$$
\begin{aligned}
& V=\frac{\sum_{i=1}^{n} x_{i} M_{i}}{\rho} \\
& V=\sum_{i=1}^{n} x_{i} \bar{V}_{i} \\
& \rho=\sum_{i=1}^{n} \frac{x_{i} M_{i}}{x_{i} \bar{V}_{i}}
\end{aligned}
$$

Where $\bar{V}_{i}$ is the partial molar volume of component $i, x_{i}$ is the mole fraction of component $i$, and $M_{i}$ is the molar mass of the component.

Table 6. Partial Molar Volumes of Components Obtained from Mills et al. (20)

\begin{tabular}{lcc}
\hline $\mathrm{Component}$ & $\mathrm{MW}, \mathrm{g} / \mathrm{mol}$ & $\bar{V}_{i}, \mathrm{~cm}^{3} / \mathrm{mol}$ \\
\hline $\mathrm{SiO}_{2}$ & 60.08 & 23.570366 \\
$\mathrm{Al}_{2} \mathrm{O}_{3}$ & 101.96 & 31.777094 \\
$\mathrm{Fe}_{2} \mathrm{O}_{3}$ & 159.69 & 38.4 \\
$\mathrm{FeO}$ & 71.85 & 15.8 \\
$\mathrm{TiO}_{2}$ & 79.88 & 24 \\
$\mathrm{P}_{2} \mathrm{O}_{5}$ & 141.94 & 65.7 \\
$\mathrm{CaO}$ & 56.08 & 20.7 \\
$\mathrm{MgO}$ & 40.30 & 16.1 \\
$\mathrm{Na}$ & 61.98 & 33 \\
$\mathrm{~K} 2 \mathrm{O}$ & 94.20 & 51.8 \\
$\mathrm{MnO}$ & 70.94 & 15.6 \\
\hline *Value obtained from Mills, K.C. Slag Atlas 1995; Verlag Stahleissen: Dusseldorf, Germany, pp 345-346. \\
Note: The density formulation above was used for both solid and liquid slags.
\end{tabular}




\section{Surface Tension}

The surface tension $(\gamma)$ was calculated using the following equation developed by Mills et al. (19):

$$
\gamma=\sum_{i=1}^{n} x_{i} \bar{\gamma}_{i}
$$

Where $\bar{\gamma}_{i}$ is the partial molar surface tension of component $i$ and $x_{i}$ is the mole fraction.

Mills et al (20) developed a more complex model to account for the influence of surfaceactive components. He divided components into surface-active and non-surface active components. The nonactive components have unique values given below, and $x_{i} \bar{\gamma}_{i}$ for active ones are parabolic functions of their mole fractions $\left(x_{i}\right)$ based on certain conditions of the constant $\mathrm{N}$, given in Table 7, obtained from Mills et al. (20).

Deposition of major components of fly ash is predicted by using information about fly ash composition and fly ash viscosity. The viscosity is used to determine the stickiness of the particles, which are then partitioned into entrained and surface particles. The surface particles are assumed to be deposited as a thin volume element.

For volatile elements, the fraction that condenses is determined at a given temperature. Three separate mechanisms are considered, including homogeneous condensation into aerosols, condensation on fly ash particles, and condensation or deposit on pipe surfaces. In general, deposition is predicted across any unit operation or process that has a temperature drop such as in the syngas cooler, hot-gas cleanup system, and acid gas removal system. For a circulating fluidbed (CFB) gasifier, deposition across the cyclones is also determined. As a result, deposition in the high-, medium-, and low-temperature regime can be predicted.

Table 7. Mills Conditional Table (19)

\begin{tabular}{lccccc}
\hline \multicolumn{2}{l}{ Non-Surface-Active Components } & \multicolumn{3}{c}{ Surface-Active Components, ref. temp. $=1723 \mathrm{~K}$} \\
\hline $\bar{\gamma}_{i}(\mathrm{~m} / \mathrm{Nm})$ at $1743 \mathrm{~K}$ & & $x_{i} \bar{\gamma}_{i} ; \mathrm{xi}<\mathrm{N}$ & $\mathrm{N}$ & $x_{i} \bar{\gamma}_{i} ; \mathrm{xi}>\mathrm{N}$ \\
\hline $\mathrm{SiO}_{2}$ & 260 & $\mathrm{Fe}_{2} \mathrm{O}_{3}$ & $-3.7-2972 x+14312 x^{2}$ & 0.125 & $-216.2+516.2 x$ \\
$\mathrm{Al}_{2} \mathrm{O}_{3}$ & 655 & $\mathrm{Na}_{2} \mathrm{O}$ & $0.8-1388 x-6723 x^{2}$ & 0.115 & $-115.9+412.9 x$ \\
$\mathrm{FeO}$ & 645 & $\mathrm{~K}_{2} \mathrm{O}$ & $0.8-1388 x-6723 x^{2}$ & 0.115 & $-94.5+254.5 x$ \\
$\mathrm{CaO}$ & 625 & $\mathrm{P}_{2} \mathrm{O}_{5}$ & $-5.2-3454 x+22178 x^{2}$ & 0.12 & $-142.5+167.5 x$ \\
$\mathrm{TiO}_{2}$ & 350 & $\mathrm{~S}$ & $-0.8-3540 x+55220 x^{2}$ & 0.04 & $-70.8+420.8 x$ \\
$\mathrm{MgO}$ & 635 & $\mathrm{Cr}_{2} \mathrm{O}_{3}$ & $-1248 x+8735 x^{2}$ & 0.05 & $-84.2+884.2 x$ \\
$\mathrm{BaO}$ & & & & & \\
$\mathrm{SrO}$ & & & & & \\
$\mathrm{MnO}$ & 645 & & & & \\
\hline
\end{tabular}




\section{Deposition}

The calculation of the amount of deposited material takes into account two major contributions: deposition due to major fly ash particles and condensation of trace elements.

\section{Fraction of Fly Ash Deposits}

Fly ash deposition of major constituents is calculated from a sticking probability function of the form:

$$
y=a *(1-b * \arctan (c * \eta+d)+e
$$

Where $a, b, c, d$, and $e$ are constants, $\eta$ is the viscosity of fly ash, and $y$ is the sticking probability.

\section{Fraction of Homogeneous Condensate Deposits}

The contribution from condensation is calculated as follows. Consider a cylindrical pipe of radius $r_{1}$ and a thin volume element condensing close to the walls to form an inner tube of radius $r_{2}$. The inside surface volume of the pipe is given by:

$$
V_{1}=\pi r_{1}^{2} l
$$

The volume of the inner condensing film element defined by a radius $r_{2}$ is given by:

$$
V_{2}=\pi r_{2}^{2} l
$$

The volume of the condensing element alone is given by:

$$
\Delta V=\pi l\left(r_{1}^{2}-r_{2}^{2}\right)
$$

The ratio of the volume of the condensing element to the surface volume of the pipe is given by

$$
\text { ratio }=\frac{\Delta V}{V_{1}}=1-\frac{r_{2}^{2}}{r_{1}^{2}}
$$

Assuming that the condensing volume element is so small, such that $r_{2}=0.999 r_{1}$, then

$$
\text { ratio }=1-\frac{a r_{1}^{2}}{r_{1}^{2}}
$$

Assuming that the pipe is completely filled and that the gas is evenly distributed in the pipe, then the fraction of homogeneous condensate on the walls is given by the solution to Equation 31 for a given constant $a$, and the fraction of gas-phase condensate is obtained by subtracting the fraction of homogeneous condensate (solution to Equation 31 ) from one, i.e.:

$$
\text { FractGPcond }=1-\text { Fracthomocond }
$$




\section{Deposition Rates}

The overall deposition rate $(\mathrm{kg} / \mathrm{hr})$ at a given point is calculated as the sum of the deposition rates for direct condensation on surfaces, homogeneous condensate on particles, and entrained fly ash deposition. Each of these deposition rates is calculated by multiplying the corresponding deposit fractions by the coal feed rate.

\section{Particle-Size Distribution in Cyclones and Filter Vessel Ash}

Fly ash particle-size distribution (PSD) is needed to calculate the removal of ash by particulate control devices (cyclones and filter) downstream from the gasifier as well as to calculate the amount of entrainment of particulate and bed material in the FBG system. The PSD of material introduced to the gasifier is assumed to follow a Rosin-Rammler distribution, shown in Figure 7.

The general form of the Rosin-Rammler equation is:

EERC JS43605.CDR

$$
R=e^{-\left(\frac{D}{D_{n}}\right)^{n}}
$$

where: $R$ is the \%retained at a size $D$, and both $D_{n}$ and $n$ are fitting parameters.

Given two points, $R_{1}$ retained at size $D_{1}$ and $R_{2}$ retained at size $D_{2}$, the two fitted parameters may be determined as follows:

$$
D_{n}=\exp \left(\frac{\ln \left(\ln \left(\frac{1}{R_{1}}\right)\right) \times \ln \left(D_{2}\right)-\ln \left(\ln \left(\frac{1}{R_{2}}\right)\right) \times \ln \left(D_{1}\right)}{\ln \left(\frac{\ln \left(\frac{1}{R_{1}}\right)}{\ln \left(\frac{1}{R_{2}}\right)}\right)}\right) \text { and } n=\frac{\ln \left(\ln \left(\frac{1}{R_{1}}\right)\right)}{\ln \left(\frac{D_{1}}{D_{n}}\right)}
$$

Once fitted, the \%retained $R$ at any size $D$ can be estimated form the general form of the equation:

$$
R=e^{-\left(\frac{D}{D_{n}}\right)^{n}}
$$

and any size $D$ that sees a \%retained $R$ can be determined by:

$$
D=\sqrt[n]{\ln \left(\frac{1}{R}\right) \times D_{n}^{n}} \text { or, rearranged as } D=\left[\ln \left(\frac{1}{R}\right) \times D_{n}^{n}\right]^{1 / n}
$$

Figure 7. Rosin-Rammler PSD formalism (22). 
This allows the PSD to be expressed as two parameters in the input data files. In the program, the $\mathrm{D}_{10}$ and $\mathrm{D}_{90}$ diameters are used, corresponding to $10 \%$ and $90 \%$ of the particle mass. For input materials (coals, additives, and bed materials), the cumulative mass at two sizes was used to determine $D_{n}$ and $n$ for each material. The $D_{n}$ and $n$ values were then used to generate the Rosin-Rammler distribution to obtain the $\mathrm{D}_{10}$ and $\mathrm{D}_{90}$ diameters for the input files. For the coals and fly ashes, the distribution of particle diameters obtained from QEMSCAN analysis was used.

After the fuel(s) and additives are selected, the $\mathrm{D}_{10}$ and $\mathrm{D}_{90}$ values are used to generate a Rosen-Rammler distribution for each individually. The fraction of particles by mass in 2000 size bins from 1 to $2000 \mu \mathrm{m}$ are then calculated (the Rosen-Rammler formulation gives a cumulative distribution). The fractions of particles in the bins are then normalized, since the RosenRammler formula asymptotically approaches 1 .

The effect of blending of fuels and additives or fuels and bed material in the case of the FBG is done by taking a weighted average by mass of the blends in each particle size bin. It should be noted that the sum of the bins for the blend components and for the weighted average always equals 1 . It should be also noted that the PSD after blending as well as after ash removal by a particulate control device now no longer corresponds to a Rosen-Rammler distribution. Since the particle composition is handled separately from the PSD, each particle size is assumed to have the same chemical composition. Although a combined PSCD would be preferable, it was not found possible to reliably predict the mineral matter transformations that would provide PSCD.

\section{Cyclone Collection Efficiency}

The cyclone collection efficiency is based on Lapple's model:

$$
d_{p 50 \%}=\sqrt{\frac{9 \mu b}{2 \pi N_{e} V_{i \rho_{p}}}}
$$

Where $\mu$ is the viscosity of air, $b$ is inlet width, $N_{e}$ is the number of effective turns, $V_{i}$ is the inlet velocity, and $\mathrm{Pp}$ is the particle density. Using this model directly requires detailed information as to the specific cyclone design and gasifier operating conditions.

Instead, the cyclone collection efficiency in the model is specified by the user as a $\mathrm{d}_{50}$ diameter. This allows the collection efficiency of the cyclone to be calculated for any other particle size, $\mathrm{d}_{\mathrm{pj}}$, using the formula:

$$
n_{j}=\frac{1}{1+\left({ }^{d_{p 50 \%}} / d_{p j}\right)^{2}}
$$

Thus the fraction of particles in each bin of the PSD can be separated into the fraction of that particle size passing and the fraction collected by the cyclone. The total mass passing and captured by the cyclone are then obtained by summing the PSDs of the passing and captured fractions, respectively. This is then used to update the elemental mass concentrations of the passing and captured fractions. The values in the two new PSD size bins are then renormalized to unity. 


\section{Filter Collection Efficiency}

The particulate filter is also modeled as a cyclone, with user input for $d_{50}$. Since the collection efficiency of a filter is usually very high, a $\mathrm{d}_{50}$ value $<1 \mu \mathrm{m}$ is best selected.

\section{Fluidized-Bed Entrainment}

Modeling of particle entrainment from a FBG would also entail obtaining detailed information on the specific gasifier dimensions and operating parameters. Instead, entrainment of the ash and bed material is treated as a special case of a cyclone. Instead, the user enters a $\mathrm{d}_{50}$ value corresponding to the mean particle size of the material entrained from the bed. The fraction of particles "passing" correspond to the entrained ash, and the fraction of particles "captured" correspond to the material remaining in the bed. In the model, the PSDs of the bed are partitioned to entrained ash and material remaining in the bed, the mass changes determined, and the PSDs renormalized as with the case of a cyclone.

\section{Model User Interface Development}

The CABRE III model program runs on any MS Windows PC via an interactive user interface that provides step-by-step guide to program input parameters. Among the many features of the interface, the user can start a new session based on a specific gasifier type (entrained flow or fluidized bed) and then can input and store data for that session. Although the current version of the program includes about four fuels in the database (the fuels selected by the sponsors of the project), users can input a fuel of their choice via an excel spreadsheet or directly through the user interface. Blending options with additional fuels or fluxing agents have also been implemented in easily accessible click-of-the-mouse steps. The existing fuel database contains analytical information on the sponsor fuels and a few other selected coals, which allows easy input of fuel parameters for a desired simulation. A brief description of the user interface is given in the following screenshots, and additional details about the user interface and program user guide are available in Appendix A.

\section{Welcome Screen}

The welcome screen of the model is shown in Figure 8, with the CABRE III gasification modeling system at the top and the images of the ConocoPhillips-type gasifier and the EERC's CFB gasifier displayed on the screen; the logos of the major sponsors are displayed at the bottom of the screen.

\section{Gasifier Session Screen}

The gasifier session screen (Figure 9) allows the user to select gasifier type, EFG or FBG, and based on the selection, the user proceeds to provide the necessary information for the gasifier definition, fuel selection, fuel percent used, run model parameters, and then to view the results. These are provided as separate input windows to enhance access and to simplify the input data types required for a successful model execution. 


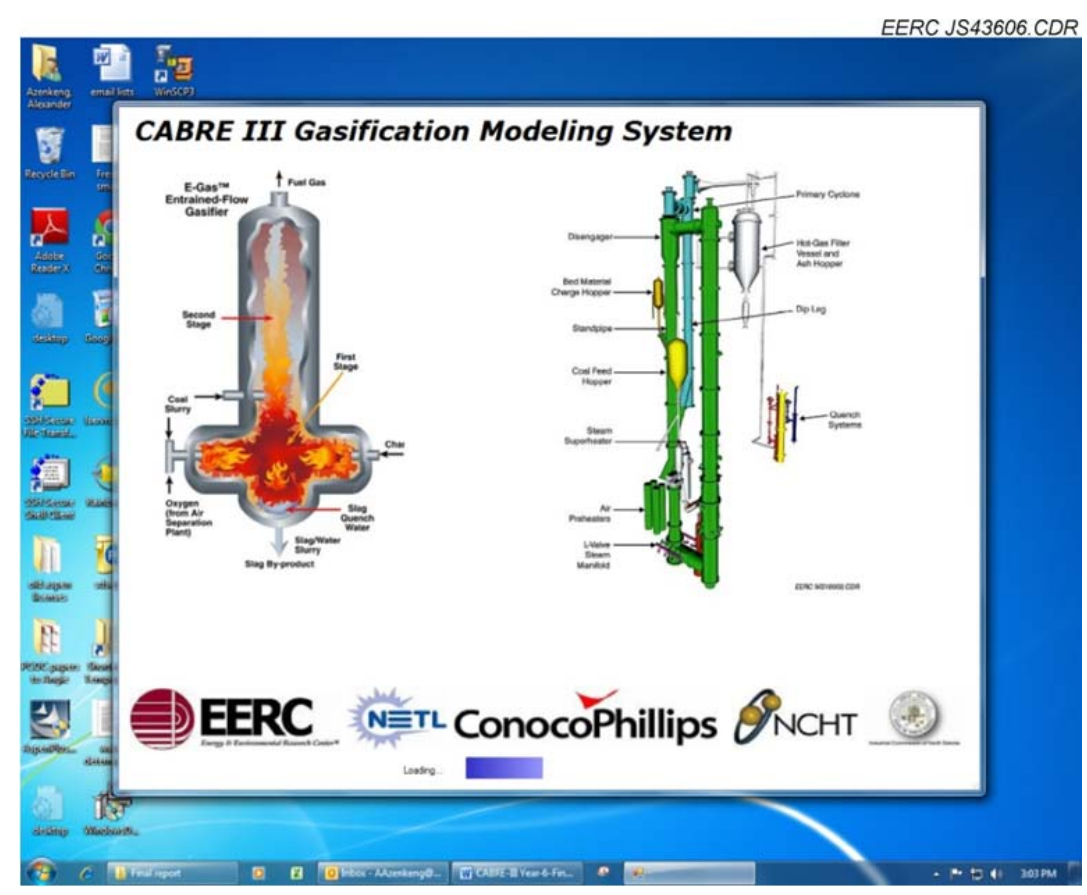

Figure 8. Welcome screen of the model.

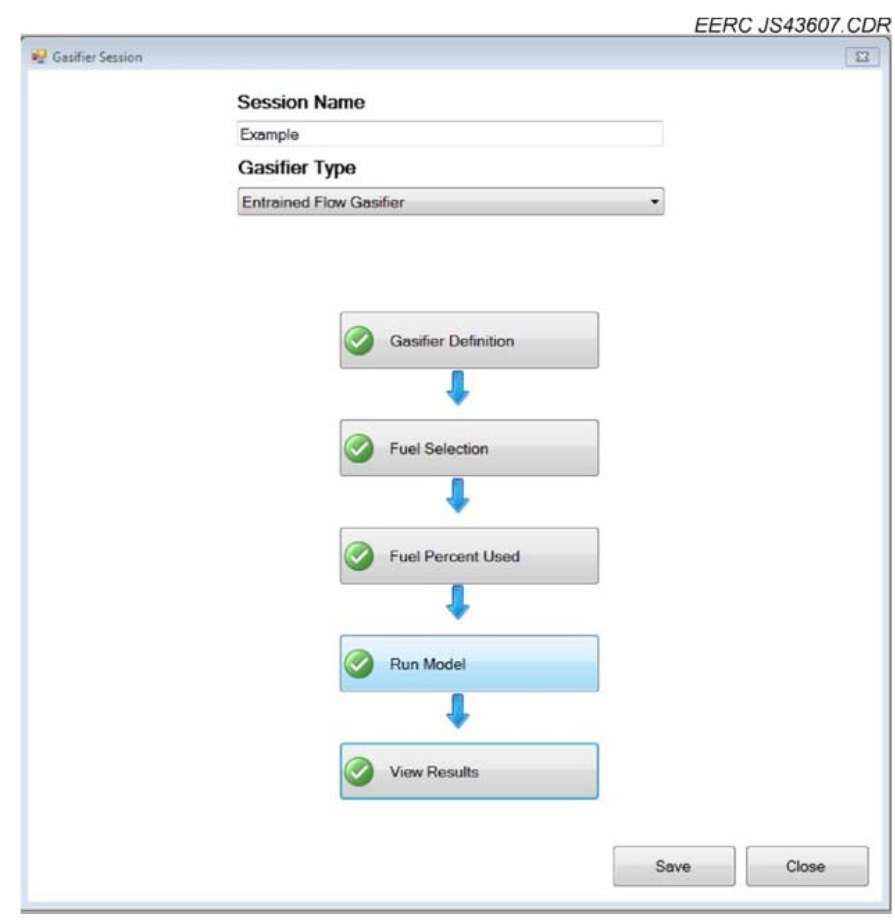

Figure 9. Gasifier session screen. 


\section{EFG Definition Input Screen}

The EFG definition input screen (Figure 10) allows the user to define the parameters and operating conditions of the gasifier. There are separate tabs to input information about the gasifier, refractory, and gas cleanup equipment.

\section{FBG Definition Input Screen}

The FBG input screen (Figure 11) is very similar to the EFG input screen, except that the refractory tab in the EFG input screen is replaced with a bed material input tab and the actual parameters input are also different to reflect FBG conditions.

The fuels selection input screen (Figure 12) allows the user to select fuels and/or blends of fuels of interest to use in the model simulation. These fuels are those that were preloaded in the database.

\section{Percent Fuel Used}

The percent fuel used screen (Figure 13) has as many entry fields as the number of fuel types and/or blends selected. The user then provides a ratio in which the fuels are mixed; a pure fuel has an entry of 1 for $100 \%$ of that fuel type. For more than one fuel and/or blend selected, the user inputs 1:1, for one part of Fuel 1 and 1 part of Fuel 2 (i.e., 50:50 blend).

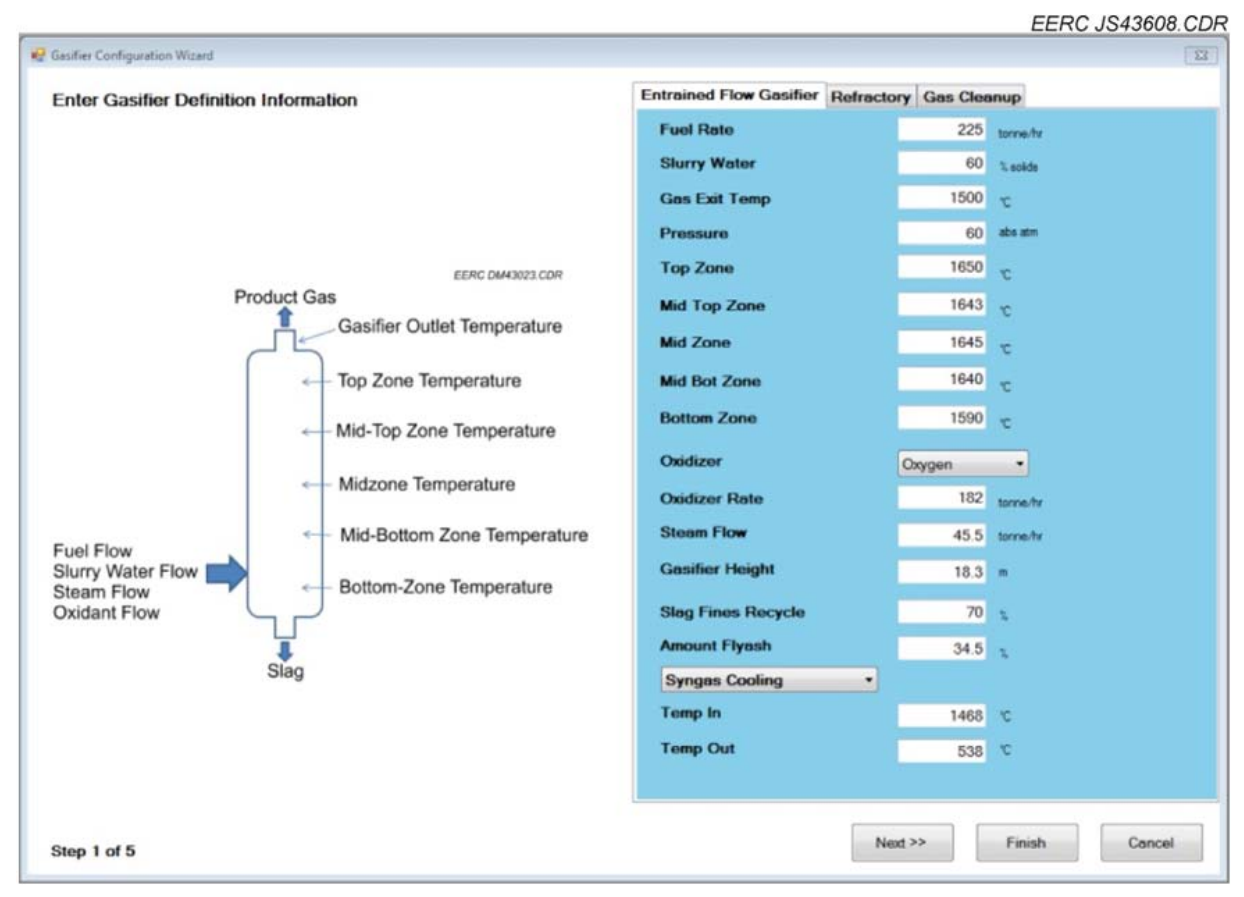

Figure 10. EFG definition input screen. 


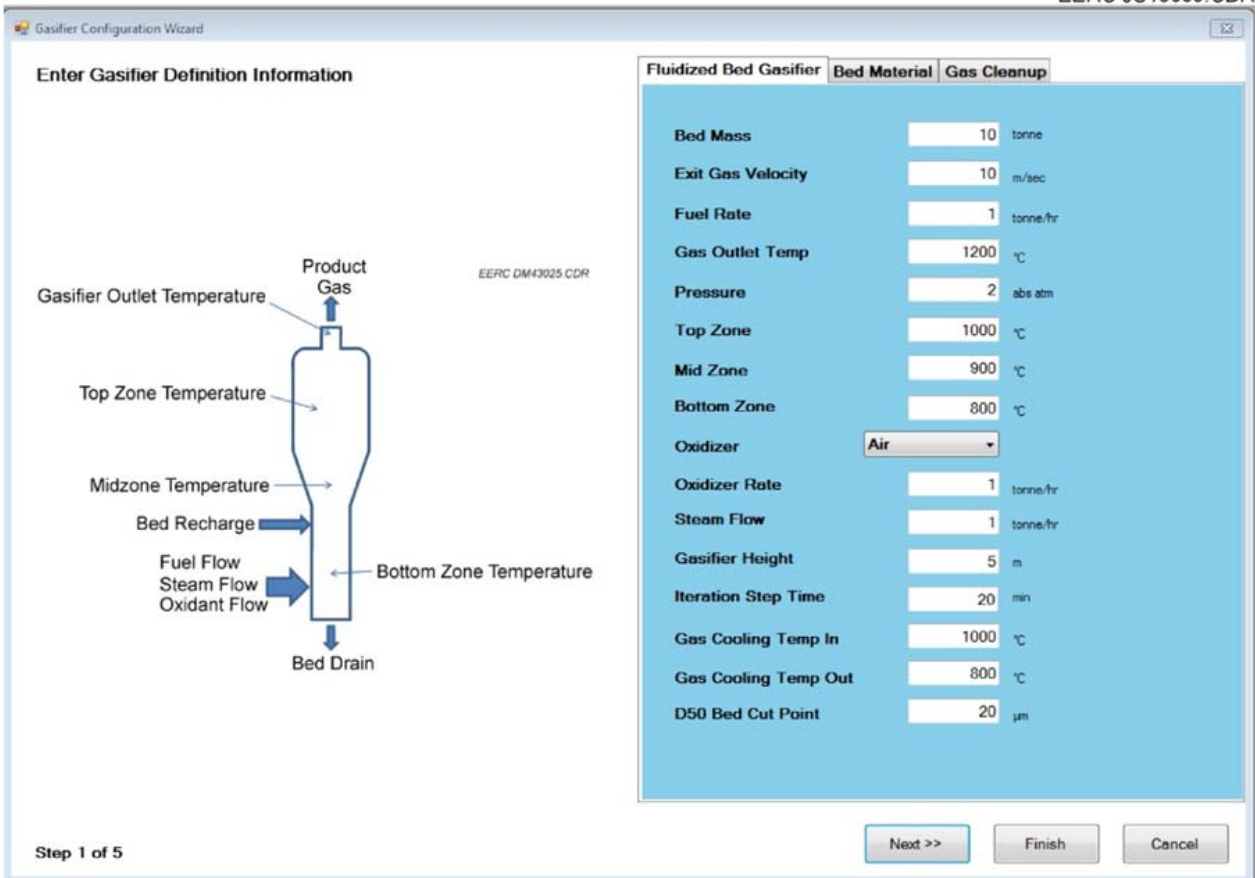

Figure 11. FBG definition input screen.

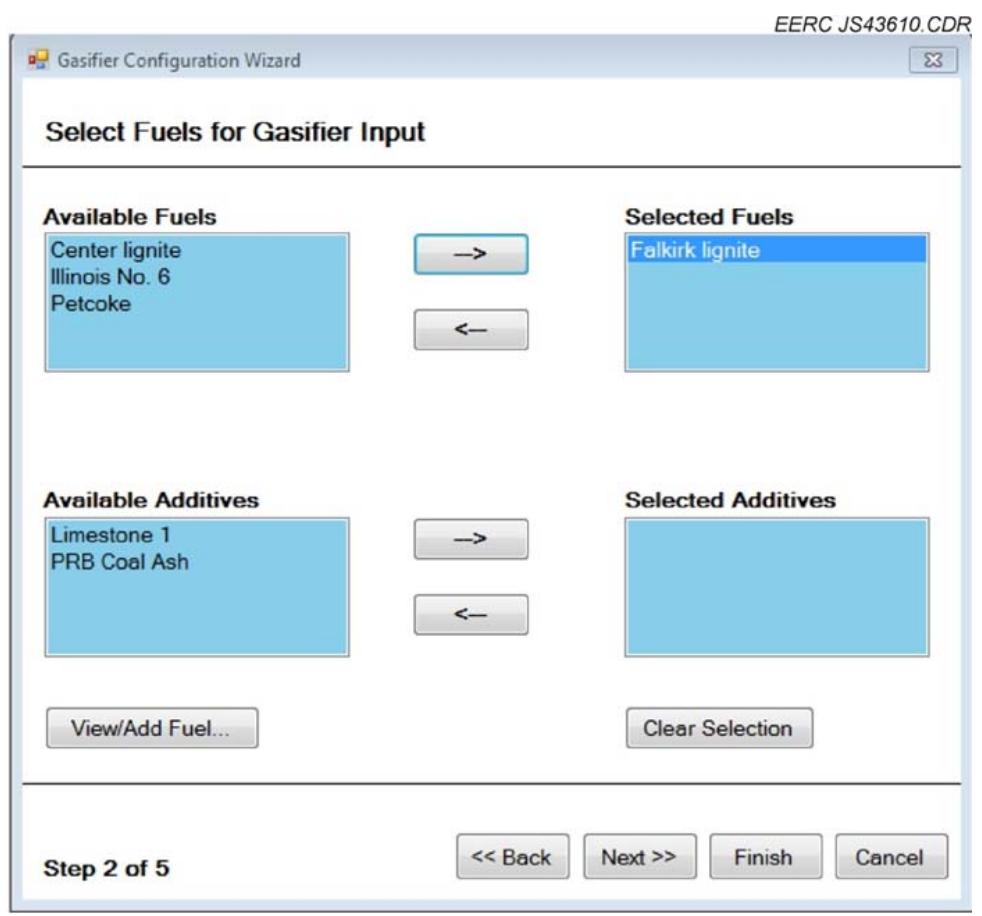

Figure 12. Fuels selection input screen. 


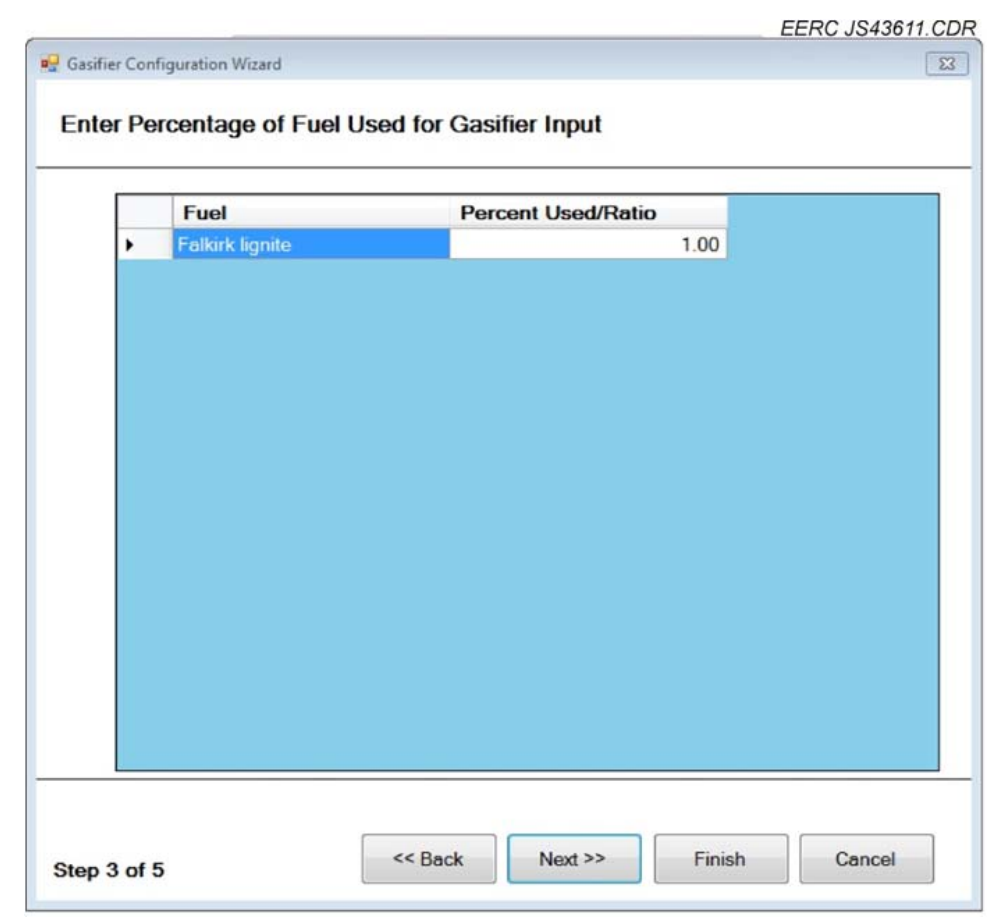

Figure 13. Percent fuel used screen.

\section{Run Model Screen}

The run model input screen (Figure 14) allows the user to specify the run control parameters such as number of iterations and/or convergence criteria.

\section{View Results Screen}

The view results screen (Figure 15) presents a results flow sheet, and the user can access results for any process equipment individually by clicking on the link for that equipment.

\section{Model Validation}

Complete validation of any computer program always takes extended periods of time because of bugs that can only be encountered during actual use of the program. However, the CABRE III model has been validated for accuracy in the calculations as expected from the algorithms in stand-alone spreadsheets. The operability of the user interface inputs and outputs, mass balance throughout the gasifier system, and partitioning between gas-phase species, fly ash, slag, and deposits in the system, have been validated based on the results obtained from pilot tests conducted during the project. A limited number of validations using full-scale gasification slags were performed. Because of intellectual property concerns, it is challenging to find clients that are willing to submit samples for model validation purposes. Nonetheless, efforts continue to be made to secure samples from commercial units for more advanced validation of the model and comparisons of the results. 


\begin{tabular}{l} 
Specify Run Criteria \\
\hline Gasifier Configuration Wizard \\
Iterations \\
Total Iterations: 2 Run to Completion \\
Step 4 of 5 Specify Iterations \\
\hline
\end{tabular}

Figure 14. Run model input screen.

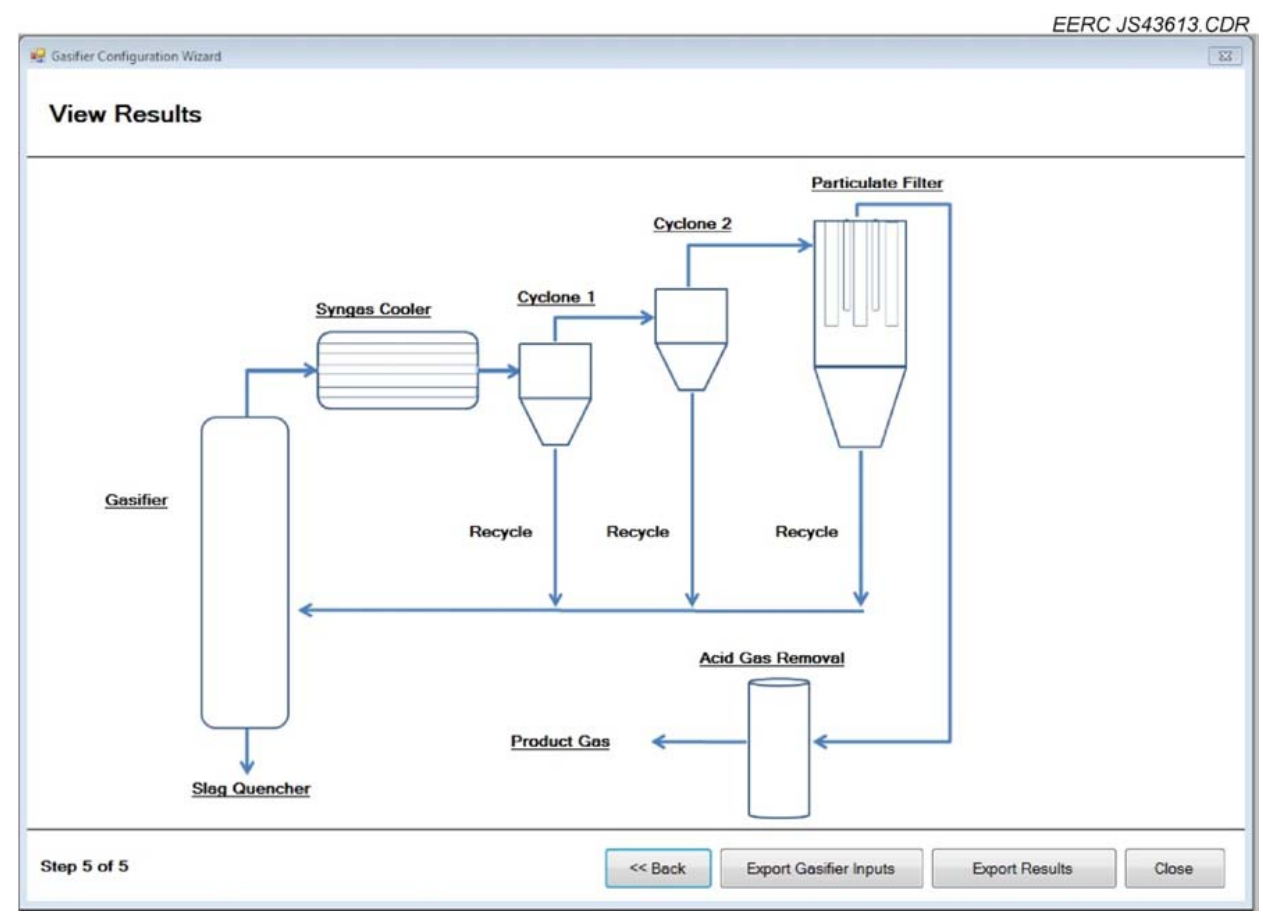

Figure 15. View results screen. 


\section{Model Results}

The flow sheet shown in Figure 16 shows the various system components on the main results page of the model's user interface. The user can click on individual components to view their specific results or click on the export results button to export the results to an excel sheet, Word document, or pdf; the program users' manual in Appendix B contains details. The arrangement is the same for a FBG except that the gasifier column has a slightly different design. Sample results categories from some of the components are presented and discussed below.

\section{Stream Compositions}

Summary and detailed tables and charts of stream compositions are provided for all major elements $(\mathrm{wt} \%)$ and selected trace elements ( $\mathrm{ppm})$. The charts are stacked column charts for a quick comparison of the amounts of major and trace elements present in fly ash and slag. Examples of such charts are shown in Figure 17, and Table 8 shows the same data in tabular form if the user chooses to use tables instead of charts.

\section{Gasifier-Related Results}

Besides partitioning and deposition data that are predicted for other downstream equipment, the gasifier has the largest amount of information that is calculated and reported. Profiles for viscosity, temperature, and solid and liquid slag thickness are provided based on data calculated for the different gasifier zones and related to the gasifier height. In addition, a typical viscosity-temperature curve is plotted, which can allow the users to predict what the $\mathrm{T}_{\mathrm{cv}}$ may be for their fuels of interest. The $\mathrm{T}_{\mathrm{cv}}$ plotted on the curve is a value used in the model for other slag

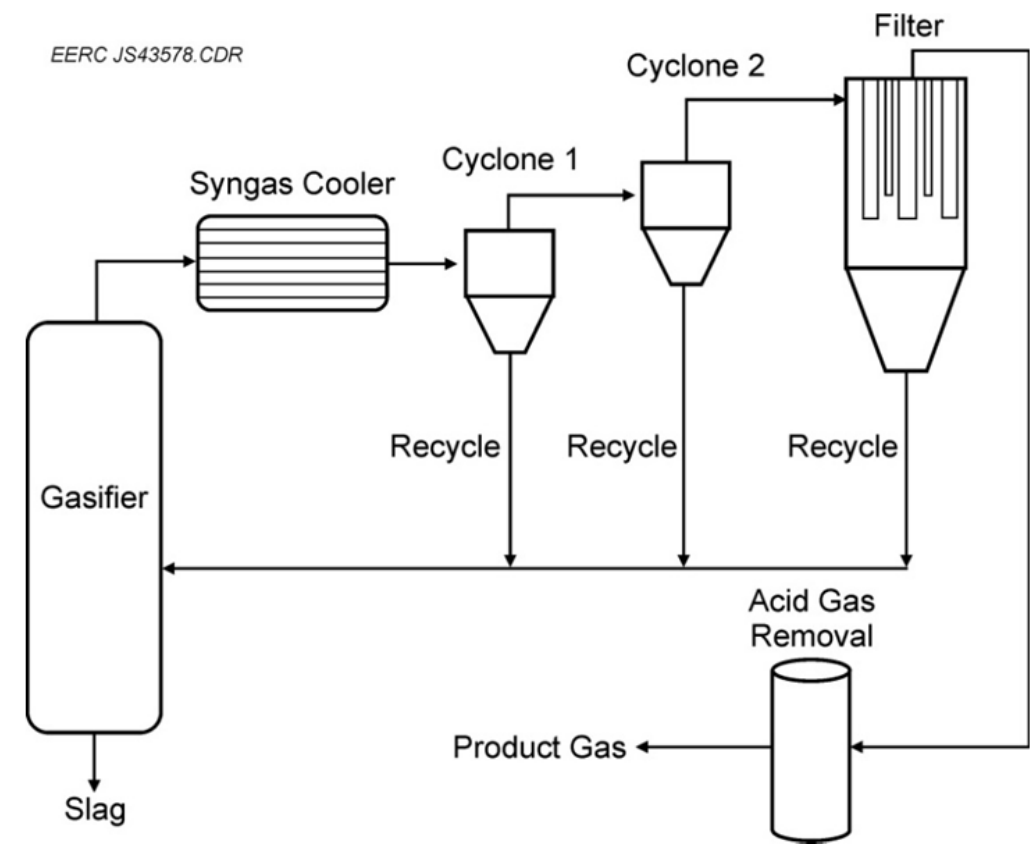

Figure 16. CABRE III program results flow sheet. 


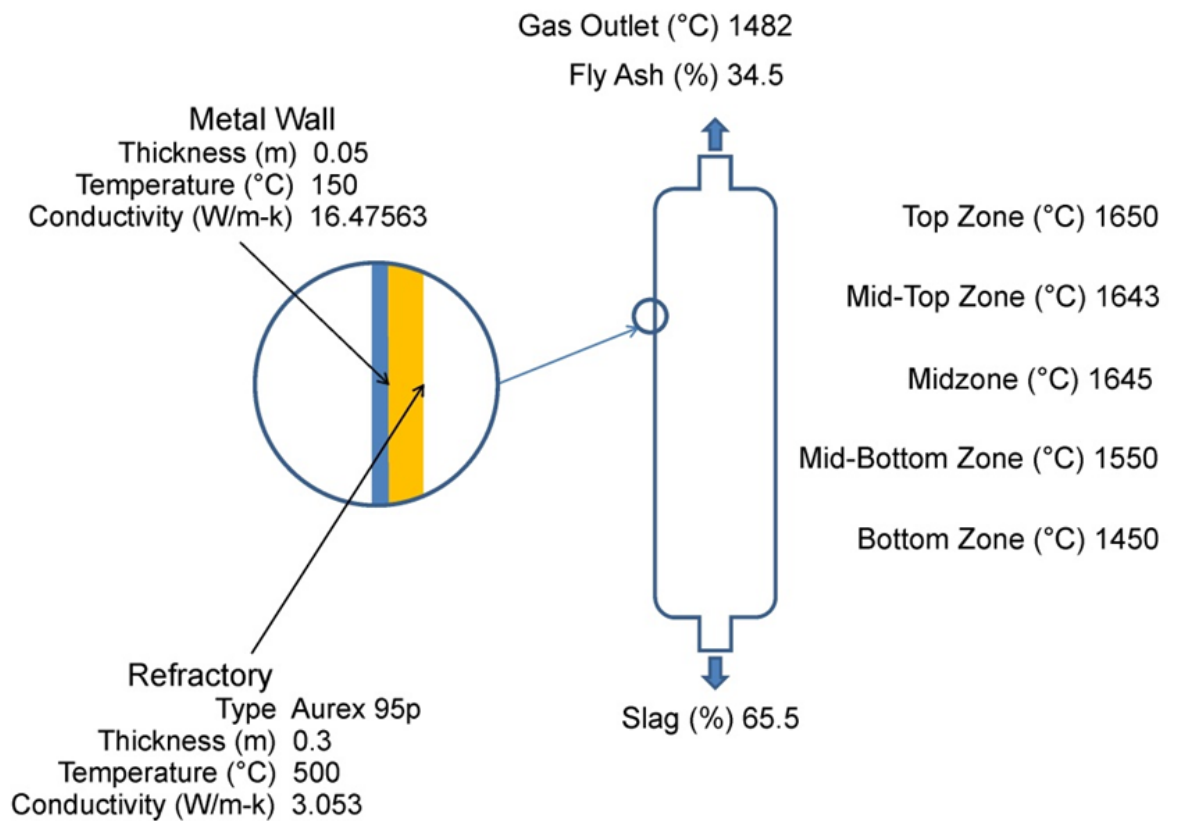

Figure 17. Distribution of major and trace elements in fly ash and slag.

Table 8. Distribution of Major and Trace Elements in Fly Ash and Slag

\begin{tabular}{lccccc}
\hline \multicolumn{2}{l}{ Distribution of Major Elements in Slag and Fly Ash } & \multicolumn{3}{c}{ Distribution of Trace Elements in Slag and Fly Ash } \\
\hline Oxide, wt $\%$ & Slag & Fly Ash & Element, ppm & Slag & Fly Ash \\
\hline $\mathrm{SiO}_{2}$ & 48.05 & 48.29 & $\mathrm{Be}$ & 0.47 & 0.12 \\
$\mathrm{Al}_{2} \mathrm{O}_{3}$ & 16.95 & 15.27 & $\mathrm{~B}$ & 0.00 & 0.00 \\
$\mathrm{Fe}_{2} \mathrm{O}_{3}$ & 9.04 & 7.65 & $\mathrm{~F}$ & 0.00 & 0.00 \\
$\mathrm{TiO}_{2}$ & 0.69 & 0.56 & $\mathrm{~V}$ & 0.00 & 0.00 \\
$\mathrm{P}_{2} \mathrm{O}_{5}$ & 0.12 & 0.49 & $\mathrm{Mn}$ & 47.97 & 4.37 \\
$\mathrm{CaO}$ & 15.72 & 14.27 & $\mathrm{Co}$ & 3.04 & 0.22 \\
$\mathrm{MgO}$ & 5.73 & 6.47 & $\mathrm{Ni}$ & 8.07 & 0.95 \\
$\mathrm{Na}$ & 1.29 & 2.45 & $\mathrm{Cu}$ & 0.00 & 0.00 \\
$\mathrm{~K}_{2} \mathrm{O}$ & 1.78 & 3.21 & $\mathrm{Zn}$ & 5.29 & 3.53 \\
$\mathrm{SO}$ & 0.11 & 0.40 & $\mathrm{Ge}$ & 2.01 & 0.29 \\
$\mathrm{BaO}$ & 0.26 & 0.48 & $\mathrm{As}$ & 8.08 & 4.49 \\
$\mathrm{SrO}$ & 0.44 & $\mathrm{Se}$ & 0.50 & 0.22 \\
$\mathrm{MnO}$ & 0.24 & 0.00 & $\mathrm{Cd}$ & 0.05 & 0.06 \\
$\mathrm{~V}_{2} \mathrm{O}_{5}$ & 0.00 & 0.00 & $\mathrm{Sb}$ & 0.11 & 0.20 \\
$\mathrm{NiO}$ & 0.00 & 0.00 & $\mathrm{Hg}$ & 0.06 & $6.63 \mathrm{e}-3$ \\
& 0.00 & & $\mathrm{~Pb}$ & 1.03 & 3.65 \\
\hline
\end{tabular}


property calculations and a reflection of where the $T_{\mathrm{cv}}$ for the particular slag may be expected. A summary of the key input parameters and the partitioning into slag and fly ash in the gasifier are shown on the main gasifier results screen shown in Figure 18, and several other buttons are provided to allow the user to access specific results pages, including the profiles as exemplified in Figures 19 and 20 and the viscosity-temperature curve shown in Figure 21.

\section{Slag Properties}

The following slag properties are calculated at various gasifier zones: viscosity, $\mathrm{T}_{\mathrm{cv}}$, surface tension, density, heat capacity, conductivity, slag mass flow rate, solid and liquid slag thickness, heat flux of leaving liquid slag, heat flux-to-refractory wall, and heat flux-to-gasifier metal shell (wall). These are presented in the form of a table as shown in Table 9.

\section{Partitioning of Inorganics}

Inorganic material in the system is partitioned between slag and fly ash, condensed and various gaseous streams, homogeneous and heterogeneous phases, and particle- and non-particleborne condensates, etc. For each of these streams, the composition, including major elements and selected trace elements, is provided in composition summary tables and charts for the major elements and selected trace elements as well as detailed tables including all elements of the periodic table that have been implemented.

\section{Deposition}

Deposition at Zones A, B, and C of various gas cleanup systems - syngas cooler, Cyclones 1 and/or 2 (if applicable), particulate filter, and acid gas removal—are calculated for every successful run. An example of a summary results page for a quick analysis of the extent and rate of deposition is presented in Figure 22. Specific streams associated with various inorganic transformations, phase transformations, and specific deposit zones are also provided, and the user can drill down into those reports to find out which specific slag or ash components are contributing to slagging, fouling, deposition, or corrosion in given equipment.
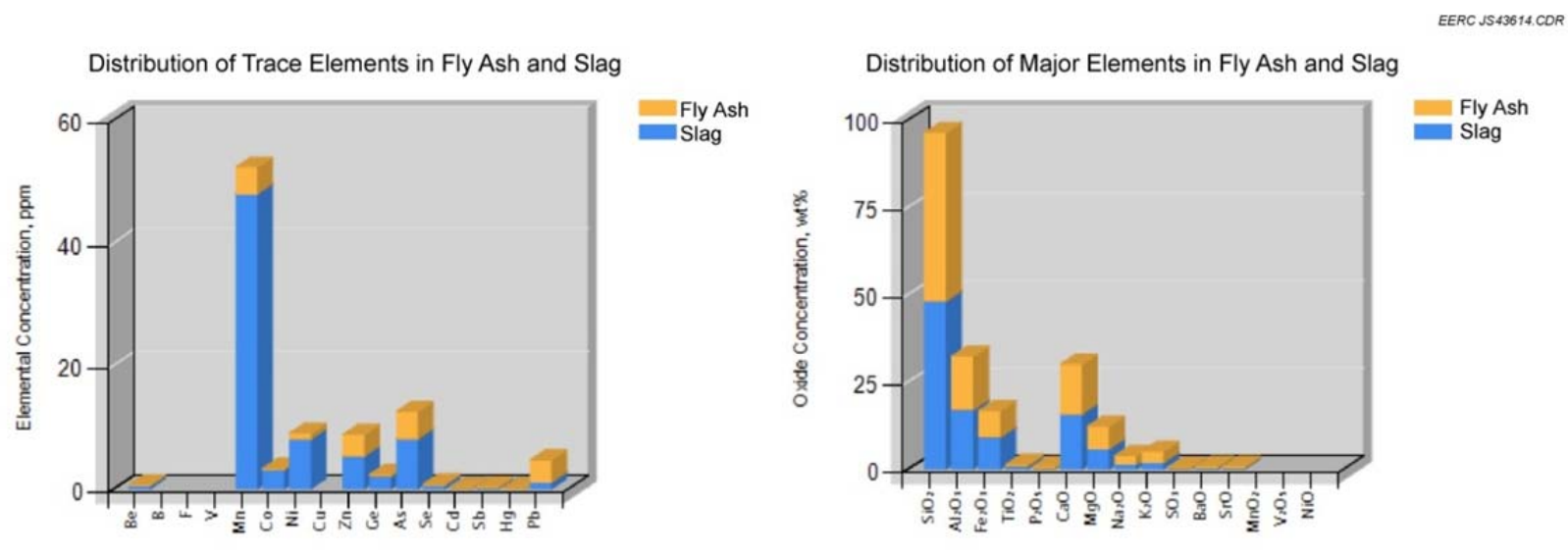

Figure 18. Gasifier results summary page. 


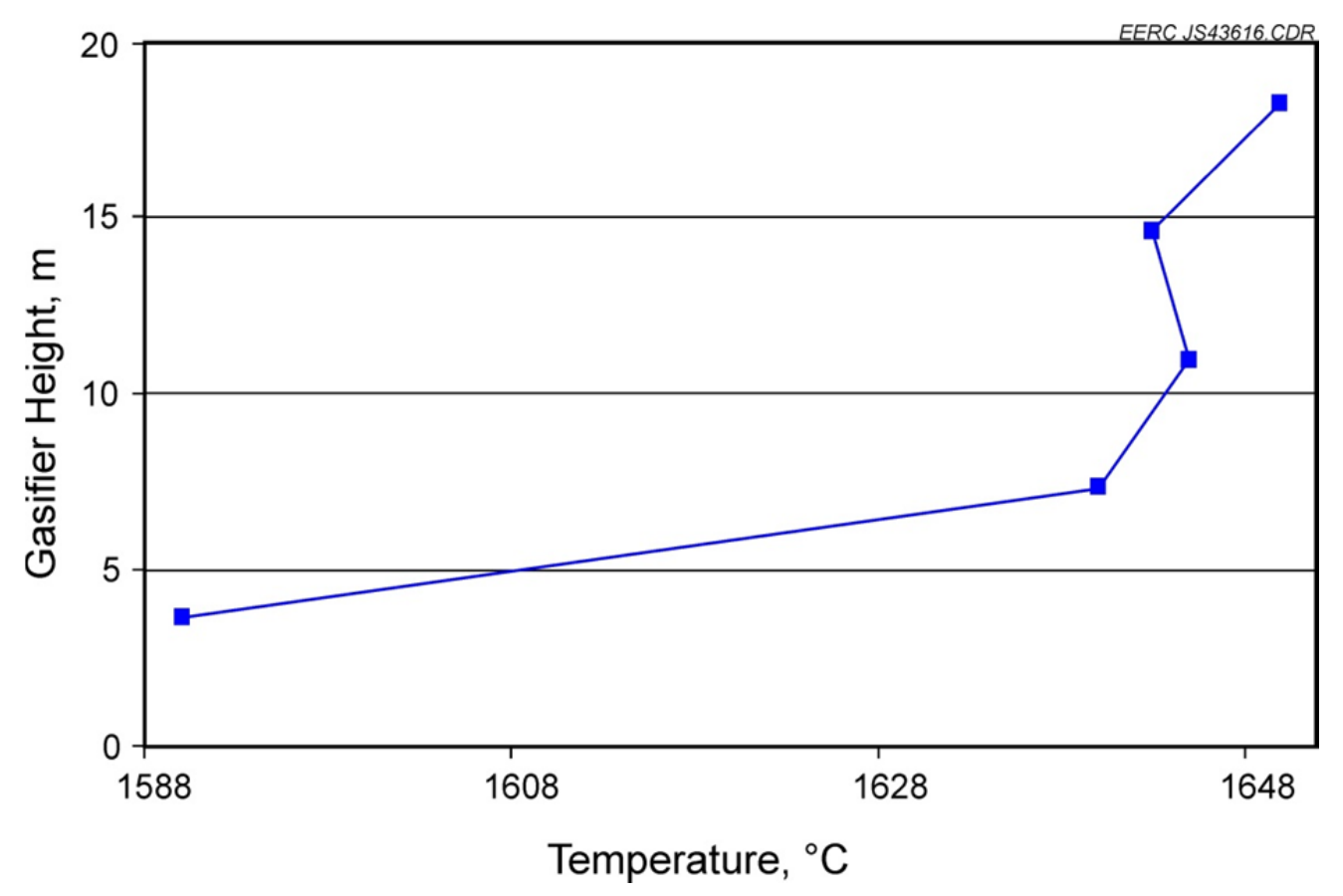

Figure 19. Gasifier temperature profile.

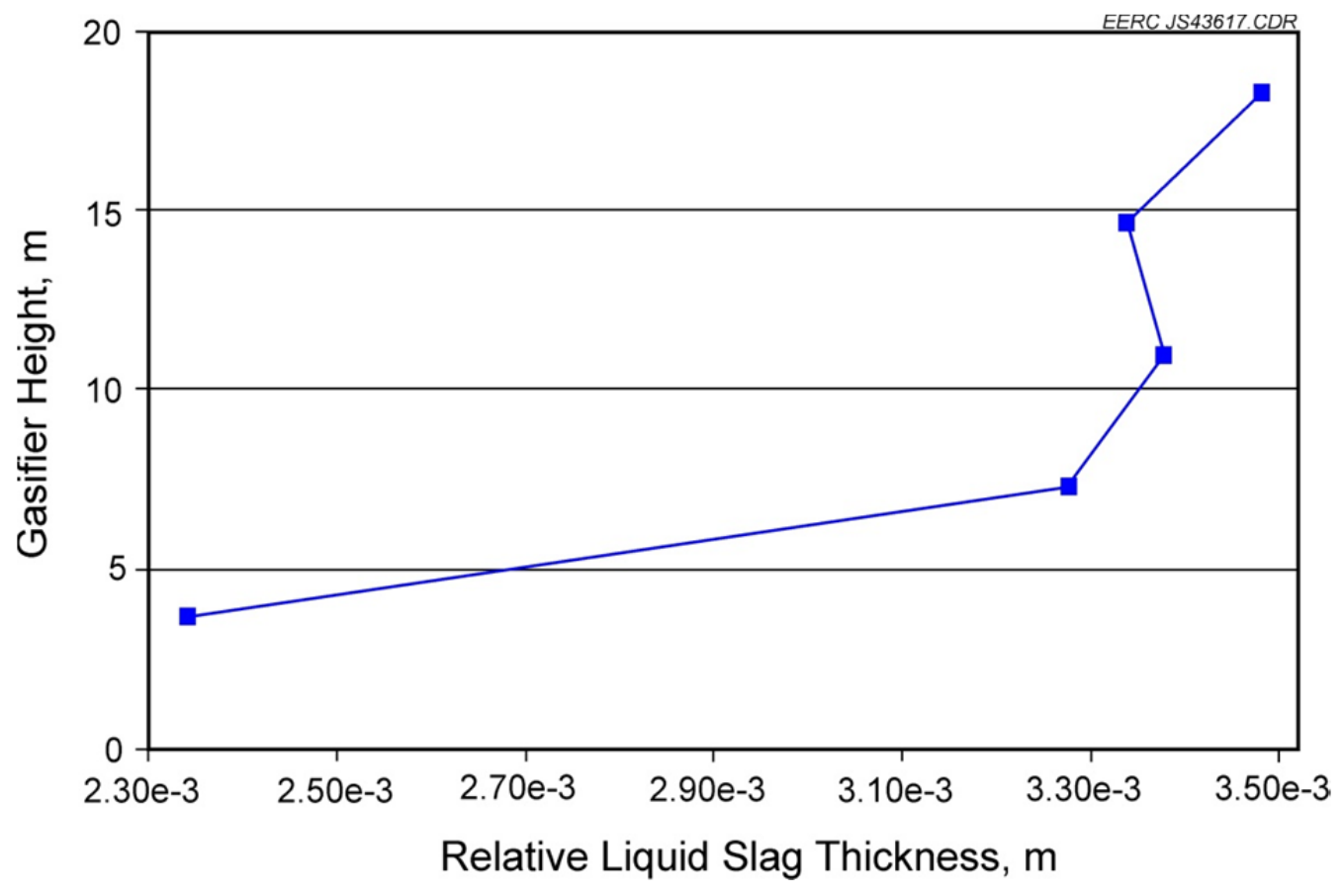

Figure 20. Gasifier liquid slag thickness profile. 


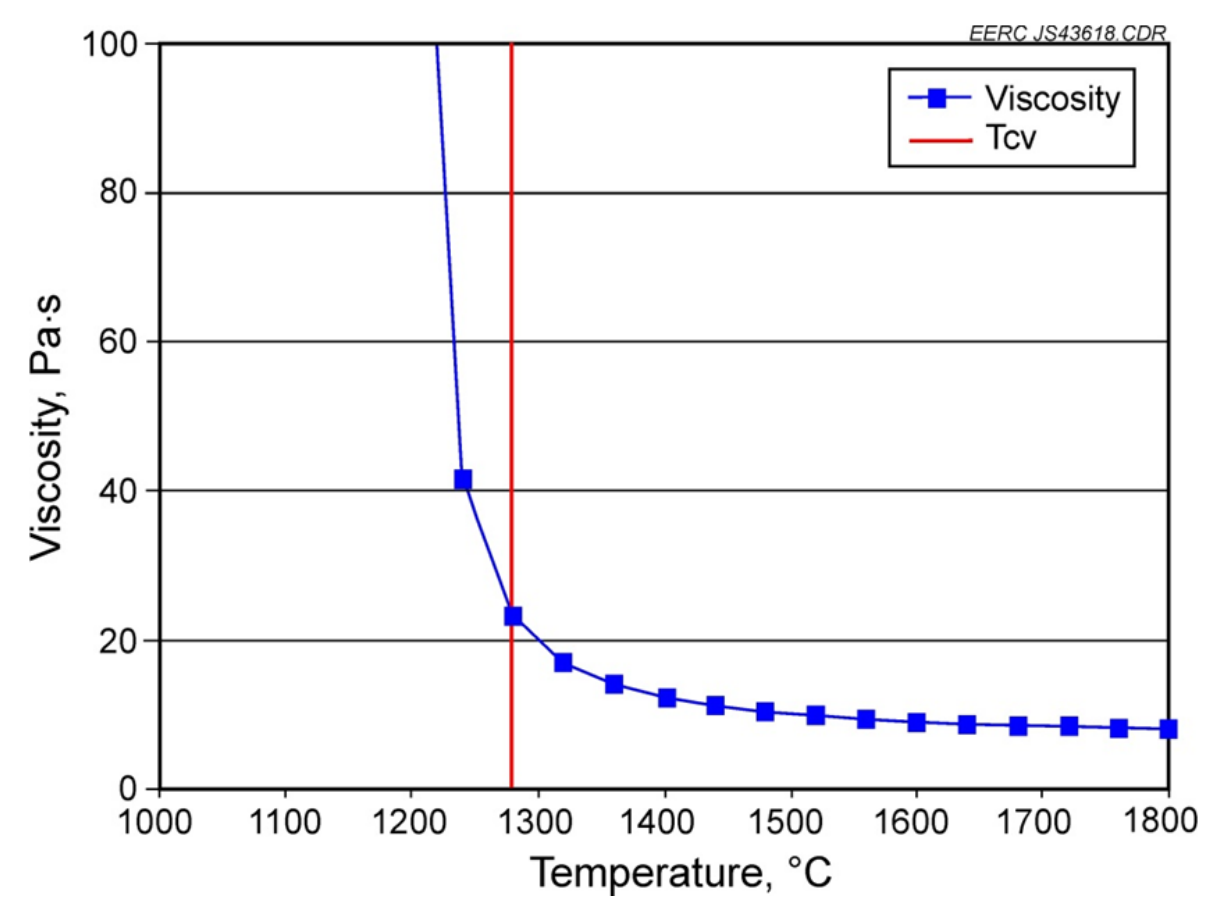

Figure 21. Viscosity-temperature curve for Falkirk lignite.

Table 9. Calculated Slag Properties at Various Gasifier Zones

\begin{tabular}{|c|c|c|c|c|c|c|c|c|c|}
\hline Zone & $\begin{array}{c}\text { Viscosity, } \\
\mathrm{Pa} \cdot \mathrm{s}\end{array}$ & $\begin{array}{l}\text { Sol. Heat } \\
\text { Capacity, } \\
\mathrm{KJ} / \mathrm{mol} \cdot \mathrm{K}\end{array}$ & $\begin{array}{l}\text { Liq. } \\
\text { Cond., } \\
\mathrm{W} / \mathrm{m} \cdot \mathrm{K}\end{array}$ & $\begin{array}{l}\text { Solid } \\
\text { Cond., } \\
\mathrm{W} / \mathrm{m} \cdot \mathrm{K}\end{array}$ & $\begin{array}{c}\text { Total } \\
\text { Thickness, } \\
\text { m }\end{array}$ & $\begin{array}{c}\text { Solid } \\
\text { Thickness, } \\
\text { m }\end{array}$ & $\begin{array}{c}\text { Liq. } \\
\text { Thickness, } \\
\text { m }\end{array}$ & $\begin{array}{l}\text { Liq. } \\
\text { Mass } \\
\text { Flow } \\
\text { Rate, } \\
\mathrm{Kg} / \mathrm{s}\end{array}$ & $\begin{array}{c}\text { Heat } \\
\text { Flux of } \\
\text { Leaving } \\
\text { Liq., } \\
\mathrm{W} / \mathrm{m}^{2}\end{array}$ \\
\hline $\begin{array}{l}\text { Top } \\
\text { Zone }\end{array}$ & 9.17 & 27.63 & $1.59 \mathrm{e}-4$ & 0.05 & 0.01 & $9.89 \mathrm{e}-3$ & $3.98 \mathrm{e}-3$ & 1.53 & 259.68 \\
\hline $\begin{array}{l}\text { Mid- } \\
\text { Top } \\
\text { Zone }\end{array}$ & 9.4 & 27.23 & $1.52 \mathrm{e}-4$ & 0.04 & 0.01 & $9.36 \mathrm{e}-3$ & $3.45 \mathrm{e}-3$ & 0.99 & 165.83 \\
\hline Midzone & 9.4 & 27.23 & $1.52 \mathrm{e}-4$ & 0.04 & 0.01 & $9.36 \mathrm{e}-3$ & $3.45 \mathrm{e}-3$ & 0.99 & 165.83 \\
\hline $\begin{array}{l}\text { Mid- } \\
\text { Bottom } \\
\text { Zone }\end{array}$ & 9.4 & 27.23 & $152 \mathrm{e}-4$ & 0.04 & 0.01 & $9.36 \mathrm{e}-3$ & $3.45 \mathrm{e}-3$ & 0.99 & 165.83 \\
\hline $\begin{array}{l}\text { Bottom } \\
\text { Zone }\end{array}$ & 10.23 & 26.19 & $1.37 \mathrm{e}-4$ & 0.04 & 0.01 & $8.12 \mathrm{e}-3$ & $2.26 \mathrm{e}-3$ & 0.27 & 44.62 \\
\hline $\begin{array}{l}\text { Other Pr } \\
\mathrm{T}_{\mathrm{cv}},{ }^{\circ} \mathrm{C} \\
\text { Density, } \\
\text { Surface } \\
\text { Liquid H } \\
\text { Heat Flu } \\
\text { Heat Flu }\end{array}$ & $\begin{array}{l}\text { perties } \\
\mathrm{kg} / \mathrm{m}^{3} \\
\text { ension, Nm } \\
\text { eat Capacity } \\
\text { to Refracto } \\
\text { to Metal W }\end{array}$ & $\begin{array}{l}\mathrm{n} \\
\mathrm{kj} / \mathrm{mol} \cdot \mathrm{K} \\
\mathrm{y} \text { Layer, } \mathrm{W} / \mathrm{s} \\
1 \mathrm{ll}, \mathrm{W} / \mathrm{m}^{2}\end{array}$ & & & $\begin{array}{r}1 \\
272 \\
34 \\
356 \\
345\end{array}$ & $\begin{array}{l}79 \\
.44 \\
.27 \\
1 \\
.83 \\
.13\end{array}$ & & & \\
\hline
\end{tabular}




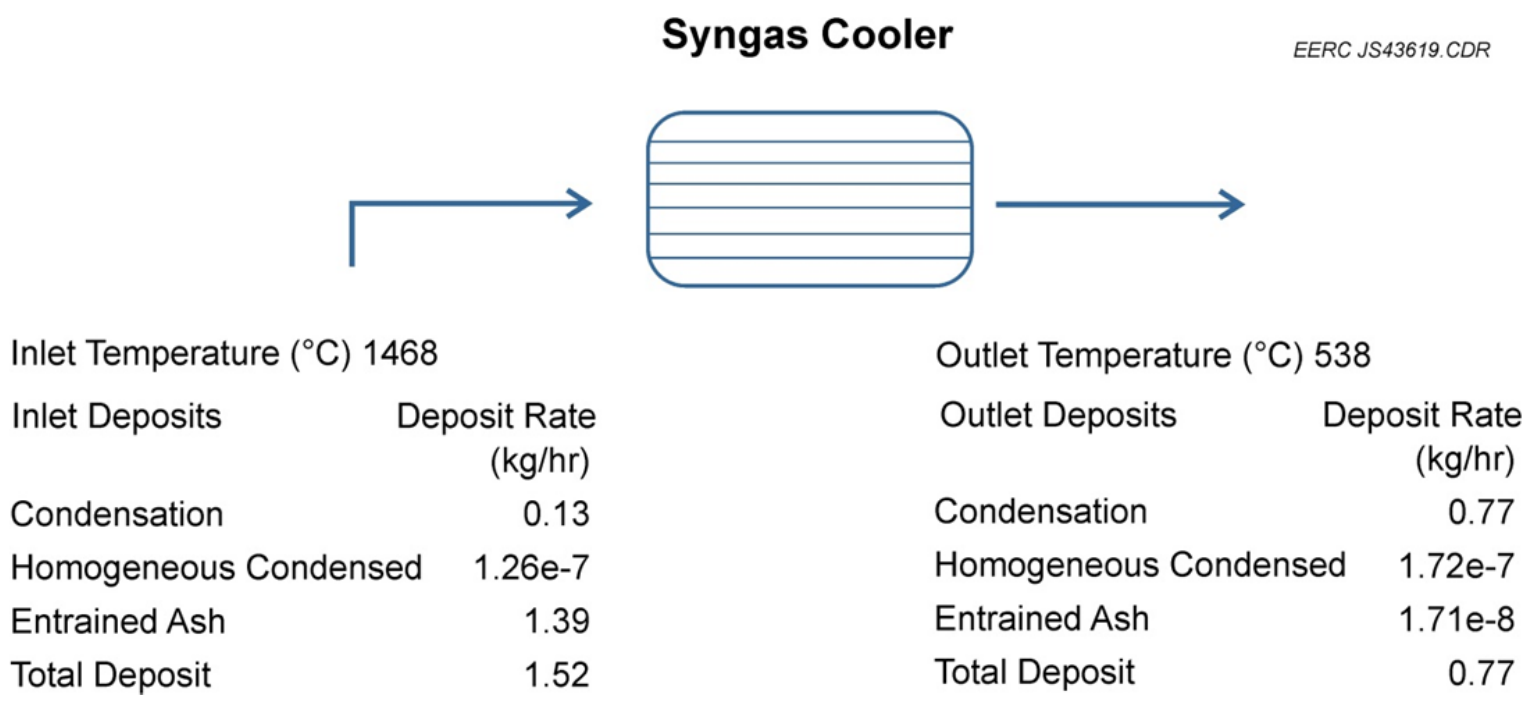

Figure 22. Results summary page for the syngas cooler.

\section{CONCLUSIONS}

The development and implementation of the CABRE III model has been completed. This model represents a significant improvement over the CABRE II model. The major achievements of the CABRE III model include the following:

- Partitioning of various inorganic transformations between various phases for specific gas cleanup equipment.

- Slag property predictions, including standard temperature-viscosity curves and slag flow and thickness.

- Deposition rates in gasification cleanup equipment.

- Provision of composition analysis for all input and output streams across all process equipment, including major elements and trace elements of interest.

- Composition analysis of deposit streams for various deposit zones: direct condensation on equipment surfaces (Zone A), homogeneous particulate deposition (Zone B), and entrained fly ash deposition (Zone C).

- Physical removal of ash in cyclones based on $\mathrm{D}_{50}$ cut points for $\mathrm{EFG}$ and FBG systems.

Also, a new feature of the CABRE III model is its user-friendly interface and detail reports that are easily exportable into Word documents, Excel spreadsheets, or pdf files. The user interface provides stepwise guides with built-in checks for efficient supply of required input data on fuels of interest to allow a successful execution of the model. 
The results from the CABRE III model are expected to further advance the knowledge base for the NCHT and, more importantly, allow for prediction of the slagging and fouling characteristics of the fuel and to evaluate its behavior under reducing environments. The information obtained from this program will potentially also assist in maintaining prolonged gasifier operation free from failure or facilitate troubleshooting to minimize downtime in the event of a problem.

The CABRE III model will help engineers and operators of EFG and FBC systems to operate their systems more efficiently with improved gasification processing. Ultimately, more efficient gasification of coal or biomass provides for more cost-effective hydrogen production; which is one of the goals of the NCHT Program.

\section{REFERENCES}

1. Stanislowski, J.J.; Laumb, J.D.; McCollor, D.P.; Schwitalla, D.H.; Galbreath, K.C.; Dockter, B.A. Coal Ash Behavior in Reducing Environments (CABRE) III: Years 3-5 - Activity 1.10 Development of a National Center for Hydrogen Technology; Topical Report for U.S. Department of Energy National Energy Technology Laboratory Cooperative Agreement No. DE-FC26-05NT42465; Energy \& Environmental Research Center: Grand Forks, ND, March 2011.

2. Erickson, T.A.; Brekke, D.W.; Nowok, J.W.; Tibbetts, J.E.; Allan, S.E.; Benson, S.A.; Steadman, E.N. Coal Ash Behavior in Reducing Environments (CABRE I); Final Technical Report; 94-EERC-05; Jan 1995.

3. Zygarlicke, C.J.; Nowok, J.W.; McCollor, D.P.; Galbreath, K.C.; Kiel, J.H.A.; Bos, A.; Jacobs, J.M.; Slort, D.; Visser, H.J.M. Coal Ash Behavior in Reducing Environments (CABRE) II; Final Proprietary Technical Report for CABRE II Sponsors and U.S. Department of Energy National Energy Technology Laboratory Cooperative Agreement No. DE-FC26-98FT40321; EERC Publication 2001-EERC-02-03; Energy \& Environmental Research Center: Grand Forks, ND, Feb 2001.

4. Galbreath, K.; Zygarlicke, C.; Casuccio, G.; Moore, T.; Gottlieb, P.; Agron-Olshina, N.; Huffman, G.; Shah, A.; Yang, N.; Vleeskens, J.; Hamburg, G. Collaborative Study of Quantitative Coal Mineral Analysis Using Computer-Controlled Scanning Electron Microscopy. Fuel 1996, 75, 424-430.

5. Miller, R.N.; Given, P.H. A Geochemical Study of the Inorganic Constituents in Some LowRank Coals; U.S. Department of Energy Report; FE-2494-TR1; 1979.

6. Benson, S.A.; Holm, P.L. Comparison of Inorganic Constituents in Three Low-Rank Coals. Ind. Eng. Chem. Prod. Res. Dev. 1985, 24, 145-149.

7. FEI Company. www.fei-natural-resources.com/products/qemscan.aspx (accessed Feb 2012). 
8. Browning, G.J.; Bryant, G.W.; Hurst, H.J.; Lucas, J.A.; Wall, T.F. An Empirical Method for the Prediction of Coal Ash Slag Viscosity. Energy Fuels 2003, 17, 731-737.

9. Vargas, S.; Frandsen, F.J.; Dam-Johansen, K. Rheological Properties of High-Temperature Melts of Coal Ashes and other Silicates. Progress Energy Combust. Sci. 2001, 27, 237-429.

10. Urbain, G.; Boiret, M. Ironmaking and Steelmaking 1990, 17, 255-260.

11. Urbain, G.; Bottinga, Y.; Richet, P. Geochim. Cosmochim. Acta 1982, 1061-1072.

12. Clarke, L.B. Management of Byproducts from IGCC Power Generation; IEACR/38; IEA Coal Research: London, May 1991.

13. Swaine, D.J. Trace Elements in Coal; Butterworths: London, 1990, 278 p.

14. Seggiani, M. Modelling and Simulation of Time-Varying Slag Flow in a Prenflo EntrainedFlow Gasifier. Fuel 1998, 77, 1611-1621.

15. Reid, W.T.; Cohen, P. Trans. ASME, 1944, 66, 685.

16. Harbison-Walker. Heat-Transfer Web Application, 2003 http://heat.hwr.com/heat.asp (accessed Dec 2011)..

17. Riboud, P.V.; Roux, Y.; Lucas, L.D.; Gaye, H. Fachber HuÈttenprax Metalweiterverarb 1981, 19, 859-869.

18. Fritz, S.F.; Popp, R.K. A Single-Dissolution Technique for Determining $\mathrm{FeO}$ and $\mathrm{Fe}_{2} \mathrm{O}_{3}$ in Rock and Mineral Samples. American Mineralogist 1985, 70, 961-968.

19. Mills, K.C.; Rhine, J.M. The Measurement and Estimation of the Physical Properties of Slags Formed During Coal Gasification 2. Properties Relevant to Heat Transfer. Fuel 1989, 68, 904-910.

20. Mills, K.C.; Rhine, J.M. The Measurement and Estimation of the Physical Properties of Slags Formed During Coal Gasification 1. Properties Relevant to Fluid Flow. Fuel 1989, 68, 193200.

21. Fine, Alan H.; Engh, T.; Elliott, John F. Measurement of the Thermal Diffusivity of Liquid Oxides and Metallurgical Slags. Metallurgical Transactions B: Process Metallurgy 1976, 7B, 277-285.

22. SAGMILLING.COM. www.sagmilling.com/articles/RosinRammlerFitting.pdf (accessed March 2012). 


\section{APPENDIX A}

\section{DATA REDUCTION AND ANALYSIS}




\section{DATA REDUCTION AND ANALYSIS}

During a 1-week gasification test run, samples were continuously collected. A complete analysis of all samples generated is a tedious process. Because of the questionable significance of some samples (i.e., samples collected during periods without carbon conversion up to that of full-scale gasification), only selected samples were fully analyzed. A loss-on-ignition (LOI) test was performed on each sample in order to get the mass balance of inorganics in the system. Several of the parameters were calculated as follows:

Fraction of Inorganics in Filter Vessel $=\frac{\text { Mass of Inorganics in Filter Ash }}{\text { Mass of All Inorganics }}$

Mass of Inorganics in Sample $=$ Mass of Sample $\cdot(1-$ LOI $)$

Fraction of Inorganics in Filter Ash = Mass of Filter Ash $\cdot(1-$ LOI $)$

Because of challenges with the coal-feeding system during each EFG test run, the feed rate was extremely unreliable at the time. Therefore, other means of calculating elemental partitioning were investigated, including:

1. Calculating the value from the elemental analyses of the fly ash and the cumulative composition of all other ash and slag samples using Equation 4.

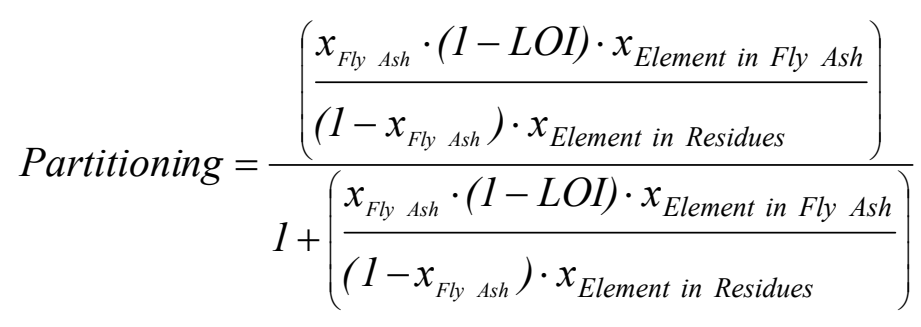

2. Calculating the value from the elemental analyses of the fly ash and the bulk coal ash using Equation 5.

$$
\text { Partitioning }=\frac{x_{\text {Fly Ash }} x_{\text {Elemental in Fly Ash }}}{x_{\text {Element in Bulk Coal Ash }}}
$$

The deviation between the two methods was calculated using Equation 6.

$$
\text { Deviation }=1-\frac{\text { Value Based on Other Residues }}{\text { Value Based on Coal }}
$$


For the evaluation of these methods to determine which one yields more reasonable results, data from EFG028 were chosen. Based on a thorough analysis of the data obtained using both equations and taking into account any contamination from handling containers and/or very small quantities that are at the limit of measuring equipment, Equation 5 turned out to be the better equation for partitioning purposes.

For elemental partitioning, Equation 7 was used to determine whether to use element-only concentrations or their oxide-based concentrations.

$$
\text { Deviation }=1-\frac{\text { Partitioning Metal }- \text { Based }}{\text { Partitioning Oxide }- \text { Based }}
$$

In this case, since x-ray fluorescence (XRF) analysis is based on the elements (not the oxides) in a given sample, little deviation between oxide-based and metal-based partitioning was observed. The highest deviation was present on the sample with the lowest closure of all XRF measurements. Since speciation of the elements is another unknown factor, the metal-based composition was chosen for the calculation of elemental partitioning. Consequently, the metal content had to be calculated from the commonly reported oxide-based concentrations using Equation 8.

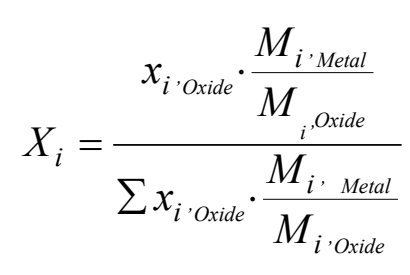

Where:

$$
\begin{array}{ll}
\mathrm{X}_{\mathrm{i}} & =\quad \text { Fraction of metal } i \text { in sample } \\
\mathrm{x}_{i} \text {,oxide } & =\quad \text { Fraction of metal oxide of metal } i \text { in sample reported by the program } \\
\mathrm{M}_{i} \text {,oxide } & =\quad \text { Molar mass of metal } i \text { in the sample } \\
\mathrm{M}_{\mathrm{i}, \text { Oxide }} & =\quad \text { Molar mass of oxide of metal } i \text { in sample }
\end{array}
$$

Although the metal-only composition was chosen to calculate the elemental partitioning, the oxide-based composition of the samples would still be valid in this study because most of these oxides are expected to be present at the temperatures relevant for EFG test runs. 


\section{Statistical Significance of Partitioning Data}

In order to determine statistically significant correlations between run parameters and elemental partitioning, two-level factorial designs are usually the preferred method. The different factors that are to be tested for correlation are set to two different levels, usually a high and a low level, and measurements of various system answers are collected. All different combinations of two or more factors are tested. The minimum number of experiments can be calculated as follows:

$$
n=F^{l}
$$

Where:

$$
\begin{aligned}
n & =\text { Number of experiments } \\
F & =\text { Number of factors } \\
l & =\text { Number of levels }
\end{aligned}
$$

Since testing all the different levels is a very costly procedure, only two levels were incorporated into the test in this project. The average main effect of a factor is calculated by taking the average difference between the values of the system answer at the high and the low level of the factor at all of the different combinations of all other considered factors. Even if no experiment is replicated, there is still the effect of one factor at two levels of the other factor, resulting in a more precise estimate than either single estimate. Also, the factorial design allows for the estimation of interaction between factors. Table A-1 gives the basic plan for a two-level design with three factors.

The values -1 and 1 represent two levels of low and high, respectively. Equation 9 gives the minimum number of experiments needed to evaluate all different interactions and the effects of all factors, which add up to a total of eight different combinations of run conditions. While the pattern of the different runs is easy to remember and reproduce, the run conditions are run in a randomized pattern so that other obvious effects do not coincide with the chosen factors.

Table A-1. Two-Level Factorial Design Plan for Three Factors

\begin{tabular}{lccc}
\hline Run & X1 & X2 & X3 \\
\hline 1 & -1 & -1 & -1 \\
2 & 1 & -1 & -1 \\
3 & -1 & 1 & -1 \\
4 & 1 & 1 & -1 \\
5 & -1 & -1 & 1 \\
6 & 1 & -1 & 1 \\
7 & -1 & 1 & 1 \\
8 & 1 & 1 & 1 \\
\hline
\end{tabular}


Interactions between the factors are calculated by simply multiplying the levels and the average effect on this run condition. The interaction between X1 and X2 at Condition 1 would then be calculated by multiplying -1 by -1 , and then multiplying the result by the measured system answer. To validate the measurements, the random noise must be calculated by determining the signal/noise t-ratio:

$$
t-\text { Ratio }=\frac{\text { Effect }}{S_{e}}
$$

Where:

$S_{e}=$ Standard deviation of an effect or interaction

Since there are not enough measurements to use only the deviation of each run condition, the standard pooled deviation has to be calculated:

$$
S_{\rho}{ }^{2}=\sum_{i}^{n}=\frac{S_{i}^{2}}{n}
$$

Where:

$$
\begin{aligned}
S_{\rho} & =\text { Standard pooled deviation } \\
S_{i} & =\text { Standard deviation of a the run condition } i \\
n & =\text { Number of experiments }
\end{aligned}
$$

The standard deviation of an effect is then calculated by using Equation 12 .

$$
S_{e}=\sqrt{S_{p}{ }^{2}\left(\frac{1}{n_{+}}+\frac{1}{n_{-}}\right)}
$$

The t-ratios are then compared to a table of values for the two-sided student's $t$ statistic to determine whether the effects or interactions are statistically significant. A process to eliminate factors that have limited or no effect must always precede the final determination of statistical significance. 
APPENDIX B

\section{CABRE III PROGRAM USER MANUAL}




\section{CABRE III PROGRAM USER MANUAL}

\section{PROGRAM DESCRIPTION}

The Coal Ash Behavior in Reducing Environments (CABRE) III program provides a prediction of coal ash behavior in reducing environments such as in gasification systems. The program is developed based on semiempirical relationships that can be found in the literature and/or correlations of experimental data obtained from a small pilot-scale entrained-flow gasifier (EFG) at the Energy \& Environmental Research Center (EERC). A limited amount of available data obtained from full-scale gasifiers was used in some cases. The main focus of the program is to predict the partitioning of coal ash as it progresses through the various unit operations beginning with the gasifier, which facilitates the understanding of various inorganic transformations and their potential impact on system equipment. At each stage, the fraction of volatile, nonvolatile, and deposited ash constituents as well as their detailed compositions, including major and trace element partitioning, is made. In addition, slag flow, corrosion, viscosity, and other slag physical properties in the gasifier are predicted. These estimates allow for prediction of the slagging and corrosion characteristics of the fuel and to evaluate its behavior under reducing environments. The information obtained from this program will assist in maintaining prolonged gasifier operation free from failure or facilitate troubleshooting to minimize downtime in the event of a problem.

\section{USER GUIDE}

This document describes the steps a user needs to follow to effectively use the CABRE III program to predict the behavior or characteristics of inorganic minerals during fuel gasification in an entrained-flow gasifier (EFG) or a fluidized-bed gasifier (FBG). The major characteristics that have been implemented include slag and fly ash partitioning, slag viscosity, slag flow in the gasifier, slag properties, and deposition. Inputs to the program are provided primarily through the graphical user interface (GUI) as described below. Although the results can also be viewed via the GUI, options are available for exporting reports to Excel spreadsheets, Word, or a pdf file.

\section{Graphical User Interface}

The program can be launched from a desktop icon shown below or from the PC start menu.

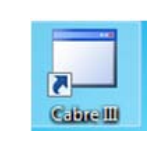

\section{General Toolbar}

The graphical user interface has a general tools bar, which contains two options: File and Help. 


\section{File}

Under File, there are five selections: New Session, Open Session, Save Session, Export, and Exit. Selecting New Session starts a new modeling session and allows the user to type in the name of the session at the beginning. Selecting Open Session allows the user to open a previously saved session to view, modify, and rerun, etc.

The Save Session allows the user to save the current session and its results for future viewing or backup or archive. The user must always save after each major modification to a session or risk losing all entered data.

The Export option allows the user to export some results output, mainly in the form of Excel spreadsheets, Word document, or pdf.

Selecting Exit terminates all open sessions and exits the main program. Any unsaved data may be lost.

\section{Help}

The Help page provides assistance with various topics in the model as well as contact information to reach the developers for questions not addressed in the Help pages.

Once the program launches, select whether to start a new session or to open an existing session from the Quick Start screen shown below. For a new session, the user must provide a session name being descriptive to assist in searching for archived files and former projects. For example, EFG-run28-2011 could be used for entrained-flow gasification Run No. 28 in 2011.

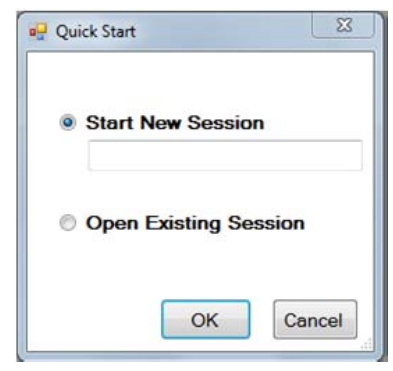

Next the user moves to the Gasifier session window, which allows selection of one of two gasifier types: EFG or FBG. There are also buttons to navigate to various input screens for Gasifier Definition, Fuel Selection, Fuel Percent Used, Run Model, and View Results, which all have a red question mark in front of them to indicate input needed. The input to these sections is described below. Again, it is important to click save each time input parameters are entered or modified. 


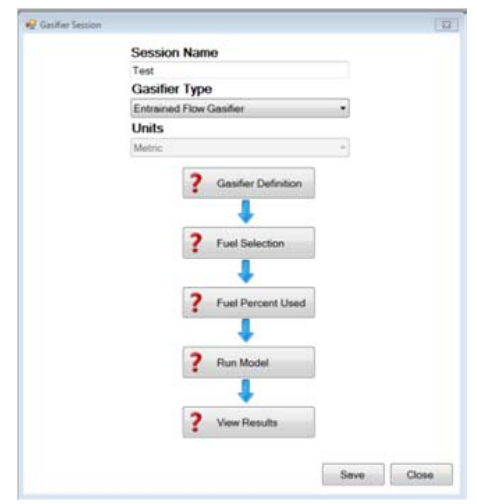

\section{Gasifier Definition}

This window allows the user to define the gasifier operating conditions, refractory information, and associated downstream gas cleanup equipment.

\section{Gasifier Tab}

Under the Gasifier tab, various input parameters are input such as temperatures for the different zones, fuel feed rate, slurry water, pressure, etc. In addition, the user can choose between air and oxygen as oxidizer and quench or syngas cooling by making the desired selection in the corresponding dropdown menus.

\section{Refractory Tab}

The refractory tab allows the user to input parameters pertinent to the refractory type and properties for use in the slag flow predictions. It is important the user inputs as accurately as possible the temperature at the slag-refractory interface (refractory slag zone temperature) for the system because this is an important input used to determine the total thickness of the slag layer in the gasifier. The average cell diameter is the gasifier diameter, and wall slope is the angle of inclination of the gasifier relative to the vertical axis ( 0 degrees for vertical wall gasifier). Only one of two refractories types, Serv95 and Aurex95p, are supported in the current version of the program and can be selected from the drop-down menu.

\section{Gas Cleanup Tab}

This allows the user to add desired gas cleanup equipment to the system. The choices available include one or two cyclone(s), a particulate filter, and acid gas removal units. For the cyclones and the filter vessel, $\mathrm{D}_{50}$ cut points and the option to recycle or not is also provided. The acid gas removal unit also requires a water flow rate. After the user is satisfied with all inputs in the different tabs, he/she clicks Next to continue to the Fuel Selection window. 

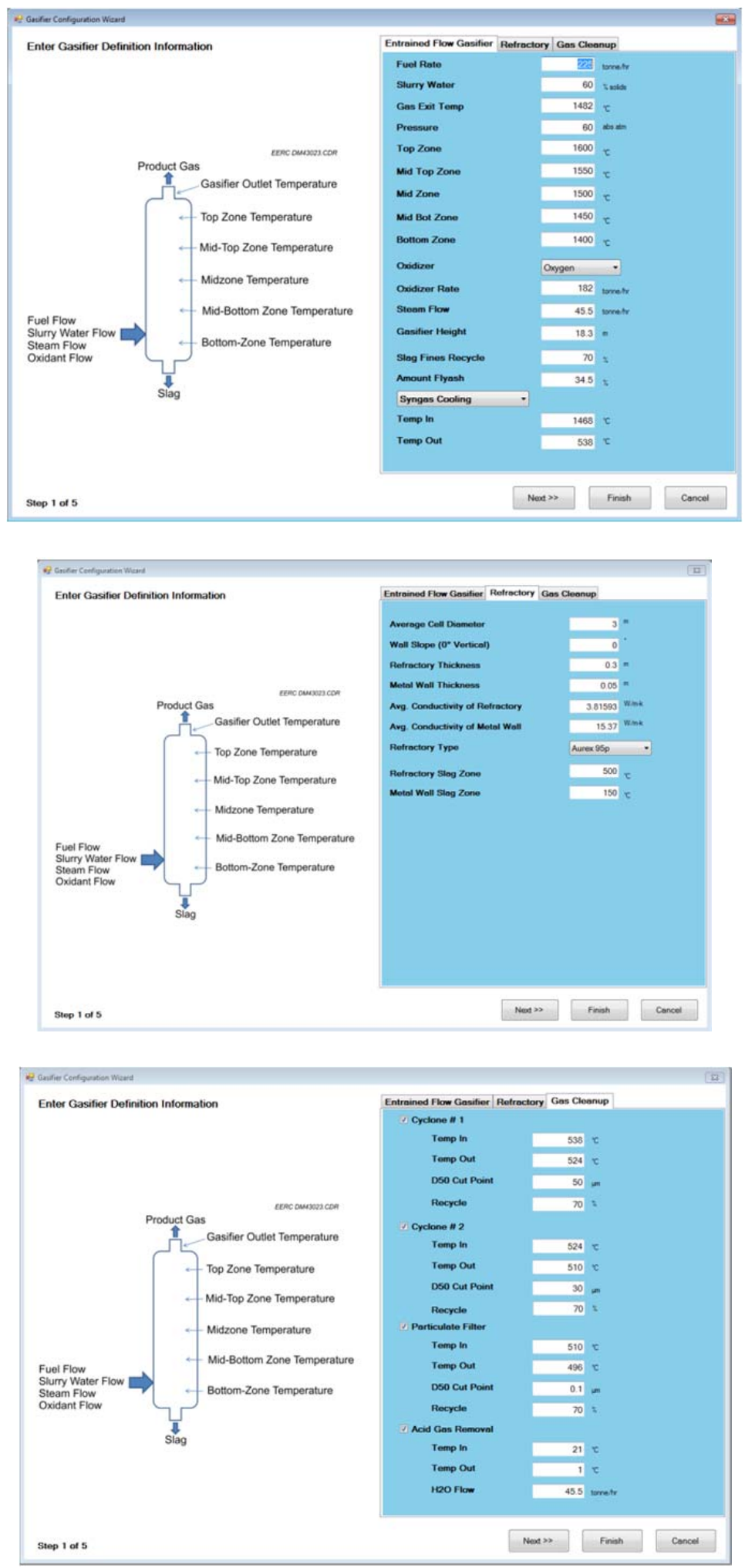


\section{Fuel Selection}

The Fuel Selection window allows the user to select a fuel of interest from the database fuels and, in addition, select a fluxing agent. The user can also choose to add a new fuel by simply modifying the input for an existing database fuel and saving under a new name. The appropriate tab for this is the View/Add Fuel button. If the user changes his/her mind, he/she can click on Clear Selection and the selected fuels and/or additives will be reset to zero for a fresh selection. After the user is satisfied with the input, he/she clicks Next to continue.

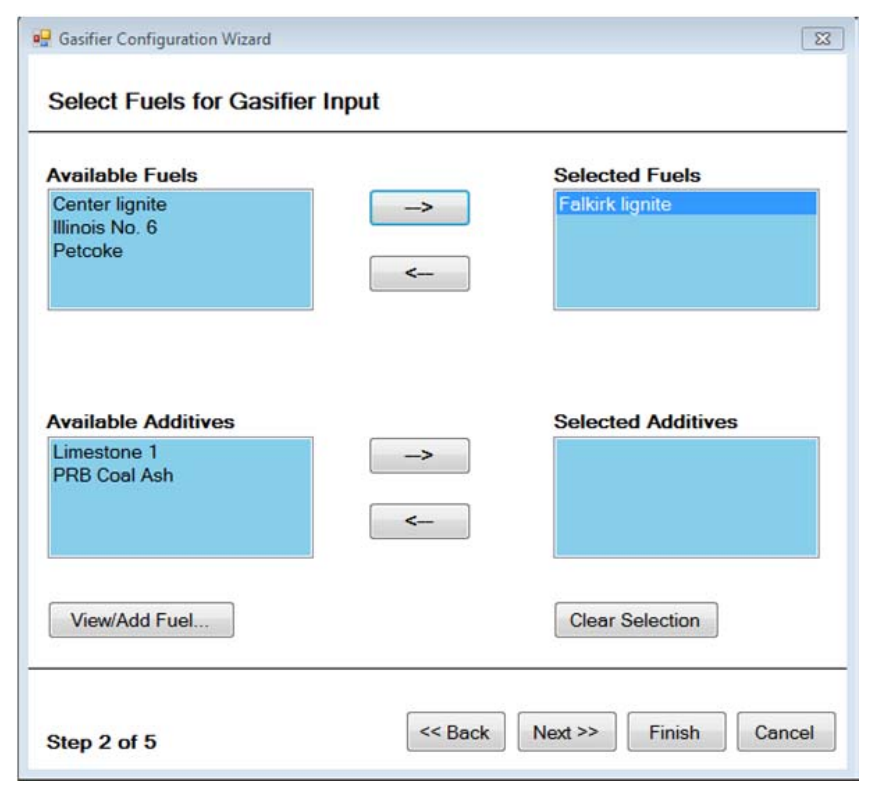

\section{Fuel Percent Used}

The next window opens the Fuel Percent Used tab, which is entered as a ratio, say 1:2 or $2: 1$, if two fuels and/or fluxes are selected.

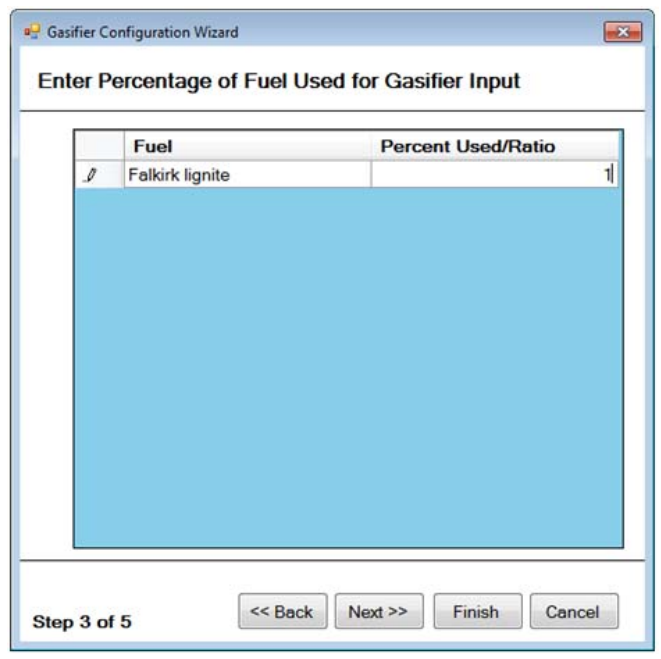




\section{Run Model}

The Run Model window allows the user to choose to run the model to completion, in which case the desired convergence criteria are required, or to run for a certain number of iterations. After selecting the desired option, the user clicks on the Run Model button. When execution is complete, a Run Completed dialogue will pop up. The user clicks OK and then Finish at the bottom of the screen. The user will then be returned to the Gasifier Session window, with the Run Model and Results tabs lit green to indicate successful completion of the run and that the results are ready for viewing.
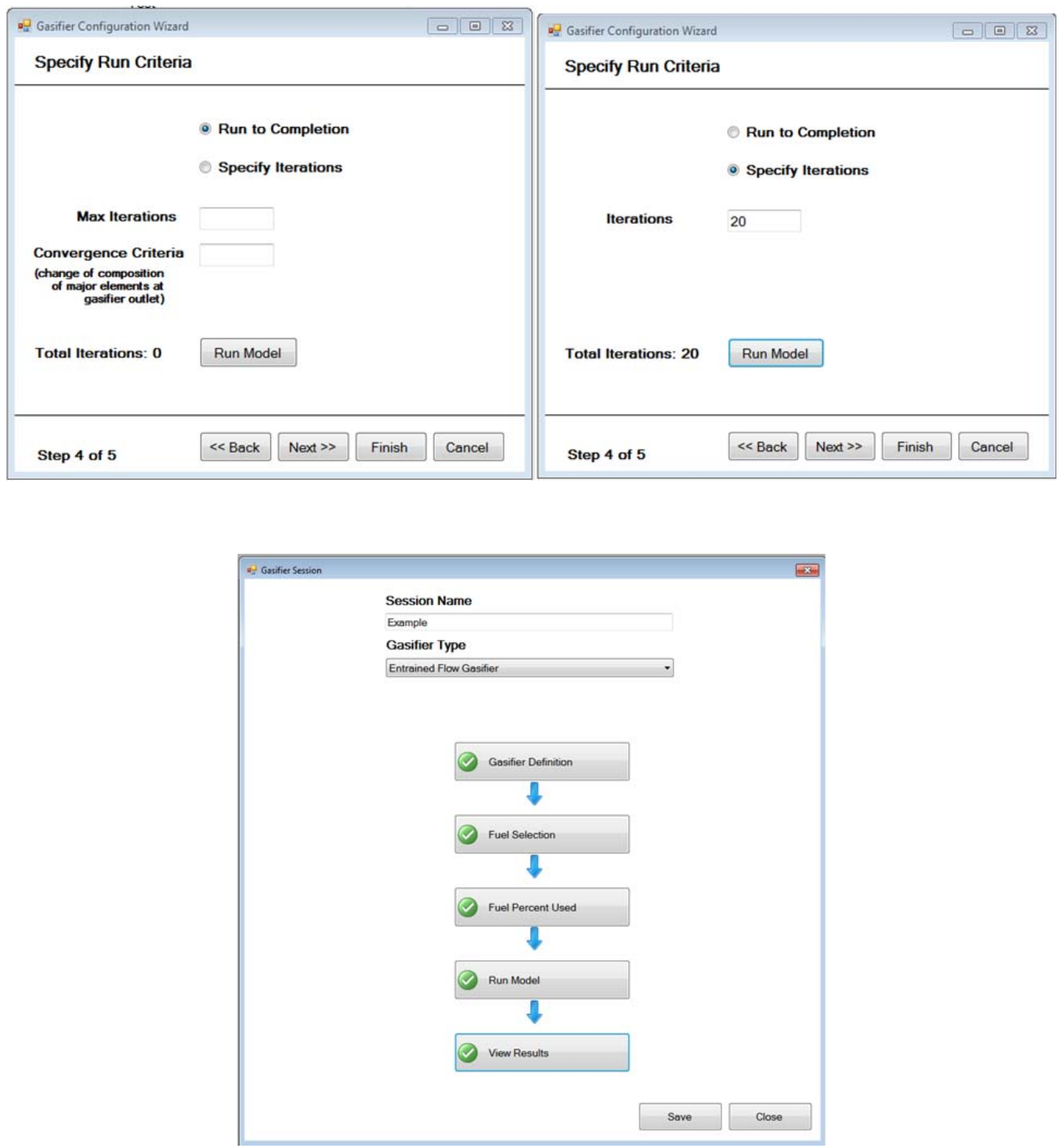


\section{View Results}

After successful completion of a run, which is either run to completion or to the maximum input number of iterations, the program returns to the Gasifier Session screen, and all buttons should be lit green. If there are errors in the run, the results and/or the particular section with errors will be lit yellow and with a bang (!) sign. The user can then select the View Results button to open the system flow sheet, with links to view results for the different unit operations in the system. Depending on the system configuration, some or all of the following units will be displayed, and the user can click on their links to view and/or export the results:

- Gasifier

- Slag Quencher

- Syngas Cooler

- Cyclone 1

- Cyclone 2

- Particulate Filter

- Acid Gas Removal

- Product Gas

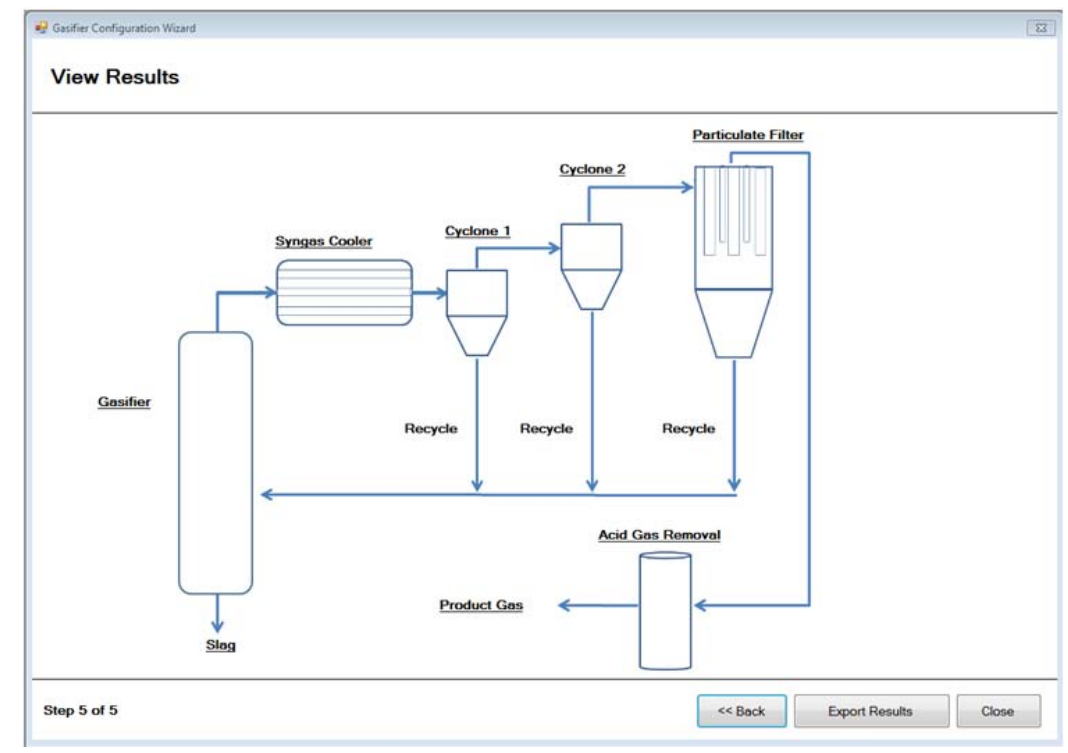

\section{Gasifier}

The gasifier link brings up the gasifier image with the mass fractions (expressed as \%) of the total fly ash and slag produced during gasification. At the bottom of the screen, there are buttons to allow the user to navigate to Composition Summary, Composition Details, Charts, Profiles, Slag Properties, and Viscosity Curves (viscosity-temperature curves). 

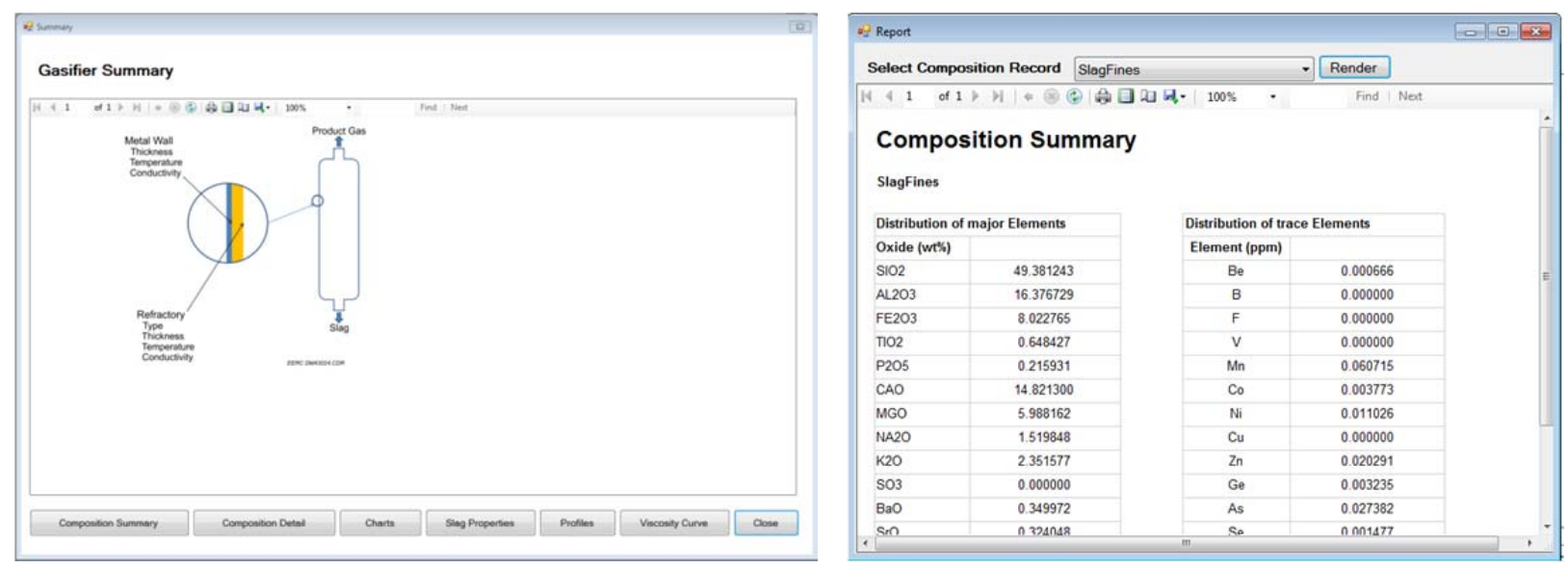

Composition Summary

The Composition Summary displays a table of major element concentrations in $\mathrm{wt} \%$ and selected trace elements in ppm.

\section{Composition Detail}

Composition Detail gives the full composition data, including the major elements and all trace elements (basically all periodic table elements included).

\section{Charts}

Charts provides stacked bar or column charts of the composition partitioned between fly ash and slag.

\section{Slag Properties}

This results page includes all calculated slag properties: surface tension, density, viscosity, heat capacity of the liquid and solid slag, conductivity of solid and liquid slag, and other properties associated with slag flow.

\section{Profiles}

The Profiles tab brings up gasifier profiles for temperature, solid and liquid slag, and viscosity as well as an area chart showing the liquid and solid slag thickness in the gasifier.

\section{Viscosity Curve}

This is a standard viscosity-temperature curve covering the maximum and minimum temperature range attained during gasifier operation.

Note: To view the results of each stream in each subreport page, the user selects the stream from the drop-down menu and then clicks on the Render button. 


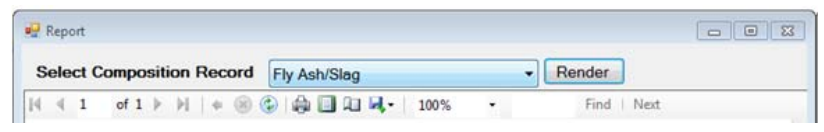

\section{Slag Quencher}

The Slag Quencher link opens a window to display the results, including composition summary, detail compositions, and charts for the input and output streams around the quencher. Stream results for slag, slag fines, quench water, and combined slag can be viewed by selecting the appropriate stream from the drop-down menu and clicking the render button.

\section{Syngas Cooler}

Several partitioning stream results are displayed on the Syngas Cooler Report screen, including information on fly ash, entrained ash, condensed ash, various zone deposits, etc. Summary tables, charts, and detailed tables are provided, and each stream report can be accessed as described in the note above.

\section{Cyclone 1 and Cyclone 2}

Depending on the specific gasifier configuration, there may be one or two cyclone units. The reports are similar to those of other units, with composition summary and detailed tables and charts. Individual stream results are similar to those of the syngas cooler and can be viewed following the steps described in the note above.

\section{Particulate Filter}

The particulate filter also has links to permit navigation to the Results Summary page, detailed tables, and charts. In each page, the stream results are viewed by following the steps outlined in the note above.

\section{Acid Gas Removal (AGR)}

The AGR unit has the same report structure as most of the other units, which includes summary tables, detailed tables, and charts. Viewing stream results is the same as described in the note.

\section{Viscosity Prediction}

In the CABRE III model, viscosity is calculated at five different temperatures corresponding to five zones along the gasifier column from top to bottom. This information is also plotted as gasifier viscosity profile and as a regular viscosity-temperature curve. The viscosity information after a successful execution of the model is associated with the Gasifier Report page. 


\section{Slag Flow and Slag Properties}

Properties related to slag flow in the gasifier are also predicted in the CABRE III model. The solid and liquid slag thickness $(\mathrm{m})$, as well as slag mass flow rate $(\mathrm{kg} / \mathrm{s})$ and the heat flux associated with the liquid slag $\left(\mathrm{W} / \mathrm{m}^{2}\right)$ exiting the gasifier are displayed in the Slag Properties report alongside other slag properties such as surface tension, density, heat capacity, and conductivity.

\section{Deposition}

Deposition is predicted by using information about fly ash composition and fly ash viscosity, which are computed for each fuel selected. The viscosity is used to determine the stickiness of the particles, which are then partitioned into entrained and surface particles. Deposition in downstream equipment is predicted at the syngas cooler, Cyclones 1 and 2 (depending on gasifier configuration), particulate filter, and acid gas removal. These results can be accessed by selecting the corresponding equipment and navigating the report sheets as described above and selecting various zone deposits. Deposition rates across each unit of downstream equipment are also predicted.

\section{Results Files}

The results files are dumped into an Excel spreadsheet and contain all major and trace element concentrations for several streams listed below. The data are reported for all given iterations; however, only results for the last iteration are reported when the user exports from individual equipment. In Tables B-1 and B-2 below, complete results output for an EFG and FBG simulation, respectively, for one iteration are shown mainly to provide a description of the different results streams that are currently being reported.

Tip: Because the Excel spreadsheet containing all results can be very large, the user can simply copy the data as a number and value format and paste into a new Excel spreadsheet. Then, they are sort by file name and by iteration to pull together all stream results for a given piece of equipment for all iterations. This allows for easy reading and/or extraction of desired data. 
Table B-1. Stream Descriptions for the EFG

\begin{tabular}{lc}
\hline Iteration No. & Stream Description \\
\hline 1 & Blended fuel input \\
1 & Combined slag \\
1 & Combined ash acid gas inlet \\
1 & Combined ash acid gas outlet \\
1 & Combined ash cooling inlet \\
1 & Combined ash cooling outlet \\
1 & Combined ash Cyclone 1 inlet \\
1 & Combined ash Cyclone 1 outlet \\
1 & Combined ash Cyclone 2 inlet \\
1 & Combined ash Cyclone 2 outlet \\
1 & Combined ash particulate filter inlet \\
1 & Combined ash particulate filter outlet \\
1 & Condensed fly ash acid gas inlet \\
1 & Condensed fly ash acid gas outlet \\
1 & Condensed fly ash cooling inlet \\
1 & Condensed fly ash cooling outlet \\
1 & Condensed fly ash Cyclone 1 inlet \\
1 & Condensed fly ash Cyclone 1 outlet \\
1 & Condensed fly ash Cyclone 2 inlet \\
1 & Condensed fly ash Cyclone 2 outlet \\
1 & Condensed fly ash particulate filter inlet \\
1 & Condensed fly ash particulate filter outlet \\
1 & Cyclone 1 capture \\
1 & Cyclone 2 capture \\
1 & Entrained ash \\
1 & Entrained ash acid gas inlet \\
1 & Entrained ash acid gas outlet \\
1 & Entrained ash cooling inlet \\
1 & Entrained ash cooling outlet \\
1 & Entrained ash Cyclone 1 inlet \\
1 & Entrained ash Cyclone 1 outlet \\
1 & Entrained ash Cyclone 2 inlet \\
1 & Entrained ash Cyclone 2 outlet \\
1 & Entrained ash particulate filter inlet \\
1 & Entrained ash particulate filter outlet \\
1 & Filter capture \\
1 & Final volatile fly ash \\
1 & Final volatile fly ash acid gas inlet \\
1 & Final volatile fly ash acid gas outlet \\
1 & Final volatile fly ash cooling inlet \\
1 & \\
1 &
\end{tabular}




\begin{tabular}{|c|c|}
\hline Iteration No. & Stream Description \\
\hline 1 & Final volatile fly ash Cyclone 1 outlet \\
\hline 1 & Final volatile fly ash Cyclone 2 inlet \\
\hline 1 & Final volatile fly ash Cyclone 2 outlet \\
\hline 1 & Final volatile fly ash particulate filter inlet \\
\hline 1 & Final volatile fly ash particulate filter outlet \\
\hline 1 & Fly ash gasifier outlet \\
\hline 1 & Gas-phase condensed acid gas inlet \\
\hline 1 & Gas-phase condensed acid gas outlet \\
\hline 1 & Gas-phase condensed cooling inlet \\
\hline 1 & Gas-phase condensed cooling outlet \\
\hline 1 & Gas-phase condensed Cyclone 1 inlet \\
\hline 1 & Gas-phase condensed Cyclone 1 outlet \\
\hline 1 & Gas-phase condensed Cyclone 2 inlet \\
\hline 1 & Gas-phase condensed Cyclone 2 outlet \\
\hline 1 & Gas-phase condensed particulate filter inlet \\
\hline 1 & Gas-phase condensed particulate filter outlet \\
\hline 1 & Gasifier input \\
\hline 1 & Gasifier quench slag gasifier outlet \\
\hline 1 & Homogeneous acid gas inlet \\
\hline 1 & Homogeneous acid gas outlet \\
\hline 1 & Homogeneous condensed acid gas inlet \\
\hline 1 & Homogeneous condensed acid gas outlet \\
\hline 1 & Homogeneous condensed cooling inlet \\
\hline 1 & Homogeneous condensed cooling outlet \\
\hline 1 & Homogeneous condensed Cyclone 1 inlet \\
\hline 1 & Homogeneous condensed Cyclone 1 outlet \\
\hline 1 & Homogeneous condensed Cyclone 2 inlet \\
\hline 1 & Homogeneous condensed Cyclone 2 outlet \\
\hline 1 & Homogeneous condensed particulate filter inlet \\
\hline 1 & Homogeneous condensed particulate filter outlet \\
\hline 1 & Homogeneous cooling inlet \\
\hline 1 & Homogeneous cooling outlet \\
\hline 1 & Homogeneous Cyclone 1 inlet \\
\hline 1 & Homogeneous Cyclone 1 outlet \\
\hline 1 & Homogeneous Cyclone 2 inlet \\
\hline 1 & Homogeneous Cyclone 2 outlet \\
\hline 1 & Homogeneous particulate filter inlet \\
\hline 1 & Homogeneous particulate filter outlet \\
\hline 1 & Homogeneous total \\
\hline 1 & Homogeneous total acid gas inlet \\
\hline 1 & Homogeneous total acid gas outlet \\
\hline 1 & Homogeneous total cooling outlet \\
\hline
\end{tabular}

Continued... 


\begin{tabular}{lc}
\multicolumn{1}{l}{ Table B-1. Stream Descriptions for the EFG (continued) } \\
\hline Iteration No. & Stream Description \\
\hline 1 & Homogeneous total Cyclone 1 inlet \\
1 & Homogeneous total Cyclone 1 outlet \\
1 & Homogeneous total Cyclone 2 inlet \\
1 & Homogeneous total Cyclone 2 outlet \\
1 & Homogeneous total particulate filter inlet \\
1 & Homogeneous total particulate filter outlet \\
1 & Particle condensed acid gas inlet \\
1 & Particle condensed acid gas outlet \\
1 & Particle condensed cooling inlet \\
1 & Particle condensed cooling outlet \\
1 & Particle condensed Cyclone 1 inlet \\
1 & Particle condensed Cyclone 1 outlet \\
1 & Particle condensed Cyclone 2 inlet \\
1 & Particle condensed Cyclone 2 outlet \\
1 & Particle condensed particulate filter inlet \\
1 & Particle condensed particulate filter outlet \\
1 & Quenchwater \\
1 & Slag \\
1 & Slag fines \\
1 & Solid fly ash gasifier outlet \\
1 & Volatile fly ash gasifier outlet \\
1 & Zone A deposit acid gas inlet \\
1 & Zone A deposit acid gas outlet \\
1 & Zone A deposit cooling inlet \\
1 & Zone A deposit cooling outlet \\
1 & Zone A deposit Cyclone 1 inlet \\
1 & Zone A deposit Cyclone 1 outlet \\
1 & Zone A deposit Cyclone 2 inlet \\
1 & Zone A deposit Cyclone 2 outlet \\
1 & Zone A deposit particulate filter inlet \\
1 & Zone A deposit particulate filter outlet \\
1 & Zone B deposit acid gas inlet \\
1 & Zone B deposit acid gas outlet \\
1 & Zone B deposit cooling inlet \\
1 & Zone B deposit cooling outlet \\
1 & Zone B deposit Cyclone 1 inlet \\
1 & Zone B deposit Cyclone 1 outlet \\
1 & Zone B deposit Cyclone 2 inlet \\
1 & Zone B deposit Cyclone 2 outlet \\
1 & Zone B deposit particulate filter inlet \\
1 & Zone B deposit particulate filter outlet \\
1 & Zone C deposit acid gas inlet \\
\hline & \\
&
\end{tabular}


Table B-1. Stream Descriptions for the EFG (continued)

\begin{tabular}{lc}
\hline Iteration No. & Stream Description \\
\hline 1 & Zone C deposit acid gas outlet \\
1 & Zone C deposit cooling inlet \\
1 & Zone C deposit cooling outlet \\
1 & Zone C deposit Cyclone 1 inlet \\
1 & Zone C deposit Cyclone 1 outlet \\
1 & Zone C deposit Cyclone 2 inlet \\
1 & Zone C deposit Cyclone 2 outlet \\
1 & Zone C deposit particulate filter inlet \\
1 & Zone C deposit particulate filter outlet
\end{tabular}

Table B-2. Stream Descriptions for the FBG

\begin{tabular}{lc}
\hline Iteration No. & Stream Description \\
\hline 1 & Blended FB input \\
1 & Blended fuel input \\
1 & Combined ash acid gas inlet \\
1 & Combined ash acid gas outlet \\
1 & Combined ash cooling inlet \\
1 & Combined ash cooling outlet \\
1 & Combined ash Cyclone 1 inlet \\
1 & Combined ash Cyclone 1 outlet \\
1 & Combined ash Cyclone 2 inlet \\
1 & Combined ash Cyclone 2 outlet \\
1 & Combined ash particulate filter inlet \\
1 & Combined ash particulate filter outlet \\
1 & Condensed fly ash acid gas inlet \\
1 & Condensed fly ash acid gas outlet \\
1 & Condensed fly ash cooling inlet \\
1 & Condensed fly ash cooling outlet \\
1 & Condensed fly ash Cyclone 1 inlet \\
1 & Condensed fly ash Cyclone 1 outlet \\
1 & Condensed fly ash Cyclone 2 inlet \\
1 & Condensed fly ash Cyclone 2 outlet \\
1 & Condensed fly ash particulate filter inlet \\
1 & Condensed fly ash particulate filter outlet \\
1 & Cyclone 1 capture \\
1 & Cyclone 2 capture \\
1 & Entrained ash \\
1 & Entrained ash acid gas inlet \\
1 & Entrained ash acid gas outlet \\
1 & Entrained ash cooling inlet \\
1 & Entrained ash cooling outlet \\
\hline
\end{tabular}

Continued... 


\begin{tabular}{|c|c|}
\hline Iteration No. & Stream Description \\
\hline 1 & Entrained ash Cyclone 1 inlet \\
\hline 1 & Entrained ash Cyclone 1 outlet \\
\hline 1 & Entrained ash Cyclone 2 inlet \\
\hline 1 & Entrained ash Cyclone 2 outlet \\
\hline 1 & Entrained ash particulate filter inlet \\
\hline 1 & Entrained ash particulate filter outlet \\
\hline 1 & Filter capture \\
\hline 1 & Final volatile fly ash \\
\hline 1 & Final volatile fly ash acid gas inlet \\
\hline 1 & Final volatile fly ash acid gas outlet \\
\hline 1 & Final volatile fly ash cooling inlet \\
\hline 1 & Final volatile fly ash cooling outlet \\
\hline 1 & Final volatile fly ash Cyclone 1 inlet \\
\hline 1 & Final volatile fly ash Cyclone 1 outlet \\
\hline 1 & Final volatile fly ash Cyclone 2 inlet \\
\hline 1 & Final volatile fly ash Cyclone 2 outlet \\
\hline 1 & Final volatile fly ash particulate filter inlet \\
\hline 1 & Final volatile fly ash particulate filter outlet \\
\hline 1 & Gas phase condensed acid gas inlet \\
\hline 1 & Gas phase condensed acid gas outlet \\
\hline 1 & Gas phase condensed cooling inlet \\
\hline 1 & Gas phase condensed cooling outlet \\
\hline 1 & Gas phase condensed Cyclone 1 inlet \\
\hline 1 & Gas phase condensed Cyclone 1 outlet \\
\hline 1 & Gas phase condensed Cyclone 2 inlet \\
\hline 1 & Gas phase condensed Cyclone 2 outlet \\
\hline 1 & Gas phase condensed particulate filter inlet \\
\hline 1 & Gas phase condensed particulate filter outlet \\
\hline 1 & Gasifier input \\
\hline 1 & Gasifier outlet \\
\hline 1 & Homogeneous acid gas inlet \\
\hline 1 & Homogeneous acid gas outlet \\
\hline 1 & Homogeneous condensed acid gas inlet \\
\hline 1 & Homogeneous condensed acid gas outlet \\
\hline 1 & Homogeneous condensed cooling inlet \\
\hline 1 & Homogeneous condensed cooling outlet \\
\hline 1 & Homogeneous condensed Cyclone 1 inlet \\
\hline 1 & Homogeneous condensed Cyclone 1 outlet \\
\hline 1 & Homogeneous condensed Cyclone 2 inlet \\
\hline 1 & Homogeneous condensed Cyclone 2 outlet \\
\hline 1 & Homogeneous condensed particulate filter inlet \\
\hline 1 & Homogeneous condensed particulate filter outlet \\
\hline 1 & Homogeneous cooling inlet \\
\hline
\end{tabular}




\begin{tabular}{|c|c|}
\hline Iteration No. & Stream Description \\
\hline 1 & Homogenous cooling outlet \\
\hline 1 & Homogenous Cyclone 1 inlet \\
\hline 1 & Homogenous Cyclone 1 outlet \\
\hline 1 & Homogenous Cyclone 2 inlet \\
\hline 1 & Homogenous Cyclone 2 outlet \\
\hline 1 & Homogenous particulate filter inlet \\
\hline 1 & Homogenous particulate filter outlet \\
\hline 1 & Homogenous total \\
\hline 1 & Homogenous total acid gas inlet \\
\hline 1 & Homogenous total acid gas outlet \\
\hline 1 & Homogenous total cooling outlet \\
\hline 1 & Homogenous total Cyclone 1 inlet \\
\hline 1 & Homogenous total Cyclone 1 outlet \\
\hline 1 & Homogenous total Cyclone 2 inlet \\
\hline 1 & Homogenous total Cyclone 2 outlet \\
\hline 1 & Homogenous total particulate filter inlet \\
\hline 1 & Homogenous total particulate filter outlet \\
\hline 1 & Particle condensed acid gas inlet \\
\hline 1 & Particle condensed acid gas outlet \\
\hline 1 & Particle condensed cooling inlet \\
\hline 1 & Particle condensed cooling outlet \\
\hline 1 & Particle condensed Cyclone 1 inlet \\
\hline 1 & Particle condensed Cyclone 1 outlet \\
\hline 1 & Particle condensed Cyclone 2 inlet \\
\hline 1 & Particle condensed Cyclone 2 outlet \\
\hline 1 & Particle condensed particulate filter inlet \\
\hline 1 & Particle condensed particulate filter outlet \\
\hline 1 & Remaining bed material \\
\hline 1 & Solid fly ash gasifier outlet \\
\hline 1 & Volatile fly ash gasifier outlet \\
\hline 1 & Zone A deposit acid gas inlet \\
\hline 1 & Zone A deposit acid gas outlet \\
\hline 1 & Zone A deposit cooling inlet \\
\hline 1 & Zone A deposit cooling outlet \\
\hline 1 & Zone A deposit Cyclone 1 inlet \\
\hline 1 & Zone A deposit Cyclone 1 outlet \\
\hline 1 & Zone A deposit Cyclone 2 inlet \\
\hline 1 & Zone A deposit Cyclone 2 outlet \\
\hline 1 & Zone A deposit particulate filter inlet \\
\hline 1 & Zone A deposit particulate filter outlet \\
\hline 1 & Zone B deposit acid gas inlet \\
\hline 1 & Zone B deposit acid gas outlet \\
\hline 1 & Zone B deposit cooling inlet \\
\hline
\end{tabular}

Continued... 
Table B-2. Stream Descriptions for the FBG (continued)

\begin{tabular}{lc}
\hline Iteration No. & Stream Description \\
\hline 1 & Zone B deposit cooling outlet \\
1 & Zone B deposit Cyclone 1 inlet \\
1 & Zone B deposit Cyclone 1 outlet \\
1 & Zone B deposit Cyclone 2 inlet \\
1 & Zone B deposit Cyclone 2 outlet \\
1 & Zone B deposit particulate filter inlet \\
1 & Zone B deposit particulate filter outlet \\
1 & Zone C deposit acid gas inlet \\
1 & Zone C deposit acid gas outlet \\
1 & Zone C deposit cooling inlet \\
1 & Zone C deposit cooling outlet \\
1 & Zone C deposit Cyclone 1 inlet \\
1 & Zone C deposit Cyclone 1 outlet \\
1 & Zone C deposit Cyclone 2 Inlet \\
1 & Zone C deposit Cyclone 2 outlet \\
1 & Zone C deposit particulate filter inlet \\
1 & Zone C deposit particulate filter outlet \\
\hline
\end{tabular}

